Conference "Proteção Radiológica na Saúde 2017"

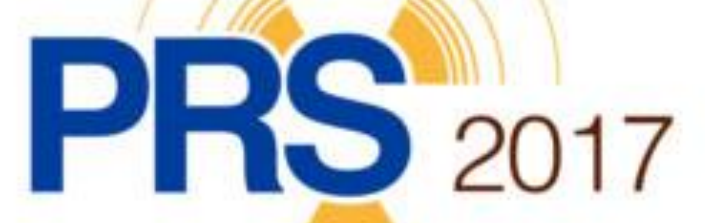

\title{
Programme and Book of Abstracts
}





\section{Sponsors}

Promoting Entities

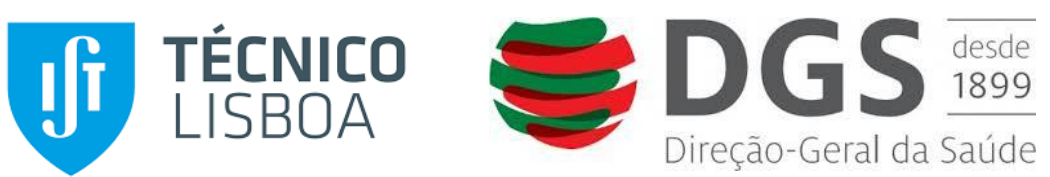

\section{Sponsorship}

WHO (World Health Organization): "Conference will be held in collaboration with WHO"

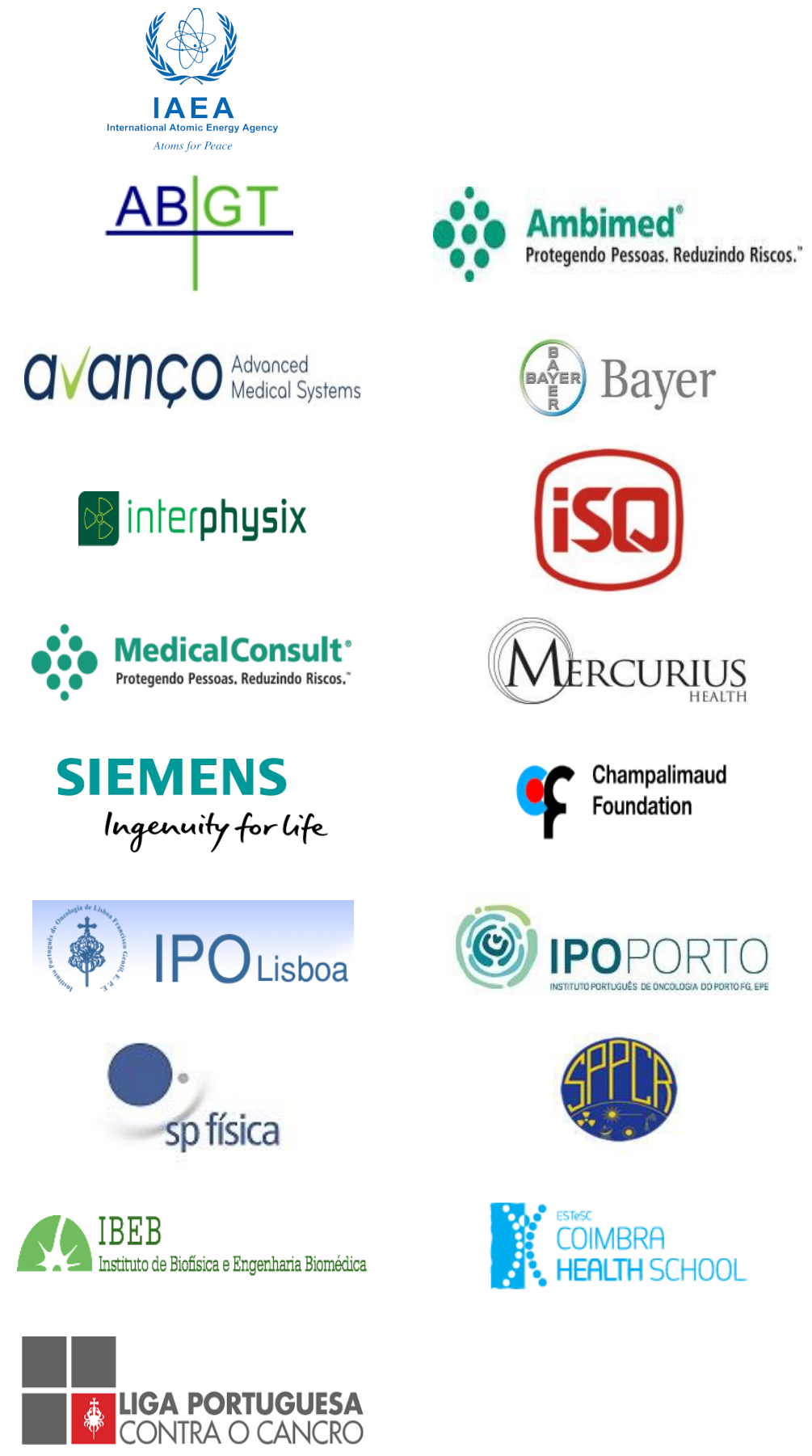

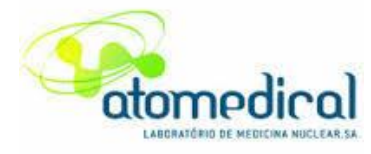

FUJIFILM

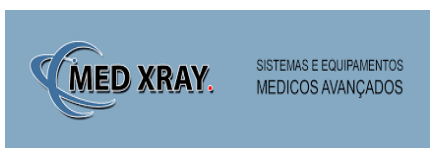

PHILIPS

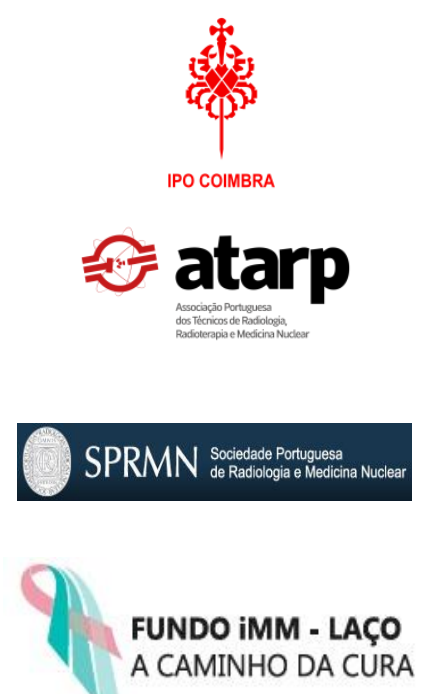





\section{Honorary Committee}

Arlindo Oliveira (Presidente do IST)

Francisco George (Diretor Geral da Saúde)

Leonor Beleza (Presidente do CA, Fundação Champalimaud)

\section{Conference Chairman}

Pedro Vaz (IST)

\section{Organizing Committee}

Catarina Antunes (IST)

Mariana Baptista (IST)

Ana Belchior (IST)

Salvatore di Maria (IST)

Paulo Diegues (DGS)

Luís Freire (ESTeSL)
Isabel Lança (ARS-Centro)

Paula Madeira (HSJ)

Octávia Monteiro Gil (IST)

Ana Pascoal (KCH, UK)

Yuriy Romanets (IST)

Pedro Rosário (DGS)
Joana Santos (ESTeSC)

João Miranda dos Santos (IPOP)

Paula Simãozinho (ARS-Algarve)

Pedro Teles (IST)

Pedro Vaz (IST)

Scientific Committee (surname by alphabetical order)

Pedro Vaz (IST)

António Abrantes (ESS, U.Algarve)

José Afonso (IPOLFG)

Pedro Almeida (IBEB/FCUL)

Filipe Caseiro Alves (SPRMN \&

HUC)

Francisco Alves (ICNAS/ESTeSC)

Catarina Antunes (IST)

Lynne Archibald (Fundo iMM-

Laço)

Maria C. Baptista (Grupo Campos

Costa)

Mariana Baptista (IST)

Ana Belchior (IST)

António Campelo (ACSS)

Gabriela Cardoso (HGO)

Nuno Carrilho (H. Curry Cabral)

João Casimiro (H. D. Estefânia)

Graça Coelho (MC)

Carla Conceição (HDE)

Durval Costa (F. Champalimaud)

Paulo Diegues (DGS)

Sofia Faustino (H. Luz)

Paulo Ferreira (F. Champalimaud)

Amália Nogueira (H. Lusíadas)

Lurdes Orvalho (H. Luz)

Ana Pascoal (KCH, UK)

Graciano Paulo (ESTeSC)

Luís Peralta (LIP/FCUL)

Helder Pereira (SPC/APIC)
Rita Ferreira (H. Luz)

Teógenes da Silva (CDTN, Brasil)

Miguel Ferro (FDUL/Sérvulo\&Ass.) Jorge Simões (ERS)

Luís Freire (ESTESL)

Rita Figueira (H. S. João)

Octávia Monteiro Gil (IST)

Fernando Godinho (Atomedical)

Pedro A. Gomes (ISQ/Labmetro)

Jorge Isidoro (HUC)

Anabela Januário (Ambimed)

Isabel Lança (ARS-Centro)

João Lavinha (INSA)

João Pedroso Lima (HUC)

Maria do Carmo Lopes (IPOC)

Paula Madeira (HSJ)

Salvatore di Maria (IST)

Bruno Martins (DCBM-UAlg)

Nuno Matela (IBEB/ERISA)

Maria Manuel Meruje (IST)

Luís Neves (SPPCR)

Maria Esmeralda Poli (HSM)

Teresa Rézio (IPOLFG)

Luis Ribeiro (ESS, U.Algarve)

Sebastião Rodrigues (NMS/FCM-

UNL)

Yuriy Romanets (IST)

Pedro Rosário (DGS)

Lucília Salgado (IPOLFG)

João Miranda dos Santos (IPOP)

Joana Santos (ESTeSC)

Ana Isabel Santos (HGO)
Paula Simãozinho (ARS-Algarve)

Maria Carmen Sousa (IPOC)

Nuno Teixeira (ESTeSL e

FCM/UNL)

Pedro Teles (IST)

Romão Trindade (Medical

Consult)

José Venâncio (IPOLFG)

Sandra Vieira (F. Champalimaud)

\section{Foreign Members}

Chris Clement (ICRP)

Steve Ebdon-Jackson (PHE, UK)

Ridwaan Esmail (Ministério da

Saúde, Moçambique, $t b c$ )

Ola Holmberg (IAEA)

Simone Kodlulovich (ALFIM \&

Brasil)

Maria Perez (WHO, tbc)

Luiz da Rosa, (IRD, Brasil)

Georgi Simeonov (EC)

Eliseo Vaño (Spain)

Lídia Vasconcellos de Sá (IRD,

Brasil)

Jenia Vassileva (IAEA)

Wolfgang Weiss (Germany) 


\title{
Conference Location
}

The PRS 2017 takes place at the

\author{
Congress Centre of IST (Civil Engineering Pavillion) \\ Instituto Superior Técnico - University of Lisbon \\ Avenida Rovisco Pais, 1 \\ 1049-001 Lisboa - Portugal
}

which is located at the IST Alameda Campus. The Congress Centre is located inside the Civil Engineering Pavilion (number 2 on the map). There is one main entrance to the campus via Alameda (marked on the map), two side entrances (from Av. Rovisco Pais and R. António de Almeida) and one back entrance from Rua Alves Redol. All events will take place at the Civil Engineering pavilion.

The IST Alameda Campus can be reached by metro to the station Alameda (a ticket costs $€ 1.95$ ) or by bus to one of the many surrounding stops (a ticket on board costs €1.85). Alternatively, you can reach the campus by Taxi/Uber/Cabify (variable prices). If you bring your own car, be aware that parking inside the Campus is available only for staff, so you will have to park your vehicle in the surrounding areas, subjected to an EMEL meter that you'll have to pay.

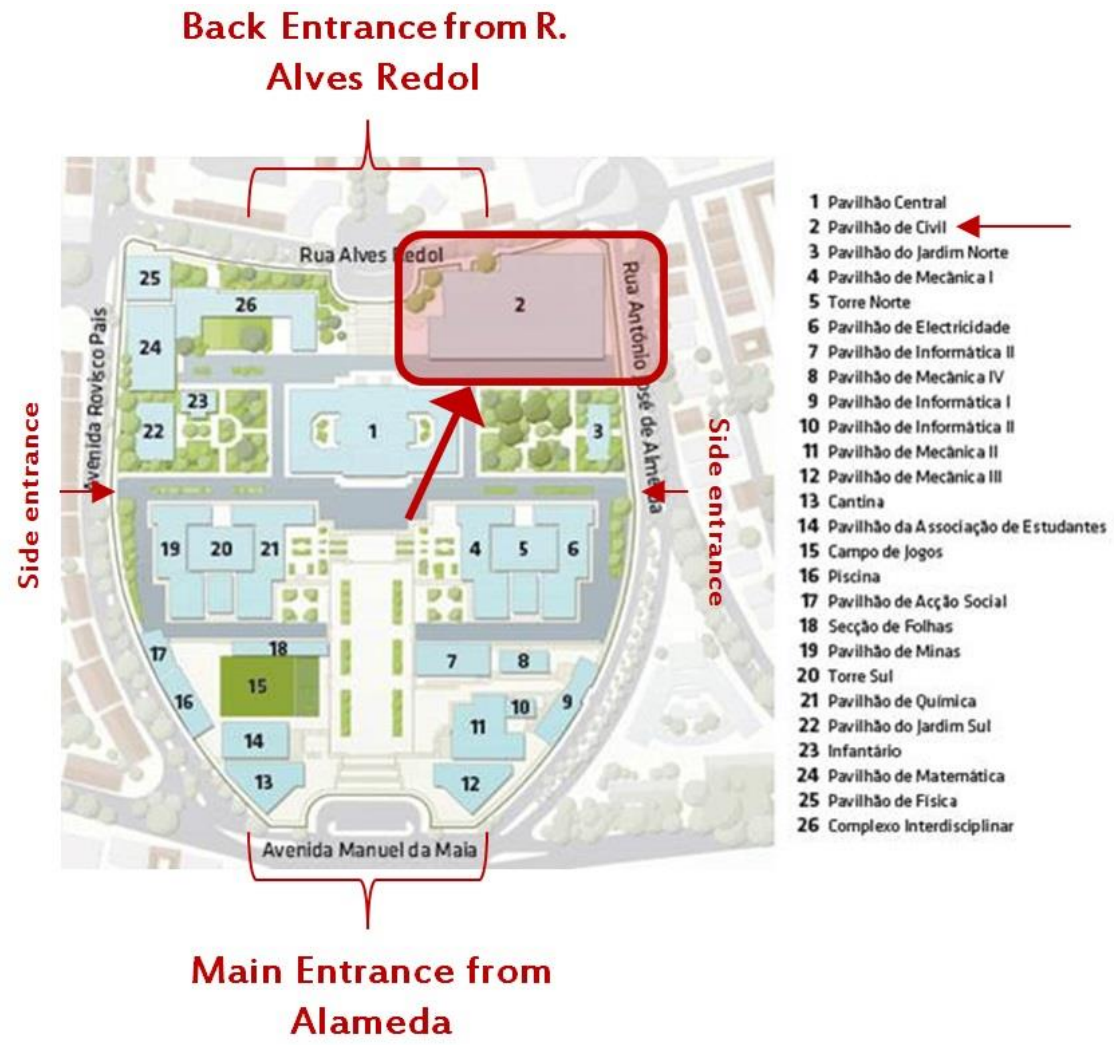


Scientific Programme

September 27-29, 2017 - Lisbon, Portugal

\begin{tabular}{|c|c|c|}
\hline \multicolumn{3}{|c|}{ Wednesday, Sep 27 } \\
\hline 08:00-08:45 & \multicolumn{2}{|c|}{ Registration } \\
\hline 08:45-09:15 & \multicolumn{2}{|c|}{ Opening and Welcome } \\
(Auditorium)
\end{tabular}

\begin{tabular}{|c|c|c|c|c|}
\hline \multicolumn{5}{|c|}{ Thursday, Sep 28} \\
\hline 08:30-09:15 & $\begin{array}{l}\text { Refresher course } 1 \\
\text { Individual } \\
\text { monitoring } \\
\text { (Room 2.1.) }\end{array}$ & $\begin{array}{l}\text { Refresher } \\
\text { Internal D }\end{array}$ & $\begin{array}{l}\text { Course } 2 \\
\text { osimetry } \\
\text { Room 1.1.) }\end{array}$ & $\begin{array}{c}\text { Refresher course } 3 \\
\text { Patient dose } \\
\text { reporting, } \\
\text { recording and } \\
\text { tracking } \\
\text { (Room 2.2.) }\end{array}$ \\
\hline 09:15-10:45 & \multicolumn{4}{|c|}{$\begin{array}{c}\text { PLENARY } 2 \text { - OPTIMIZATION } \\
\text { (Auditorium) }\end{array}$} \\
\hline 10:45-11:15 & \multicolumn{4}{|c|}{ Coffee break / Poster Session } \\
\hline 11:15-12:45 & Radon and Public & $\begin{array}{l}\text { Health } \\
\text { (Room 2.2.) }\end{array}$ & & $\begin{array}{l}\text { otimization } 1 \\
\text { (Auditorium) }\end{array}$ \\
\hline 12:45-14:00 & \multicolumn{4}{|c|}{ Lunch break } \\
\hline $14: 00-15: 30$ & \multicolumn{4}{|c|}{$\begin{array}{l}\text { Break-out session } 2 \text { - Implementation of DRLs - examples of their } \\
\text { use and usefulness } \\
\text { (Auditorium) }\end{array}$} \\
\hline $15: 30-15: 50$ & \multicolumn{4}{|c|}{ Coffee break / Poster Session } \\
\hline $15: 50-17: 10$ & $\begin{array}{r}\text { External Radiother } \\
\text { Brachytherap }\end{array}$ & $\begin{array}{l}\text { apy \& } \\
\text { Auditorium) }\end{array}$ & $\begin{array}{r}\text { Computa } \\
\text { radiolog }\end{array}$ & $\begin{array}{l}\text { ional applications in } \\
\text { ical protection and } \\
\text { dosimetry } \\
\text { (Room 2.1.) }\end{array}$ \\
\hline $17: 10-18: 30$ & \multicolumn{4}{|c|}{$\begin{array}{l}\text { Panel } 2 \text { - Directive 2013/59/EURATOM contents, impact and } \\
\text { consequences - where do we stand in Portugal? } \\
\text { (Auditorium) }\end{array}$} \\
\hline
\end{tabular}

\begin{tabular}{|c|c|c|c|c|}
\hline \multicolumn{5}{|c|}{ Friday, Sep 29} \\
\hline 08:30-09:15 & $\begin{array}{l}\text { Refresher course } 4 \\
\text { Micro- and } \\
\text { Nanodosimetry } \\
\text { (Room 2.3.) }\end{array}$ & $\begin{array}{r}\text { Refresher } \\
\text { Commun } \\
\text { radiation } \\
\text { medical } \\
\text { ( }\end{array}$ & $\begin{array}{l}\text { ourse } 5 \\
\text { cating } \\
\text { isks in } \\
\text { etting } \\
\text { Dom 2.1.) }\end{array}$ & $\begin{array}{l}\text { Refresher course } 6 \\
\text { Dosimetry audits in } \\
\text { radiotherapy } \\
\text { (Room 1.1.) }\end{array}$ \\
\hline 09:15-10:45 & \multicolumn{2}{|c|}{$\begin{array}{r}\text { Diagnostic Radiology } \\
\text { (Room 2.1.) }\end{array}$} & \multicolumn{2}{|c|}{$\begin{array}{r}\text { Radiobiology and low doses of } \\
\text { ionizing radiation } \\
\text { (Auditorium) }\end{array}$} \\
\hline 10:45-11:15 & \multicolumn{4}{|c|}{ Coffee break / Poster Session } \\
\hline 11:15-12:45 & \multicolumn{2}{|c|}{$\begin{array}{l}\text { Optimization } 2 \\
\text { (Room 2.1.) }\end{array}$} & \multicolumn{2}{|c|}{$\begin{array}{l}\text { Nuclear Medicine and } \\
\text { Molecular Imaging } 3 \\
\text { (Auditorium) }\end{array}$} \\
\hline $12: 45-14: 00$ & \multicolumn{4}{|c|}{ Lunch break } \\
\hline 14:00-15:30 & \multicolumn{4}{|c|}{$\begin{array}{l}\text { Panel } 3 \text { - Radiation Safety Culture, accidents and near misses in } \\
\text { medical uses of radiation } \\
\text { (Auditorium) }\end{array}$} \\
\hline $15: 30-16: 30$ & \multicolumn{2}{|c|}{$\begin{array}{l}\text { Radiation Safety Culture } \\
\text { (Auditorium) }\end{array}$} & \multicolumn{2}{|c|}{$\begin{array}{l}\text { Methodologies and systems of } \\
\text { dose assessment (patient and } \\
\text { personnel) } \\
\text { (Room 2.1.) }\end{array}$} \\
\hline 16:30-17:00 & \multicolumn{4}{|c|}{ Closing Session } \\
\hline
\end{tabular}

CONFERENCE DINNER - Thursday, Sep 28 (only for Regular 3 days fee) 



\section{Wednesday, September 27, 2017}

\begin{tabular}{|c|c|c|}
\hline 08:00-08:45 & \multicolumn{2}{|c|}{ Registration } \\
\hline 08:45-09:15 & \multicolumn{2}{|c|}{$\begin{array}{l}\text { Opening and Welcome } \\
\text { Chair: Pedro Vaz } \\
\text { Invited guests: Adalberto Campos Fernandes (Portuguese Minister of Health; tbc), Luís Castro (Vice-President of IST), Manuel Heitor (Portuguese } \\
\text { Minister of Science, Technology and Higher Education) }\end{array}$} \\
\hline \multirow{6}{*}{ 09:15-10:55 } & \multicolumn{2}{|c|}{$\begin{array}{l}\text { PLENARY - JUSTIFICATION of medical exposures } \\
\text { Chairs: Maria Perez and José Venâncio }\end{array}$} \\
\hline & \multicolumn{2}{|l|}{$\begin{array}{l}\text { Justification of medical exposures: first do not net harm } \\
\text { Maria Perez }(20 \mathrm{~min})\end{array}$} \\
\hline & \multicolumn{2}{|l|}{$\begin{array}{l}\text { Justification of medical exposures: a clinical perspective } \\
\text { José Venâncio ( } 20 \mathrm{~min})\end{array}$} \\
\hline & \multicolumn{2}{|c|}{$\begin{array}{l}\text { Justification of individual medical exposures - a regulators views on the process and responsibilities } \\
\text { Steve Ebdon-Jackson ( } 20 \mathrm{~min} \text { ) }\end{array}$} \\
\hline & \multicolumn{2}{|c|}{$\begin{array}{l}\text { Justification of health protection measures in a nuclear emergency } \\
\text { Wolfgang Weiss ( } 20 \mathrm{~min})\end{array}$} \\
\hline & \multicolumn{2}{|l|}{$\begin{array}{l}\text { Justification of Precision Medicine } \\
\text { José Rueff (20 } \mathrm{min})\end{array}$} \\
\hline 10:55-11:15 & \multicolumn{2}{|c|}{ Coffee break / Poster Session } \\
\hline \multirow{5}{*}{ 11:15-12:45 } & $\begin{array}{l}\text { Paediatric Exposures } \\
\text { Chairs: Carla Conceição, João Casimiro }\end{array}$ & $\begin{array}{l}\text { Nuclear Medicine and Molecular Imaging } 1 \\
\text { Chairs: Durval Costa, João Pedroso de Lima }\end{array}$ \\
\hline & $\begin{array}{l}\text { ALARA - a concept to maintain or to abandon? Recent controversies } \\
\text { Carla Conceição ( } 20 \mathrm{~min})\end{array}$ & $\begin{array}{l}\text { Radionuclide Therapy Dosimetry Under The New EU BSS } \\
\text { João Santos ( } 20 \mathrm{~min} \text { ) }\end{array}$ \\
\hline & $\begin{array}{l}\text { Cancer incidence after low dose radiation exposure: the Portuguese } \\
\text { tinea capitis X-irradiated cohort } \\
\text { Paula Boaventura }(20 \mathrm{~min})\end{array}$ & $\begin{array}{l}\text { Acridine-Orange derivates as DNA-targeted radiopharmaceuticals for Auger } \\
\text { therapy } \\
\text { Ana Belchior ( } 20 \mathrm{~min})\end{array}$ \\
\hline & $\begin{array}{l}\text { Non-Accidental Injury (NAI) Paediatric Radiography - an optimisation } \\
\text { study } \\
\text { Ana Pascoal (20 min) }\end{array}$ & $\begin{array}{l}\text { Patient-personalized Voxel-based Dosimetry Planning for Liver Tumor } \\
\text { Radioembolization } \\
\text { Paulo Ferreira }(20 \mathrm{~min})\end{array}$ \\
\hline & $\begin{array}{l}\text { Clinical Diagnostic Reference Levels in Pediatric CT } \\
\text { João Casimiro (20 min) }\end{array}$ & $\begin{array}{l}\text { Deposited energies distribution comparison between }{ }^{125} \mathrm{I},{ }^{99 \mathrm{~m}} \mathrm{Tc},{ }^{161} \mathrm{~Tb},{ }^{111} \mathrm{In} \\
\text { and }{ }^{177} \mathrm{Lu} \text { at micro and nano-scale } \\
\text { Salvatore di Maria ( } 20 \mathrm{~min} \text { ) }\end{array}$ \\
\hline 12:45-13:15 & \multicolumn{2}{|l|}{$\begin{array}{l}\text { Tribute to the late Professor J.J. Pedroso de Lima } \\
\text { Fernando Godinho }\end{array}$} \\
\hline $13: 15-14: 00$ & \multicolumn{2}{|c|}{ Lunch break } \\
\hline \multirow{6}{*}{$14: 00-15: 20$} & Sponsored Presentations & $\begin{array}{l}\text { Nuclear Medicine and Molecular Imaging } 2 \\
\text { Chairs: Pedro Almeida, Lurdes Gano }\end{array}$ \\
\hline & $\begin{array}{l}\text { Bayer: Radiometrics } \\
\text { (20 min) }\end{array}$ & $\begin{array}{l}{ }^{131} \text { I therapy in Thyroid Cancer and Benign Thyroid Diseases: Personal Dose } \\
\text { Equivalent } \mathrm{H}_{\mathrm{p}}(10) \text { Assessment in Patient's Close Family Members } \\
\text { Maria João Carapinha (20 min) }\end{array}$ \\
\hline & $\begin{array}{l}\text { Philips: Take control of Dose Management across your organization: } \\
\text { The current situation on Dose Management } \\
\text { Rodolfo del Moral ( } 20 \mathrm{~min})\end{array}$ & $\begin{array}{l}\text { Relationship between cervical/abdomino-pelvic activity and effective dose at } \\
1 \text { meter (ED1M) in patients with differentiated thyroid carcinoma submitted } \\
\text { to lodine-131 therapy }\end{array}$ \\
\hline & $\begin{array}{l}\text { Interventional image guided procedures } \\
\text { Chairs: Nuno Teixeira, Luis Pedro Ribeiro }\end{array}$ & Manuel Rio Carvalho (20 min) \\
\hline & $\begin{array}{l}\text { Occupational radiation exposure from C-Arm Fluoroscopy during hip } \\
\text { surgeries } \\
\text { Oksana Lesyuk ( } 20 \mathrm{~min})\end{array}$ & $\begin{array}{l}\text { Assessment of lodine-131 in the Urine of the Patient's Family Members after } \\
\text { Differentiated Thyroid Carcinoma Therapy } \\
\text { Maria João Carapinha ( } 20 \mathrm{~min})\end{array}$ \\
\hline & $\begin{array}{l}\text { Feasibility for Implantation of a Patient Dosage Management System } \\
\text { for Patients Submitted to Procedures in Interventional Cardiology } \\
\text { Luciana Rodrigues ( } 20 \mathrm{~min} \text { ) }\end{array}$ & $\begin{array}{l}\text { Validation and Functional Characterization of Biomarkers for Cancer } \\
\text { Theranostics with }{ }^{64} \mathrm{CuCl}_{2} \\
\text { Joana Guerreiro }(20 \mathrm{~min})\end{array}$ \\
\hline $15: 20-15: 45$ & Coffee bre & k / Poster Session \\
\hline \multirow{5}{*}{ 15:45-17:00 } & \multicolumn{2}{|c|}{$\begin{array}{l}\text { Break-out session } 1 \text { - Education, training, qualification and certification in radiological protection } \\
\text { Chairs: Graciano Paulo, Rita Figueira }\end{array}$} \\
\hline & \multicolumn{2}{|l|}{$\begin{array}{l}\text { MEDRAPET: An Overview of a European Commission DG ENER Project } \\
\text { Graciano Paulo (15 } \mathrm{min})\end{array}$} \\
\hline & \multicolumn{2}{|c|}{$\begin{array}{l}\text { Preliminary results from the } 2016 \text { "Inquérito Nacional sobre Educação e Formação em Proteção Radiológica na Saúde" } \\
\text { Rita Figueira (15 min) }\end{array}$} \\
\hline & \multicolumn{2}{|l|}{$\begin{array}{l}\text { Radiation Protection in the Healthcare Field in Spain. A General Outlook } \\
\text { Lorenzo Carretero (15 min) }\end{array}$} \\
\hline & \multicolumn{2}{|l|}{ Open discussion (30 $\mathrm{min})$} \\
\hline $17: 00-18: 30$ & \multicolumn{2}{|c|}{$\begin{array}{l}\text { Panel } 1 \text { - Bonn Call for Action - where do we stand in Portugal? } \\
\text { Chair: Wolfgang Weiss, Pedro Vaz } \\
\text { Panelists: Jenia Vassileva, Maria Perez, José Venâncio, Rita Figueira, Graciano Paulo, Pedro Vaz }\end{array}$} \\
\hline
\end{tabular}


Thursday, September 28, 2017

\begin{tabular}{|c|c|c|c|}
\hline 08:30-09:15 & $\begin{array}{l}\text { Refresher course } 1 \\
\text { Individual monitoring } \\
\text { João Schiappa }\end{array}$ & $\begin{array}{l}\text { Refresher course } 2 \\
\text { Internal Dosimetry } \\
\text { Pedro Teles } \\
\end{array}$ & $\begin{array}{c}\text { Refresher course } 3 \\
\text { Patient dose reporting, recording and tracking } \\
\text { Jenia Vassileva }\end{array}$ \\
\hline \multirow{5}{*}{ 09:15-10:45 } & \multicolumn{3}{|c|}{$\begin{array}{c}\text { PLENARY - OPTIMIZATION } \\
\text { Chairs: Chris Clement, Jenia Vassileva }\end{array}$} \\
\hline & \multicolumn{3}{|c|}{$\begin{array}{l}\text { ICRP Recommendations on Radiological Protection in Medicine: Recent Achievements and Priorities for the 2017-2021 Term } \\
\text { Chris Clement ( } 20 \mathrm{~min} \text { ) }\end{array}$} \\
\hline & \multicolumn{3}{|l|}{$\begin{array}{l}\text { Practical steps for optimizing diagnostic radiological procedures } \\
\text { Jenia Vassileva ( } 20 \mathrm{~min})\end{array}$} \\
\hline & \multicolumn{3}{|c|}{$\begin{array}{l}\text { Optimisation of protection in medical imaging according to the BSS Directive 2013/59/Euratom: DRLs, MPE, team work } \\
\text { Georgi Simeonov ( } 20 \mathrm{~min} \text { ) }\end{array}$} \\
\hline & \multicolumn{3}{|c|}{$\begin{array}{l}\text { Optimization in medical imaging. Practical examples in Interventional Radiology } \\
\text { Eliseo Vaño }(20 \mathrm{~min})\end{array}$} \\
\hline 10:45-11:15 & \multicolumn{3}{|c|}{ Coffee break / Poster Session } \\
\hline \multirow{5}{*}{ 11:15-12:45 } & $\begin{array}{l}\text { Radon and Health Public } \\
\text { Chairs: Mário Reis, Sandra Soares }\end{array}$ & & $\begin{array}{l}\text { Optimization } 1 \\
\text { rs: Ana Pascoal, Hugo Trindade }\end{array}$ \\
\hline & $\begin{array}{l}\text { The exposure to radon gas - causes and effects in human health } \\
\text { Maria de Lurdes Dinis ( } 30 \mathrm{~min} \text { ) }\end{array}$ & $\begin{array}{l}\text { Dose values } \\
\text { multicenter } \\
\text { Joana Santo }\end{array}$ & ional computed tomography procedures: a \\
\hline & $\begin{array}{l}\text { Geogenic radon in Portugal: summary and contribution for the } \\
\text { conception of risk maps } \\
\text { Alcides Pereira ( } 30 \mathrm{~min})\end{array}$ & $\begin{array}{l}\text { A Portugues } \\
\text { intraoral rad } \\
\text { Guilherme C }\end{array}$ & $\begin{array}{l}\text { regarding dose assessment and image quality in } \\
\operatorname{min)}\end{array}$ \\
\hline & $\begin{array}{l}\text { Temporal variability of gamma radiation at the Eastern North Atlantic } \\
\text { (ENA) site (Azores) } \\
\text { Susana Barbosa (15 } \mathrm{min})\end{array}$ & $\begin{array}{l}\text { Image qualit } \\
\text { for routine c } \\
\text { Hugo Trinda }\end{array}$ & $\begin{array}{l}\text { nammography- evaluation of protocols and guides } \\
\text { ol }\end{array}$ \\
\hline & $\begin{array}{l}\text { Radon Concentration Assessment in Water Sources of Public Drinking } \\
\text { of Covilhã's County, Portugal } \\
\text { Margarida Inácio (15 min) }\end{array}$ & & \\
\hline $12: 45-14: 00$ & & ch break & \\
\hline \multirow{7}{*}{ 14:00-15:30 } & \multicolumn{3}{|c|}{$\begin{array}{l}\text { Break-out session } 2 \text { - Implementation of DRLs - examples of their use and usefulness } \\
\text { Chairs: Eliseo Vaño, Jenia Vassileva, Joana Santos }\end{array}$} \\
\hline & \multicolumn{3}{|c|}{$\begin{array}{l}\text { The ICRP recommendation on establishing and using DRLs } \\
\text { Eliseo Vaño (15 } \mathrm{min})\end{array}$} \\
\hline & \multicolumn{3}{|l|}{$\begin{array}{l}\text { Experiences of IAEA Member States with setting and using DRLs } \\
\text { Jenia Vassileva (15 } \mathrm{min})\end{array}$} \\
\hline & \multicolumn{3}{|c|}{$\begin{array}{l}\text { Spanish experience with DRLs and optimization in interventional cardiology and radiology } \\
\text { Eliseo Vaño (15 } \mathrm{min})\end{array}$} \\
\hline & \multicolumn{3}{|c|}{$\begin{array}{l}\text { Portuguese DRLs approaches. Promoting a new national survey } \\
\text { Joana Santos (15 } \mathrm{min})\end{array}$} \\
\hline & \multicolumn{3}{|l|}{$\begin{array}{l}\text { The impact of optimization program on DRLs } \\
\text { Graciano Paulo }(15 \mathrm{~min})\end{array}$} \\
\hline & \multicolumn{3}{|l|}{ Open discussion (15 min) } \\
\hline $15: 30-15: 50$ & \multicolumn{3}{|c|}{ Coffee break / Poster Session } \\
\hline \multirow{5}{*}{ 15:50-17:10 } & $\begin{array}{l}\text { External Radiotherapy \& Brachytherapy } \\
\text { Chairs: Sandra Vieira, Maria do Carmo Lopes }\end{array}$ & Computa & $\begin{array}{l}\text { Aations in radiological protection and dosimetry } \\
\text { Ana Belchior, Salvatore di Maria }\end{array}$ \\
\hline & $\begin{array}{l}\text { Target Definition: the Weakest Link in (Single dose) RT? } \\
\text { Sandra Vieira ( } 20 \mathrm{~min})\end{array}$ & $\begin{array}{l}\text { Dose conver } \\
\text { Carlo calcula } \\
\text { Pedro Teles }\end{array}$ & $\begin{array}{l}\text { for the kidney of paediatric patients from Monte } \\
N \text { paradigm }\end{array}$ \\
\hline & $\begin{array}{l}\text { lodine-125 Brachytherapy in chroidal melanoma } \\
\text { Paulo César Simões }(20 \mathrm{~min})\end{array}$ & $\begin{array}{l}\text { Clinical issue } \\
\text { intervention } \\
\text { Ana Belchior }\end{array}$ & $\begin{array}{l}\mathrm{m} \text { patients' organ dose and risk assessment in } \\
\text { y procedures }\end{array}$ \\
\hline & $\begin{array}{l}\text { The HESE Radiotherapy Methods for Pretreatment Patient Quality } \\
\text { Assurance (QA) using Intensity Modulated Techniques } \\
\text { Carlos Marcelino ( } 20 \mathrm{~min} \text { ) }\end{array}$ & $\begin{array}{l}\text { Organ Dose } \\
\text { Matching W } \\
\text { Jorge Borbin }\end{array}$ & $\begin{array}{l}\text { Thorax CT through CAD: Voxel Phantom Organ } \\
\text { I Patient Anatomy }\end{array}$ \\
\hline & $\begin{array}{l}\text { From Image-Guided to Adaptive Radiotherapy in Helical Tomotherapy } \\
\text { Josefina Mateus ( } 20 \mathrm{~min} \text { ) }\end{array}$ & $\begin{array}{l}\text { Monte Carlo } \\
\text { therapy } \\
\text { Francisco Lib }\end{array}$ & at a sub-cellular scale of targeted $\alpha$-particle \\
\hline \multirow{5}{*}{ 17:10-18:30 } & \multicolumn{3}{|c|}{$\begin{array}{l}\text { Panel } 2 \text { - Directive 2013/59/EURATOM contents, impact and consequences - where do we stand in Portugal? } \\
\text { Chair: Pedro Rosário, João Oliveira Martins } \\
\text { Panelists: Georgi Simeonov, Steve Ebdon-Jackson, Rita Figueira, Anabela Januário, Graciano Paulo, Lucília Salgado }\end{array}$} \\
\hline & \multicolumn{3}{|c|}{$\begin{array}{l}\text { Overview of the current status of transposition of the BSS Directive in Member States } \\
\text { Georgy Simeonov (10 } \mathrm{min} \text { ) }\end{array}$} \\
\hline & \multicolumn{3}{|l|}{$\begin{array}{l}\text { The transposition in Portugal - a status report } \\
\text { Members of the Interministerial Working Group on the BSS Directive (20 min) }\end{array}$} \\
\hline & \multicolumn{3}{|l|}{ Commentary by panelists ( 5 min each) } \\
\hline & \multicolumn{3}{|l|}{ Open discussion (15 min) } \\
\hline
\end{tabular}


Friday, September 29, 2017

\begin{tabular}{|c|c|c|c|c|}
\hline 08:30-09:15 & $\begin{array}{l}\text { Refresher course } 4 \\
\text { Micro- and Nanodosimetry } \\
\text { Ana Belchior }\end{array}$ & \multicolumn{2}{|c|}{$\begin{array}{c}\text { Refresher course } 5 \\
\text { Communicating radiation risks in medical setting } \\
\text { Maria Perez, Steve Ebdon-Jackson }\end{array}$} & $\begin{array}{l}\text { Refresher course } 6 \\
\text { Dosimetry audits in radiotherapy } \\
\text { Maria do Carmo Lopes }\end{array}$ \\
\hline \multirow{7}{*}{ 09:15-10:45 } & \multicolumn{4}{|c|}{$\begin{array}{l}\text { Radiobiology and low doses of ionizing radiation } \\
\text { Chairs: Sebastião Rodrigues, Octávia Monteiro Gil }\end{array}$} \\
\hline & \multicolumn{2}{|c|}{$\begin{array}{l}\text { Dose and reconstruction algorithm optimization in simultaneous } \\
\text { breast/lung CT imaging } \\
\text { Débora António ( } 20 \mathrm{~min} \text { ) }\end{array}$} & \multicolumn{2}{|c|}{$\begin{array}{l}\text { Genotoxicity Biomarkers: applications and challenges in Radiobiology } \\
\text { Nuno Oliveira }(20 \mathrm{~min})\end{array}$} \\
\hline & \multicolumn{2}{|c|}{$\begin{array}{l}\text { Dosimetric link between Computed Dose Tomography Dose index (CTDI) } \\
\text { and Cone Beam CT organ doses: case study for thorax scan protocol } \\
\text { Mariana Baptista ( } 20 \mathrm{~min})\end{array}$} & \multicolumn{2}{|c|}{$\begin{array}{l}\text { Low doses of ionizing radiation induce angiogenesis: benefits, concerns } \\
\text { and challenges to health and science } \\
\text { Susana Constantino }(20 \mathrm{~min})\end{array}$} \\
\hline & \multicolumn{2}{|c|}{$\begin{array}{l}\text { CT Radiation Dose Optimization - Clinical Practice Approach } \\
\text { Filipa Borlinhas (20 } \mathrm{min})\end{array}$} & \multicolumn{2}{|c|}{$\begin{array}{l}\text { Radiopharmacy - Radiobiological concerns regarding } \\
\text { radiopharmaceuticals applications } \\
\text { Lurdes Gano }(20 \mathrm{~min}) \\
\end{array}$} \\
\hline & & & \multicolumn{2}{|c|}{$\begin{array}{l}\text { Low doses of ionizing radiation induce angiogenesis: therapeutic } \\
\text { implications } \\
\text { Filipa Marques }(10 \mathrm{~min})\end{array}$} \\
\hline & & & \multicolumn{2}{|c|}{$\begin{array}{l}\text { Genetic damage induced in exfoliated buccal cells after } \\
\text { orthopantomography } \\
\text { Octávia Monteiro Gil }(10 \mathrm{~min})\end{array}$} \\
\hline & & & \multicolumn{2}{|c|}{$\begin{array}{l}\text { Low-dose ionizing radiation induces therapeutic neovascularization in a } \\
\text { pre-clinical model of hindlimb ischemia } \\
\text { Paula de Oliveira }(10 \mathrm{~min})\end{array}$} \\
\hline 10:45-11:15 & \multicolumn{4}{|c|}{ Coffee break / Poster Session } \\
\hline \multirow{5}{*}{ 11:15-12:45 } & $\begin{array}{r}\text { Optimiz } \\
\text { Chairs: Paula Madeir }\end{array}$ & Baptista & \multicolumn{2}{|c|}{$\begin{array}{l}\text { Nuclear Medicine and Molecular Imaging } 3 \\
\text { Chairs: João Santos, Pedro Teles }\end{array}$} \\
\hline & \multicolumn{2}{|c|}{$\begin{array}{l}\text { Influence of the axial scan orientation angle and gantry tilt in Head CT } \\
\text { dose exposure } \\
\text { Rui Pereira }(20 \mathrm{~min}) \\
\end{array}$} & \multicolumn{2}{|c|}{$\begin{array}{l}\text { Online monitoring of Nuclear Medicine services } \\
\text { Maria do Carmo Baptista (20 min) }\end{array}$} \\
\hline & \multicolumn{2}{|c|}{$\begin{array}{l}\text { Effective dose to patients from PET/CT procedures } \\
\text { Sara Russo }(20 \mathrm{~min})\end{array}$} & \multicolumn{2}{|c|}{$\begin{array}{l}\text { Skin Contamination Survey on the Daily Practice of Nuclear Medicine Staff } \\
\text { Nélio Fernandes ( } 20 \mathrm{~min})\end{array}$} \\
\hline & \multicolumn{2}{|c|}{$\begin{array}{l}\text { Dose and Image Quality in Computed Tomography: an overview of } \\
\text { Portuguese Data } \\
\text { Ana Margarida Coutinho (20 min) }\end{array}$} & \multicolumn{2}{|c|}{$\begin{array}{l}\text { Minimisation of acquisition time in a TOF PET/CT scanner without } \\
\text { compromising image quality } \\
\text { Joana Oliveira ( } 20 \mathrm{~min} \text { ) }\end{array}$} \\
\hline & & & \multicolumn{2}{|c|}{$\begin{array}{l}\text { Radionuclides in Waste Discharges from Health Establishments } \\
\text { Nélia Soares (20 min) }\end{array}$} \\
\hline $12: 45-14: 00$ & \multicolumn{4}{|c|}{ Lunch break } \\
\hline \multirow[t]{2}{*}{ 14:00-15:30 } & \multicolumn{4}{|c|}{$\begin{array}{l}\text { Panel } 3 \text { - Radiation Safety Culture, accidents and near misses in medical uses of radiation } \\
\text { Chairs: Steve Ebdon-Jackson, Georgi Simeonov } \\
\text { Panelists: Wolfgang Weiss, Jenia Vassileva, Luís Neves, Maria do Carmo Lopes, Ana Pascoal, Jorge Isidoro }\end{array}$} \\
\hline & \multicolumn{4}{|c|}{$\begin{array}{l}\text { Managing Radiation Incidents in Radiology in a Busy Hospital } \\
\text { Ana Pascoal (15 min) }\end{array}$} \\
\hline \multirow{5}{*}{ 15:30-16:30 } & $\begin{array}{r}\text { Radiation Saf } \\
\text { Chairs: Paula Simãozinho, }\end{array}$ & rmen de Sousa & $\begin{array}{r}\text { Methodolog } \\
\text { Chairs }\end{array}$ & $\begin{array}{l}\text { systems of dose assessment } \\
\text { and personnel) } \\
\text { eralta, Yuriy Romanets }\end{array}$ \\
\hline & \multicolumn{2}{|c|}{$\begin{array}{l}\text { Working with ionization radiation: what do you know about it? } \\
\text { Risk perception when working with radiation } \\
\text { Ana Sofia Pinheiro (15 min) }\end{array}$} & \multicolumn{2}{|c|}{$\begin{array}{l}\text { Metrological comparison of two thermoluminescent dosimeters (TLD) } \\
\text { types using a linear accelerator and a new methodology for beam } \\
\text { heterogeneity correction in the clinical dose range } \\
\text { Andreia Oliveira ( } 20 \mathrm{~min} \text { ) }\end{array}$} \\
\hline & \multicolumn{2}{|c|}{$\begin{array}{l}\text { Preliminary Results of a Multidisciplinary Approach for Clinical Auditing } \\
\text { in Radiology Departments - The Primary Care Experience in the Algarve } \\
\text { Margarida Faria (15 min) }\end{array}$} & \multicolumn{2}{|c|}{$\begin{array}{l}\text { Dosimetry of kV Cone Beam CT with scintillation dosimeter } \\
\text { Luis Peralta ( } 20 \mathrm{~min})\end{array}$} \\
\hline & \multicolumn{2}{|c|}{$\begin{array}{l}\text { Radiation Protection and Safety at Portuguese Institute of Oncology of } \\
\text { Coimbra: } 15 \text { years of experience } \\
\text { Maria Carmen de Sousa (15 min) } \\
\end{array}$} & \multicolumn{2}{|c|}{$\begin{array}{l}\text { Development of home-made primary standards for ionizing radiation: a } \\
\text { cavity chamber for the measurement of air-kerma } \\
\text { Margarida Caldeira ( } 20 \mathrm{~min} \text { ) }\end{array}$} \\
\hline & \multicolumn{2}{|c|}{$\begin{array}{l}\text { Hospital Survey on Patient Safety Culture - The Radiology Department } \\
\text { Kevin Azevedo (15 min) }\end{array}$} & & \\
\hline $16: 30-17: 00$ & \multicolumn{4}{|c|}{ Closing Session } \\
\hline
\end{tabular}





\section{Presentations - Index}

Plenary - Justification of medical exposures

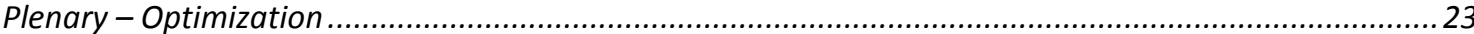

Break-out Session - Education, training, qualification and certification in radiological protection ..........29

Break-out Session - Implementation of DRLs - examples of their use and usefulness ............................33

Panel - Radiation safety culture, accidents and near misses in medical uses of radiation .......................37

Oral Presentations - Computacional applications in radiological protection and dosimetry .................... 39

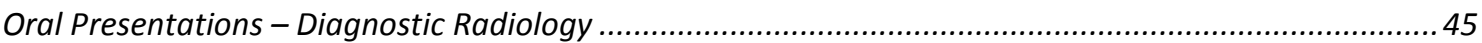

Oral Presentations - External Radiotherapy and Brachytherapy .......................................................... 49

Oral Presentations - Interventional image guided procedures ..........................................................55

Oral Presentations - Methodologies and systems of dose assessment (patient and personnel) ..............59

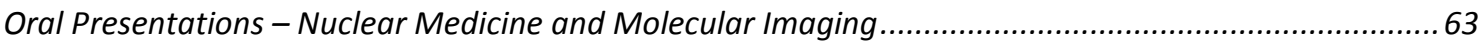

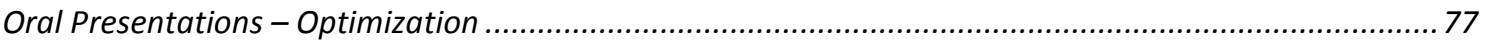

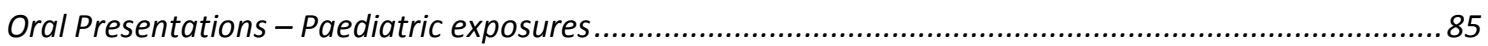

Oral Presentations - Radiation and safety culture ........................................................................ 91

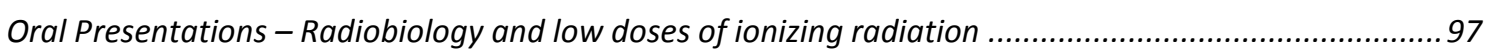

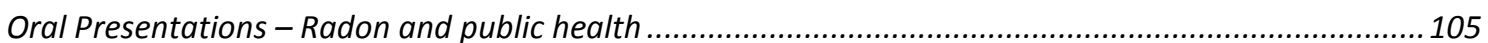

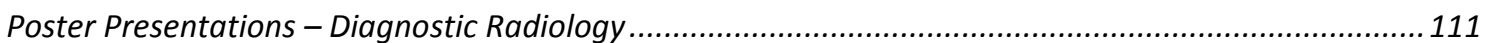

Poster Presentations - Education, training, qualification and certification in radiological protection .... 113

Poster Presentations - External Radiotherapy and Brachytherapy................................................... 115

Poster Presentations - Imaging in pregnancy and foetal exposure ...................................................117

Poster Presentations - Interventional image guided procedures....................................................... 119

Poster Presentations - Methodologies and systems of dose assessment (patient and personnel) ......... 121

Poster Presentations - Nuclear Medicine and Molecular Imaging ................................................... 125

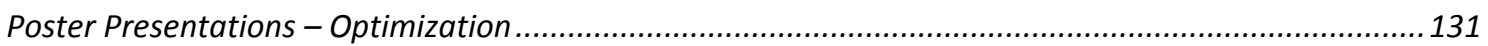

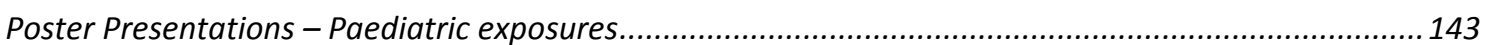

Poster Presentations - Procedures performed outside the imaging service ......................................... 147

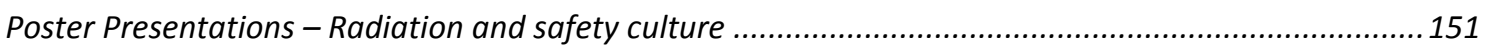

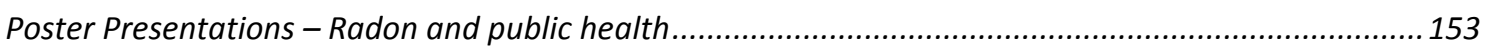

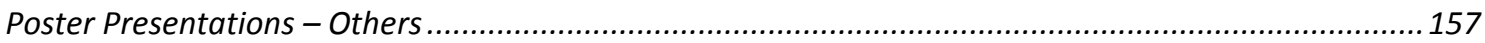





\title{
Justification of individual medical exposures - a regulators views on the process and responsibilities
}

\author{
Steve Ebdon-Jackson $^{1}$ \\ ${ }^{1}$ Centre for Radiation, Chemical and Environmental Hazards, Public Health England, UK \\ Corresponding author: Steve.ebdon-jackson@phe.gov.uk \\ Introduction \\ Justification is one of the two principles of radiation protection that apply to medical \\ exposures. It is a key aspect of the EC Directive 2013/59/Euratom Chapter VII on Medical \\ Exposures.
}

\section{Methods}

The Directive requires that Member States ensure that justification is carried out in advance of the exposure, that previous relevant information is obtained where practicable, that the principle applies to a range of medical exposures and that the involvement of referrers and practitioners is defined.

\section{Results}

Approaches to justification vary among EU Member States and for different types of medical exposure. Diagnostic radiology offers specific challenges regarding the discharge of responsibilities prior to the exposure taking place.

\section{Conclusions}

Clarity regarding the justification process is an essential element of good, safe and appropriate medical exposures and healthcare. 


\section{Justification of medical exposures: first do not net harm}

\section{Maria del Rosario Perez ${ }^{1}$}

${ }^{1}$ World Health Organization (WHO), Department of Public Health, Environmental and Social Determinants of Health (PHE), Radiation Programme

Corresponding author: perezm@who.int

\section{Introduction}

The system of radiological protection aims to control radiation risks to provide an adequate level of protection without unduly limiting the potential benefits for individuals and for society. The principle of justification is generically applied by ensuring that any decision that alters a radiation exposure situation should do more good than harm. In medical exposures, justification means that the radiological procedure will result in more benefit than risk (i.e. a net benefit). In this context, the process of generic and individual justification has to consider the radiation dose and associated risks together with clinical evidence, medical expertise, values and prevalent circumstances to decide what is appropriate for an individual or population.

\section{Methods}

This paper discusses the principle of justification and the key elements to be considered for its implementation in different scenarios, with a focus on generic and individual justification of medical exposures.

\section{Results}

While evidence-based guidelines can assist decision-making for patients with clinical signs and/or symptoms, there is lack of evidence regarding radiological procedures in asymptomatic individuals. The situation differs in the case of approved population-screening programs for specific diseases (e.g. mammography screening), long-term follow-up of affected populations (e.g. after an accidental exposure), and opportunistic screening (e.g. individual health assessment). Justification of these practices requires multiple considerations which go beyond the assessment of the radiation risk, such as overdiagnosis / overtreatment, false positives, false negatives, incidental findings, health financing and ethical dilemmas.

\section{Conclusions}

Ensuring justification of radiological procedures is implicit in the notion of good medical practice. Its implementation eliminates unnecessary or inappropriate referrals and is therefore a key measure to control unnecessary radiation exposures in healthcare. 


\title{
Justification of Precision Medicine
}

\author{
José Rueff $^{1}$ \\ ${ }^{1}$ Centre for Toxicogenomics and Human Health, Genetics, Oncology and Human Toxicology. \\ Nova Medical School/Faculdade de Ciências Médicas Universidade Nova de Lisboa. Rua \\ Câmara Pestana 6, 1150-008 Lisboa, Portugal \\ Corresponding author: rueff.gene@nms.unl.pt
}

\section{Introduction}

Precision medicine can be broadly defined as the selection of a treatment modality which may better suit the condition of the patient. Thus precision medicine is clearly a justification of the need to assess individual response to radiation. In the case of cancer it may better enhance the response with a minimal of side effects, or treatment modality that is tailored to the genetic and phenotypic characteristics of a particular cancer. The aim in cancer is to use agents that inhibit cell signaling pathways that drive uncontrolled proliferation and dissemination of the disease. To reach the best results radiotherapy has been combined with chemotherapy.

\section{Methods}

Current predictors of a radiation response rely essentially in clinical and histopathologic data. However, the potential correlation between radiation sensitivity and genomic parameters are now by and large available to serve the purpose of precision medicine. Indeed, this era of precision medicine may allow -omic determinants to guide personalization of radiation therapy to the unique characteristics of each patient's cancer. Ascertaining the -omic determinants of radiation sensitivity of cancer has great potential in enhancing efficacy and limiting toxicity.

\section{Results}

Amongst the set of genes that may serve as potential predictors of radiation response (e.g. $B R C A n e s s$ as defined as traits that some cancers may share with those occurring in either $B R C A 1$ - or BRCA2-mutation carriers) or, conversely of radiation resistance, are the DNA damage response (DDR) genes. Whether loss-of-function of DDR genes may increase susceptibility to oncogenesis and may, even if simply polymorphic (SNVs) behave as etiologic, with challenges to genomic integrity increasing the probability that cells acquire the alterations that drive uncontrollable cell division, these alterations may confer therapeutic sensitization. On the other hand, alterations in DDR genes, namely DNA repair genes that enhance varied aspects of the DDR (particularly in the case of the homologous recombination repair (HRR) genes, can bypass the DNA-damage effects of radiotherapy allowing cancer cell survival and growth by sustaining genomic integrity conferring therapeutic resistance.

\section{Conclusions}

The currently available -omic procedures namely through 'liquid biopsy' approaches (cell-free tumor DNA; DNA and/or miRNAS in exomes) open new avenues of early detection of relapse of tumors and therefore timely adaptation and justification of the therapy, not only searching for BRCAness-like events in HRR genes but also probably in other biomarkers detectable in circulation in early stages of resistance. 


\title{
Justification of Medical Exposures: A Clinical Perspective
}

\author{
José Venâncio ${ }^{1}$ \\ ${ }^{1}$ Instituto Português de Oncologia de Lisboa Francisco Gentil, EPE. R. Prof. Lima Basto, 1099- \\ 023 Lisboa, Portugal \\ Corresponding author: jvenancio@ipolisboa.min-saude.pt
}

\section{Introduction}

More than one century of utilization of X-Rays for Medical purposes, Health Professionals must be aware and well informed about the safe use of ionizing radiations in Medicine.

We need a Radiological Protection Culture in Medicine.

Justification is one of the Basic Principles of Radiation Protection, and probably the more important one concerning Medical exposures and it has been used empirically for many decades. By definition Justification means that: "any practice involving radiation exposure should overall do more good than harm to the exposed individual or to the society, and that any intervention with the purpose to reduce existing doses should be more beneficial than harmful".

Justification is obviously used jointly with the other basic principle or Radioprotection: optimization and respecting the practical aspects of Diagnostic Reference Levels.

\section{Methods}

The decision to practice a radiological examination versus another method without ionizing radiation like ultrasound or MRI is based on experience, clinical sense and decision, guidelines and the agreement between the practitioner and the radiologist. We must consider several points like the justification and the urgency of any procedure during pregnancy or possible pregnancy; the problems of justification, repeat films and previous examinations; for economic reasons and due to some countries availability, we can choose fluoroscopy instead of radiological examinations; other objectives, like insurance purposes instead of clinical benefits...

In some practices like Interventional, Vascular Radiology or dental practitioners there are an increasing number of procedures that are done by non-radiologists in facilities outside the Radiology Departments, without the adequate supervision and knowledge of radiation protection. Radiographers and Medical Physicist, must be involved in the elaboration of protocols to get confidence in medical examinations.

There are several levels of responsibility in the Justification of exposure: the employer or the owner of the facility; the referrer, who must provide adequate clinical data to justify the medical exposure; the clinical practitioner that include Radiologists, radiographers, cardiologists, surgeons or others; the operator, that carry out the medical exposure, according to adequate guidelines.

\section{Results}

Imaging plays a central role in Modern Medicine. Several papers show that $30 \%$ of radiological studies are inappropriate. A useful investigation is one in which the result, positive or negative, will inform clinical management and/or add confidence to the clinician's diagnosis. A significant number of investigations do not fulfill these aims and with plain films and CT may add unnecessarily irradiation to patient.

Justification with its three levels, is established through evidence based Clinical Guidelines and the European BSS Directive 2013/59/EURATOM, obliges all the European Countries to the 
transposition to National Law. Concerning Justification there are important changes, and the most significant respects to patient information, responsibilities and dose reporting.

\section{Conclusions}

Radiation Protection (RP) must be understood as a priority of the hospital/ radiological facility and as important as diagnose, teaching or research and need to have human resources and adequate material.

How to implement Justification?

-Ensure that those referred for radiological examinations really need them

-The audit of the effectiveness of the referral and related processes

-Effectively communicate about radiation risk to: patients, physicians, surgeons, and of course the Radiologists/Radiographers who are responsible for performing them.

Clinical Decision Support in Imaging is based on Imaging Guidelines. Worldwide there are several National Guidelines. European Society of Radiology negotiates a Transatlantic partnership with the American College of Radiology and adapted their Appropriateness Criteria, which are now in an independent Pilot Phase in Barcelona. After this phase, we hope that the general use of Imaging Guidelines in Europe will be a fact. 


\title{
Justification of health protection measures in a nuclear emergency
}

\author{
Dr. Wolfgang Weiss ${ }^{1}$ \\ ${ }^{1}$ Federal Office for Radiation Protection (retired) \\ Corresponding author: wolfganq.weiss1@googlemail.com

\section{Introduction} \\ The goals of any health protection measure in a nuclear or radiological emergency is to do \\ more good than harm. In order to meet the overall objectives justification considerations for \\ health protection measures have to address both the radiation induced health risks as well as \\ health risks not directly related to radiation (psychological and other health effects). This is of \\ particular importance at low exposure levels for which psychological and other health effects \\ may dominate the harm to health of the affected population.
}

\section{Methods}

IAEA GSR Part 7 defines generic criteria, which are used to justify urgent protective measures (like evacuation) to avoid exposures resulting in deterministic health effect and to reduce to the extent practicable the radiation induced risks for stochastic health effects. The early identification of the remaining radiation induced health risks by medical screening can improve the success of medical treatment and psychological counselling. There are different criteria available for the establishment of medical screening programs and longer-term medical actions after a nuclear or radiological emergency, eg. (a) to identify people with an exposure which would require medical treatment and/or follow up, (b) to provide an opportunity for reassurance to the remaining part of the affected population for whom a medical follow-up would not be required. On the other hand medical screening can result in public concerns and a variety of non-radiological health effects. There is a need to develop criteria during preparedness to justify or to object against the implementation of urgent protective measures like evacuation and of unjustified medical screening programmes and longer term medical actions. These criteria as well as the results of medical screening have to be communicated to the concerned people.

\section{Results}

According to ICRP 109 "a dose rising towards $100 \mathrm{mSv}$ will almost always justify protective measures"; a value of $100 \mathrm{mSv}$ in 7 days is recommended for the justification of urgent protective measures like evacuation, sheltering, etc.. The available evidence from Fukushima clearly shows that at doses well below $100 \mathrm{mSv}$ the disaster related health effects can dominate the harm caused by radiation. A similar kind of imbalance can be observed for unjustified screening programs. For IAEA GSR Part 7 recommends an equivalent dose to "specific radiosensitive organs" of $100 \mathrm{mSv}$ in a month for the justification of health screening. Key questions require further considerations: is the numerical value of $100 \mathrm{mSv}$ in a month applicable for different organs, cancer types, age groups, etc., can screening be justified (well) below the generic value, how can the non-radiological consequences (psycho-social health consequences) addressed to avoid unwanted health risks?

\section{Conclusions}

It is important to include in the conceptual framework for health protection of the affected population considerations about the justification of different types of health protective measures as well as of medical screening programs. 



\title{
ICRP Recommendations on Radiological Protection in Medicine: Recent Achievements and Priorities for the 2017-2021 Term
}

\author{
Christopher Clement $^{1}$ \\ ${ }^{1}$ International Commission on Radiological Protection \\ Corresponding author: sci.sec@icrp.org

\section{Introduction} \\ The International Commission on Radiological Protection (ICRP), formed in 1928, develops the \\ System of Radiological Protection for the public benefit. The objective is to contribute to an \\ appropriate level of protection for people and the environment against the harmful effects of \\ radiation exposure without unduly limiting the individual or societal benefits of activities \\ involving radiation. It is the basis of RP standards and practice worldwide. RP in medicine has \\ been a core feature of ICRP work since its inception.
}

\section{Methods}

ICRP operates on four-year terms, the next beginning July 1, 2017. The three key ICRP priorities are to: (i) increase engagement with professionals, policymakers, and the public; (ii) promote awareness of radiological protection and broaden access to ICRP recommendations; and, (iii) maintain and continue to improve the system of RP. The coming term will see an emphasis on integrating protection of people and the environment within the system, with a programme of work and revised Committee structure to support this.

\section{Results}

Many ICRP publications are in RP in medicine. Recently, these have included: RP in Cone Beam Computed Tomography (Publication 129), Radiation Dose to Patients from Radiopharmaceuticals: A Compendium of Current Information Related to Frequently Used Substances (Publication 128), and RP in Ion Beam Radiotherapy (Publication 127). Reports in advanced drafting cover topics including: occupational RP in interventional procedures, and diagnostic reference levels in medical imaging.

\section{Conclusions}

The mandate of ICRP Committee 3 on RP in medicine is being revised to explicitly include veterinary medicine. This area will be explored more fully in the coming term. As well, it is expected that the coming term will include an initiative on the ethics of RP in medicine, as part of the wider effort to consider ethics more explicitly throughout the system. 


\title{
Optimisation of protection in medical imaging according to the BSS Directive 2013/59/Euratom: DRLs, MPE, team work
}

\author{
Georgi Simeonov $^{1}$ \\ ${ }^{1}$ European Commission, Directorate-General for Energy \\ Corresponding author: georgi.simeonov@ec.europa.eu
}

\section{Introduction}

The "Basic Safety Standards" (BSS) Directive 2013/59/Euratom was published in 2014 and has to be implemented in the EU Member States by 6 February 2018. The BSS Directive updates and consolidates previous pieces of European legislation and introduces some important changes, including in relation to protection of patients. The Directive introduces, inter alia, stronger requirements for DRLs, involvement of MPE in imaging and professional co-operation in optimisation.

\section{Methods}

The European Commission is empowered to monitor the implementation of the European BSS in the Member States and take corrective action, wherever necessary. The Commission implements also a series of 'soft measures' to support the implementation of the BSS Directive into the regulatory system and everyday practice. Most recently, the Commission launched studies, some resulting in practice guidelines, on the MPE qualification, education and training of medical professionals and on paediatric DRLS. The main focus in the next years will be on ensuring full implementation of the BSS Directive. One specific area, where the Commission will focus further efforts, is the development and use of DRLs; a European survey aiming to advance the concept of clinically-specified DRLs has been recently launched.

\section{Results}

The status of implementation of the BSS Directive 2013/59/Euratom varies among the EU Member States. In recent years, important progress has been achieved in many countries towards the introduction and update of DRLs. The involvement of the MPE in radiological imaging is now foreseen in many national legislations. The concept of the clinical ALARA-team was developed some years ago (EMAN project) and its implementation into practice will depend on strong local support by the professionals concerned.

\section{Conclusions}

Advancing optimisation of protection in medical imaging is among the main objectives of the BSS Directive 2013/59/Euratom. The Directive defines the DRLs, the involvement of an MPE and the team work as the key elements of a successful approach to optimisation in clinical environment. Top-down and bottom-up European, national and local action is needed, and is in many cases underway, to guarantee full and correct BSS implementation by February 2018. 


\title{
Optimization in medical imaging. Practical examples in Interventional Radiology
}

\author{
Eliseo Vano $^{1}$ \\ ${ }^{1}$ Complutense University. Radiology Department and San Carlos Hospital. 28040 Madrid. Spain \\ Corresponding author: eliseov@med.ucm.es
}

\section{Introduction}

Optimization in medical imaging is not always equivalent to minimize patient doses. ALARA is only part of the concept of optimization in Medicine. The image quality, or more precisely, the required diagnostic information when many images are used, should be the priority. Staff doses should also be considered during optimization in interventional radiology. Some examples for fluoroscopy guided procedures are presented.

\section{Methods}

Optimization requires to manage patient dose parameters (Kerma Area Product -KAP, Air Kerma -AK, etc.) and the required diagnostic information. During interventional procedures, several imaging acquisition modes and several options on the number of images per second, together with the X-ray beam angulations, need to be selected. Skin dose distribution to the patient is relevant for complex procedures. Static image quality evaluation is not enough and interventionalists need to be involved to define the diagnostic information required as part of the optimization process. The availability of real time dosimetric parameters (for patient and staff) facilitate the "proactive optimization" during interventional procedures. The documentation on the individual radiation events may be available at the automatic patient dose registries, allowing new strategies for optimization.

\section{Results}

KAP and AK are the main dose quantities used as part of the DRLs for interventional radiology, but fluoroscopy time and number of acquired images are also recommended. Optimization methods may be different if some of these dosimetric indicators are higher than the DRLs. If interventionalists take into account the dosimetric parameters during the procedures and if the skin dose map is available in real time, it will be possible to modify the angulations of the $\mathrm{C}$-arm and the collimation of the X-ray beam to reduce the peak skin dose. The DICOM radiation dose structured report (RDSR) allows the automatic patient dose registration for all the radiation events during the procedures. The post-procedure analysis of these patient dose registries may suggest the appropriate optimization strategy. Staff doses for the different patient radiation events (when available) should also be considered during the optimization.

\section{Conclusions}

New technology in the X-ray interventional systems (real time patient and staff dose information and patient skin dose maps) complemented with more efforts in training of the staff are allowing more effective optimization actions. 


\title{
Practical steps for optimizing diagnostic radiological procedures
}

\author{
Jenia Vassileva ${ }^{1}$ \\ ${ }^{1}$ International Atomic Energy Agency, Division of Radiation, Transport and Waste Safety, \\ Radiation Protection of Patients Unit, Vienna, Austria \\ Corresponding author: j.vassileva@iaea.org

\section{Introduction} \\ According to the International Basic Safety Standards (GSR Part 3), the application of the \\ optimization principle to the medical exposure requires a special approach. Too low a radiation \\ dose could be as bad as too high radiation dose, and it is of paramount importance that the \\ medical exposure leads to the required outcome. In diagnostic and interventional medical \\ exposure, optimization means keeping the exposure to the minimum necessary to achieve the \\ required clinical objective.
}

\section{Methods}

Key personnel in the optimization process are the radiological medical practitioner, the medical radiation technologist and the medical physicist. It also requires involvement of the governmental bodies and relevant professional bodies for establishing diagnostic reference levels (DRLS) for medical exposures and dose constraints for carers and volunteers in biomedical research programmes, and ensuring their proper utilization.

\section{Results}

The first step in optimization is selection of the appropriate and well-designed radiological equipment. Quality assurance (QA) system should be in place, including acceptance testing, commissioning and periodic constancy tests, aimed to ensure that, at all times, equipment is performing correctly, reproducibly and predictably. Appropriate technique and parameters (protocols) should be used to perform procedure with the minimum exposure to patient necessary to fulfill the clinical task. These protocols should be specific to the modality, clinical task and patient size. Local assessments of typical doses to patients for common procedures and their comparison to the relevant DRLs should be performed, and review conducted to determine whether protocols and procedures need correction. Periodic 'checks and balances' ensure that the protocols and procedures are being followed. Regular independent clinical audits are an asset to the QA program. Examples will be given for successful optimization in diagnostic radiology.

\section{Conclusions}

Optimization is a prospective iterative process that requires understanding of factors contributing to patient and staff radiation dose, and team work to achieve best result. 



\section{Radiation Protection in the Healthcare Field in Spain. A General Outlook $\underline{\text { Lorenzo Carretero Guisado }}^{1}$}

${ }^{1}$ Ad Qualitas, SAU (Group TUV Austria)

Corresponding author: Icarretero@adq.es

Introduction

A general presentation of the current situation in Spain of the radiological protection of workers, the public and patients in the healthcare environment in Spain

Methods

Spanish legal framework on health protection against ionizing radiation Spanish Protocol on Quality Control in Radiodiagnosis

Required qualifications

The homologation of training courses or programs for the personnel who have responsibilities or operate the $\mathrm{X}$-ray equipment for the purpose of medical diagnosis

\section{Results}

Technical aspects of safety and radiological protection of the facilities

\section{Conclusions}

Role of the Technical Units Of Radiological Protection authorized by the Nuclear Safety Council in this field. 


\title{
Preliminary results from the 2016 "Inquérito Nacional sobre Educação e Formação em Proteção Radiológica na Saúde"
}

\author{
$\underline{\text { Rita Figueira }}^{1,4}$, Jorge Isidoro ${ }^{2,4}$, Esmeralda Poli ${ }^{3,4}$ \\ ${ }^{1}$ Serviço de Radioterapia, Centro Hospitalar São João \\ ${ }^{2}$ Serviço de Medicina Nuclear, Centro Hospitalar e Universitário de Coimbra \\ ${ }^{3}$ Unidade de Física Médica, Centro Hospitalar Lisboa Norte \\ ${ }^{4}$ DFM-SPF, Divisão de Física Médica da Sociedade Portuguesa de Física
}

Corresponding author: arfiqueira@gmail.com

\section{Introduction}

It has been recognized by leading international organizations that adequate education and training are essential requirements to ensure the quality and safety of medical procedures using ionizing radiation and to minimize the risks of their use, safeguarding patients, professionals and the general public. DFM-SPF promoted a national survey with the intention of assessing the professionals' perspective on their training in radiological protection and, also, how institutions in Portugal work on this topic.

\section{Methods}

A survey with approximately 20 questions was prepared and advertised using the help of different professional and scientific associations and societies and also sent directly to the main national hospitals with a request of dissemination among health professionals exposed to ionizing radiation.

\section{Results}

The survey got more than 350 participants from different professional groups (48.4\% radiation technologists, $17.9 \%$ medical physicists, $14.7 \%$ medical doctors and $13.4 \%$ nurses). The majority of the responders work in Diagnostic Radiology, followed by Radiotherapy and Nuclear Medicine. 92.5\% would like to complement their knowledge and education in radiation protection and the training procedure considered more appropriate was practical training in work environment. Even tough, $48.8 \%$ of the participants state that the institution they work for does not provide regular training in radiation protection.

\section{Conclusions}

The results of the survey were analyzed and resulted in compiled specific information from our country, available to help organizations and professionals in the area to update their training in radiation protection and contributing to the improvement of safety and radiation protection in the medical applications of ionizing radiation. Medical physicists can play an important role in this subject since "training of practitioners and other staff in relevant aspects of radiation protection" is one of their recognized attributes. 


\title{
MEDRAPET: An Overview of a European Commission DG ENER Project*
}

\author{
$\underline{\text { Graciano Paulo }^{1}}$
}

${ }^{1}$ IPC-ESTESC

*invited talk

Corresponding author: graciano@estescoimbra.pt

\section{Introduction}

Medical exposures constitute a considerable source of radiation exposure to human population.

The European Commission initiated the MEDRAPET project (MEDical RAdiation Protection Education and Training, MEDRAPET) to a) perform a study on the implementation of the Medical Exposure Directive requirements on radiation protection training of medical professionals in the EU Member States and b) update the existing European Guidance.

The professional organizations involved in MEDRAPET include the main European stakeholders and professional groups involved with radiation protection training in the medical field i.e. the European Society of Radiology, the European Federation of Organizations for Medical Physics, the European Federation of Radiographer Societies, the European Society for Therapeutic Radiology and Oncology, the European Association of Nuclear Medicine and the Cardiovascular and Interventional Radiological Society of Europe.

\section{Methods}

A web-based survey was accomplished through development of an online questionnaire. All relevant categories of health care staff were considered in the study, including referrers, practitioners, radiographers, medical physicists and nurses.

\section{Results}

A total of 1023 contacts were obtained. Considering the 3 main groups targeted through the survey, the response rate was $57,1 \%$ for Radiation Protection Authorities, $25,3 \%$ for Professional Societies and 19,8\% for Education institutions.

\section{Conclusions}

All consortium members considered the reply rates positive.

The survey was targeted to the main stakeholders of European countries, with responsibility for ensuring the application of the MED. As expected by the MEDRAPET consortium members, Radiation Protection Education and Training (RP E\&T) are far from being harmonized and in some instances not even implemented in EU countries. 


\title{
The ICRP recommendation on establishing and using DRLs
}

\author{
Eliseo Vano ${ }^{1}$ \\ ${ }^{1}$ Complutense University. Medical School. Radiology Department and San Carlos Hospital \\ (IdISSC) 28040 Madrid. Spain
}

Corresponding author: eliseov@med.ucm.es

\section{Introduction}

The International Commission on Radiological Protection (ICRP) has approved a new document on "Diagnostic Reference Levels (DRLs) in Medical Imaging" to be published before the end of this year. The DRL has been proven to be an effective tool to aid in optimisation of protection in the medical exposure of patients for diagnostic and interventional procedures. There are issues requiring update or new advice: definitions of the terms used in previous guidance, determination of the values for DRLs, the appropriate interval for re-evaluating and updating these values, appropriate use of DRLs in clinical practice, methods for practical application of DRLs, and application of the DRL concept to newer imaging technologies.

\section{Methods}

The ICRP document contains chapters on: Considerations in conducting surveys to establish DRLs; Radiography and diagnostic fluoroscopy; Interventional procedures; Digital radiography, $\mathrm{CT}$, nuclear medicine, and multimodality procedures; Paediatrics and Application of DRLs in clinical practice. A summary of 72 main points (recommendations) are also included at the end of the document.

\section{Results}

In addition to the definitions of DRL quantity and DRL value, for multimodality imaging it is recommended to set DRLs for the different modalities independently (e.g.- PET-CT). DRL quantity should be a commonly and easily measured or determined radiation dose quantity or metric that assesses the amount of ionising radiation used to perform a medical imaging task. DRLs should be revised at regular intervals of 3-5 years, or more frequently. Weight bands are recommended for establishing paediatric DRLs. Phantoms were often used in the past, but now ICRP recommends setting DRL values based on surveys of patient examinations, because the DRL value should be tied to defined clinical and technical requirements for the medical imaging task. Assessment of clinical image quality or the proper diagnostic information when multiple images are used, should be performed as part of the optimisation process.

\section{Conclusions}

It is expected that this set of recommendations to establish and use the DRLs will help in the implementation of the new European and International Basic Safety standards helping to improve the use of radiation in medical imaging. The target audience for this publication is national, regional, and local authorities; professional societies; and facilities that use ionising radiation for medical purposes, and responsible staff within these facilities. 


\title{
Spanish experience with DRLs and optimization in interventional cardiology and radiology
}

\author{
Eliseo Vano ${ }^{1}$, Roberto Sanchez ${ }^{1}$, Jose M Fernandez ${ }^{1}$, Rafael Ruiz-Cruces ${ }^{2}$ \\ ${ }^{1}$ Medical Physics Service. Hospital Clinico San Carlos. Radiology Department. Medical School. \\ Complutense University. Instituto de Investigación Sanitaria del Hospital Clínico San Carlos \\ (IdISSC), Spain \\ ${ }^{2}$ Medical School. Malaga University. Spain
}

Corresponding author: eliseov@med.ucm.es

\section{Introduction}

The impact of interventional techniques on the radiation dose received by the population is relevant. The Spanish legislation requires since 1999, individual registration of the radiation dose received in interventional procedures and the new European Directive 2013/59/EURATOM supports this requirement. The Spanish Society of Cardiology and the Spanish Society of Vascular and Interventional Radiology (SERVEI) have promoted, in cooperation with medical physics experts from several universities and public hospitals, patient dose surveys to establish and update national diagnostic reference levels (DRLs) for interventional procedures.

\section{Methods}

The DOCCACI (DOsimetría y Criterios de CAlidad en Cardiología Intervencionista) group was established in 2010, following the experience of a similar group created in 2006, with the involvement of SERVEI, for interventional radiology. A sample of 10-12 public hospitals from all over the Country, with the only condition that they would contribute a minimum set of patient dose values per year, selected at random, perform a common set of quality controls to the $X$ ray systems and participate in the coordination meetings with a medical physics expert and a cardiologist or interventional radiologist. The survey was limited to only a few centers for financial reasons. For interventional radiology, it has already been possible, to evaluate the impact of complexity levels in the evaluation of DRLs.

\section{Results}

Values of DRLs (published as kerma area product, cumulative air kerma at the patient entrance reference point, fluoroscopy time and number of acquired images) for a set of common interventional procedures have been established and are updated periodically.

\section{Conclusions}

The cooperation between medical physics experts and interventionalists, under the umbrella of the corresponding medical societies, allowed the establishment of national DRLs and optimization actions. This is also o good strategy to implement the radiation safety culture during interventional practices. See (for interventional cardiology) https://www.hemodinamica.com/actividad/actividad/regisros-y-trabajos/proyecto-doccaci/ and http://servei.org/profesion/proteccion-radiologica/ (for interventional radiology). For population doses in Spain, see: http://proyectodopoes.es/ 

Panel - Radiation safety culture, accidents and near misses in medical uses of radiation 


\title{
Managing Radiation Incidents in Radiology in a Busy Hospital
}

\author{
A Pascoal $^{1}$, I Honey ${ }^{1}$, C Jerome $^{1}$, D Gallacher ${ }^{1}$ \\ ${ }^{1}$ Guy's and St Thomas' NHS Foundation Trust, Medical Physics, Radiation Safety \\ Corresponding author: apascoal74@gmail.com
}

An adverse incident ( $\mathrm{Al}$ ) is an unplanned event that caused, or almost caused ('near miss), an injury to a patient or other person, or resulted in a wrong or delayed diagnosis and/or treatment of a patient.

Ideally, Als wouldn't occur and preventive actions put in place would be $100 \%$ effective. In practice, Als are a matter of fact in large, busy hospitals involving many people, equipment, and multiple processes.

The UK regulation requires healthcare provider's employers to establish a radiation incident management policy and procedures. In the UK, this is enforced by the Ionising Radiation regulations IRR99 (focus on radiation safety of staff and public) and by lonising Radiation (Medical Exposure) Regulatory frameworks (known as IR(ME)R, focus on the radiation protection of the patient). These regulations steam from the basic radiation safety standards and are due to be updated by February 2017 (Basic Safety Standards, Council Directive 2013/59 EURATOM).

In compliance with IRR and IR(ME)R hospitals must put in place procedures to ensure that incidents of all causes (e.g. equipment faults, human error) are avoided as much as possible, that when they occur are dealt with promptly and appropriately, and that actions are put in place to prevent reoccurrence. An additional requirement of incident management is that lessons are learned and shared with all those concerned.

In this talk the following topics will be covered with emphasis on incidents in Radiology

- Legal framework that underpins radiation incident's management in hospitals in the UK;

- Practical aspects of incident management and reporting (internally and externally);

- Important immediate actions following an incident;

- Examples of radiation incidents, its causes, and consequences;

The Al policies and procedures to manage incidents in a large NHS hospital in the UK will be reviewed. The typical workflow for managing radiation incidents will be discussed with reference to actions required and key people involved. The concept of radiation doses 'Much greater than intended' resulting from accidental exposures will be reviewed along with the most updated (January 2017) guidance for reporting incidents externally, in the UK. Examples of anonymised radiation incidents will be discussed with the participants along with national statistics of radiation incidents in the UK.

This talk it is expected to highlight good practice in the management of incidents in a busy hospital and contribute to improve preparedness of all participants to deal with incidents and promote a radiation safety culture in Radiology. 
Oral Presentations - Computacional applications in radiological protection and dosimetry 


\title{
Clinical issues arising from patients' organ dose and risk assessment in interventional cardiology procedures
}

\author{
Ana Belchior ${ }^{1}$, Maria Portugal $^{2}$, Mariana Baptista ${ }^{1}$, Pedro Vaz ${ }^{1}$ \\ ${ }^{1}$ Centro de Ciências e Tecnologias Nucleares, Instituto Superior Técnico, Universidade de \\ Lisboa, Estrada Nacional 10, km 139,7, Bobadela LRS 2695-066, Portugal \\ ${ }^{2}$ FCT UNL - Faculdade de Ciências e Tecnologia, FCT, Universidade Nova de Lisboa, Caparica \\ 2829-516, Portugal
}

\section{Corresponding author: anabelchior@tecnico.ulisboa.pt}

\section{Introduction}

Interventional cardiology (IC) procedures can be complex, leading to long exposure times to ionizing radiation that may cause deterministic effects and an increased risk of stochastic effects. Therefore, there is a growing need, for studies such as the ones reported in this work, correlating the patient effective dose and the radiological cancer risk.

\section{Methods}

For an accurate patient dose calculation, a female voxel phantom, LAURA, was implemented using the state-of-the-art Monte Carlo simulation program PENELOPE, to assess organ doses per unit dose-area product (DAP), both in target and critical organs. Aiming at assesses the radiological risk associated to typical IC examinations, this work includes demographic and exposure data, from 27 female patients. In detail, 16 patients underwent coronariography (CA) and 11 were submitted to coronary angioplasty (PTCA).

\section{Results}

The obtained results shows that for critical organs, such as lungs and thyroid, the higher values of dose per unit DAP are observed for RAO30 projection. An exception was registered for breast and stomach, which receive higher doses per unit DAP for the RLAT projection. For CA, an effective dose ranging from $15.25 \pm 0.17 \mathrm{mSv}$ to $44.78 \pm 0.35 \mathrm{mSv}$ was found, whereas for PTCA, the resulting median effective dose was $109.75 \pm 0.86 \mathrm{mSv}$. The lung is the main organ at risk (OAR), with lung cancer risk incidence and mortality as high as 1/196 and 1/182, respectively. The calculated life-time attributable risk (LAR) for stochastic effects varies from $0.085 \%$ (for CA) to $0.528 \%$ (for PTCA).

\section{Conclusions}

The effective doses calculated in this study, highlight the importance of accurately assessing the risk of cancer incidence and mortality in IC examinations. Furthermore, for the sake of reducing the risk of stochastic effects, as low as possible peak voltages of the X-ray equipment should be used, as long as the resulting image quality does not jeopardize the clinical result of the intended IC procedure. 


\title{
Organ Dose Estimates in Thorax CT through CAD: Voxel Phantom Organ Matching With Individual Patient Anatomy
}

\author{
$\underline{\text { Jorge Borbinha }}^{1,2}$, Salvatore Di Maria ${ }^{2}$, Paula Madeira ${ }^{3}$, Ana Belchior ${ }^{2}$, Mariana \\ Baptista2, Pedro Vaz ${ }^{2}$ \\ ${ }^{1}$ FCT UNL - Faculdade de Ciências e Tecnologia, FCT, Universidade Nova de Lisboa, Caparica \\ 2829-516, Portugal \\ ${ }^{2}$ Centro de Ciências e Tecnologias Nucleares, Instituto Superior Técnico, Universidade de \\ Lisboa, Estrada Nacional 10, km 139,7, Bobadela LRS 2695-066, Portugal \\ ${ }^{3} \mathrm{CHLC}$-HSJ - Centro Hospitalar Lisboa Central-Hospital de São José, Rua José António Serrano, \\ 1150-199, Lisboa, Portugal
}

Corresponding author: jc.borbinha@campus.fct.unl.pt

\section{Introduction}

Given the continuous usage and spread of computed tomography (CT), the potential harmful effects and the radiation dose to the patient have become high interest topics among the scientific community.

The main objective of this investigation was to modify - through computed-aided diagnosis (CAD) methods - existing 3D voxel phantom models resembling real patients as much as possible, as well as assessing the variation of organ doses when a standard phantom is used instead. This work focused essentially in one of the biggest and most radiosensitive organs in the thorax, the lungs.

\section{Methods}

During the course of this work a FORTRAN-based routine was developed, which is able to semiautomatically modify the volumetric information of organs of interest in a standard voxel phantom (ICRP Adult Female Reference). The voxel resolution was also altered so the phantom's diameters match the patient's ones. Monte Carlo (MC) PENELOPE simulation code was used in order to generate $2 \mathrm{D}$ projections that were then used for the organ matching with clinical patient $\mathrm{CT}$ images through the method above described.

Moreover, MC simulations mimicking CT scan conditions were performed to assess organ dose in both phantoms (ICRP standard and ICRP modified).

\section{Results}

Preliminary absorbed dose results, after lung phantom/patient matching, point out that the standard ICRP model overestimates the considered patient's lung tissue dose by $17,7 \%$ in the right lung and by $56,6 \%$ in the left lung. In addition, it was established that the resizing of the ICRP model's lungs without changing the voxel resolution results in similar lung tissue dose values between the two phantoms.

\section{Conclusions}

This study demonstrates that voxel phantoms developed using single patient data provide a better and more precise organ dose assessment by MC methods than a standard phantom. The presented methodology should be of interest for dose optimization studies and quick enough for routine clinical use. 


\title{
Monte Carlo Evaluation at a sub-cellular scale of Targeted $\alpha$-particle Therapy
}

\author{
Francisco Guerra Liberal $^{1{ }^{2}{ }^{2}}$, Hugo Moreira ${ }^{1,2}$, Stephen J. McMahon ${ }^{2}$, Kevin M. Prise ${ }^{2}$ \\ ${ }^{1}$ Faculdade de Ciências e Tecnologia, Universidade Nova de Lisboa, Lisboa, Portugal \\ ${ }^{2}$ Centre for Cancer Research and Cell Biology, Queen's University Belfast, Belfast, UK \\ Corresponding author:f.liberal@campus.fct.unl.pt
}

\section{Introduction}

Radionuclides have been increasingly used in cancer treatment, with varying degrees of success as both diagnostic and therapeutic agents. $\alpha$-particles are of particular interest for the treatment of micrometastases. However, the stochastic nature of $\alpha$-particles poses some challenges for dosimetric studies. One emitter, Astatine-211 offers many advantages for targeted therapy.

\section{Methods}

The TOPAS modelling tool was used to simulate the effects of ${ }^{211} \mathrm{At}$. The deposited dose and number of particle hits were calculated for two different cell models, one with a central nucleus and the other with the nucleus located at the periphery to evaluate the effects of the nucleus eccentricity. Cross-fire doses to non-target cells was also evaluated as a function of the source separation. Lastly, we explored the relationship between the energy deposited in the target and that in nearby marrow.

\section{Results}

The influence of cellular geometry on the internal-dose shows an increased effect of the radiation on the nucleus in the eccentric model when the activity is distributed on the membrane. This effect decreases when the activity is distributed in the cytoplasm or medium. For the cross-fire dose, the dose and number of hits decrease with distance and for distances equal or greater than $5 \mu \mathrm{m}$ the sub-cellular localization of the activity in the source cell does not influence the cross-fire dose. Lastly, the limited range of the energy deposited is clearly shown as significant fractions of adjacent normal marrow components would see no $\alpha$ particle radiation.

\section{Conclusions}

As the clinical implementation of $\alpha$-particles emitters is increasing, this type of study may be useful in interpreting clinical results. Currently, ${ }^{211} \mathrm{At}$ is the subject of extensive study for targeted therapy. Due to its production cost and the capability to produce a stable radiopharmaceutical in addition to our simulations, ${ }^{211} \mathrm{At}$ is an optimal candidate for the application of targeted $\alpha$ therapy. 


\title{
Dose coefficients for radiopharmaceuticals used in nephrology paediatric patients using Monte Carlo calculations - a new paradigm
}

\author{
P. Teles $^{1}$, J. Costa ${ }^{1,2}$, D. Costa ${ }^{3}$, M. Zankl ${ }^{4}$ \\ ${ }^{1}$ Grupo de Protecção e Segurança Radiológica, Centro de Ciências e Tecnologias Nucleares, \\ Pólo de Loures, Instituto Superior Técnico, Estrada Nacional 10 (km 139,7), 2695-066 \\ Bobadela-LRS, Portugal \\ ${ }^{2}$ Faculdade de Ciências e Tecnologia, Universidade Nova de Lisboa, Quinta da Torre, Campus \\ Universitário, 2829-516 Caparica, Portugal \\ ${ }^{3}$ Serviço de Medicina Nuclear, Champalimaud Centre for the Unknown, Av. Brasília, 1400-038 \\ Lisboa \\ ${ }^{4}$ Helmholtz Zentrum München - German Research Center for Environmental Health (HMGU), \\ Department of Radiation Sciences, Research Unit Medical Radiation Physics and Diagnostics, \\ Ingolstaedter Landstr. 1, 85764 Neuherberg, Germany
}

Corresponding author:ppteles@ctn.tecnico.ulisboa.pt

\section{Introduction}

Dose coefficients have been estimated and published for most radiopharmaceuticals utilized in Nuclear Medicine, for adults, newborn, children and adolescents. In the case of children and adolescents values are usually provided for 2 months, 1, 5, 10, and 15 year old patients without specification for patients with ages in between.

Results obtained in this study indicate that it is more accurate and convenient to use a patient body mass function to determine the dose coefficients for these patients.

\section{Methods}

Monte Carlo simulations were performed using the MCNPX 2.7 code and tw paediatric voxel phantoms (of 2 months and 7 years old) as well as the adult Golem and Laura phantoms developed by the GsF to determine the dose coefficients of 22 paediatric patients submitted to nuclear nephrology exams. The voxel phantoms were scaled to fir the body mass of the patients.

\section{Results}

Dose coefficients were determined as a function of body mass, and other parameters. They were also compared with the values found in the literature (ICRP 107). Results show small deviations from the literature, when the body mass hugely differs from the reference values provided by the ICRP.

\section{Conclusions}

The dose coefficients using a continuous body mass function rather than an age step function are better suited to estimate organ dose in paediatric patients. This is particularly true for newborns and babies. 



\title{
Dose and reconstruction algorithm optimization in simultaneous breast/lung CT imaging
}

\author{
Débora António ${ }^{1}$, Salvatore Di Maria ${ }^{2}$, Nuno Matela ${ }^{3}$, Mariana Baptista ${ }^{2}$, Ana \\ Belchior ${ }^{2}$, Sandra Vieira ${ }^{4}$, Pedro Vaz ${ }^{2}$ \\ ${ }^{1}$ Departamento de Física, Faculdade de Ciências e Tecnologia, Universidade Nova de Lisboa, \\ Quinta da Torre, 2829-516 Caparica, Portugal \\ ${ }^{2}$ Centro de Ciências e Tecnologias Nucleares, Instituto Superior Técnico, Universidade de \\ Lisboa, Estrada Nacional 10, Km139,7, 2695-066 Bobadela, Portugal \\ ${ }^{3}$ Universidade de Lisboa, Faculdade de Ciências, Instituto de Biofísica e Engenharia Biomédica, \\ Campo Grande, 1749-016 Lisboa, Portugal \\ ${ }^{4}$ Radioncologia, Centro Champalimaud, Avenida Brasília, 1400-038 Lisboa, Portugal \\ Corresponding author: dd.antonio@campus.fct.unl.pt
}

\section{Introduction}

The number of diagnosed cases of cancer has grown at an alarming pace and was the leading cause of death in the world in 2012. Thus there is an undeniable need to ensure early screening and detection systems worldwide. The aim of this investigation is to study the feasibility of a Cone Beam Computed Tomography (CBCT) scanner for simultaneous breast and lung imaging. Optimal tube voltage was determined, in order to maximize the image quality and minimize the dose delivered to patient. Additionally, the development of reconstruction algorithms and the study of their effect in the image quality will be considered.

\section{Methods}

Monte Carlo (MC) simulations were performed, using the penEasy (v2015) program. A MC model of a CBCT scanner was implemented in order to simulate CBCT scan acquisitions for energies of $30 \mathrm{keV}$ and $80 \mathrm{keV}$, and angles that differed in 10\%. Micro calcifications were inserted into the lung and breast of the adult female reference computational phantom ("REGINA"), used in the MC model for dose calculation and projections acquisition. Image quality was analyzed in terms of the Signal-Difference to Noise Ratio (SDNR) and dose calculations were performed for a normalization factor of $5 \mathrm{mGy}$ in the lungs.

\section{Results}

Preliminary results of the SDNR for the projections acquired at 00 and 180 o (regarding source position), using energies of $30 \mathrm{keV}$ and $80 \mathrm{keV}$, suggest that the $30 \mathrm{keV}$ energy maximizes the SDNR, regardless of the organ. However, dose calculations show a significantly higher dose delivered to the breast with $30 \mathrm{keV}$ compared to $80 \mathrm{keV}$, for the 0 o projection. These results also suggest that for $80 \mathrm{keV}$ the SDNR regarding the breast is maximized at $0 \circ$, however for the lungs the SDNR is maximized at 180 .

\section{Conclusions}

This study suggests promising data for the possibility of developing a CBCT modulated beam scanner. Not only does it stand as a diagnostic method for breast cancer, but also for lung cancer, which has a very low 5-year survival rate. 


\title{
Dosimetric link between Computed Dose Tomography Dose index (CTDI) and Cone Beam CT organ doses: case study for thorax scan protocol
}

\author{
M. Baptista ${ }^{1}$, S. Di Maria ${ }^{1}$, S. Vieira ${ }^{2}$, J. Santos ${ }^{3}$, P.Vaz $^{1}$ \\ ${ }^{1}$ Centro de Ciências e Tecnologias Nucleares, Instituto Superior Técnico, Campus Tecnológico e \\ Nuclear, Estrada Nacional 10, km 139,7, 2695-066 Bobadela LRS, Portugal \\ ${ }^{2}$ Fundação Champalimaud, Centro Clínico Champalimaud, Avenida de Brasília, 1400-038 \\ Lisboa, Portugal \\ ${ }^{3}$ Instituto Politécnico de Coimbra, ESTESC, DIMR, Rua 5 de Outubro, 3046-854 Coimbra, \\ Portugal
}

\section{Corresponding author: marianabaptista@ctn.tecnico.ulisboa.pt}

\section{Introduction}

Cone beam CT (CBCT) is used for pre-treatment verification and patient setup in Image Guided Radiation Therapy (IGRT). Radiation doses from CBCT scans have become of concern, since CBCT imaging is employed daily and several times per patient, causing high cumulative imaging doses to healthy tissues. As a rough indication for dose delivered to patients, Computed Tomography Dose Index (CTDI) is the parameter used by CBCT equipment, but for broad beam configurations this concept does not provide an accurate dose value. This work aims at establishing a dosimetric link between CBCT organ doses and weighted CTDI (CTDI ${ }_{W}$ ) values.

\section{Methods}

A CBCT scanner was modelled with MCNPX2.7.0 and the simulation results were validated against Entrance Surface Dose (ESD) and CTDI measurements. ESD was measured using Patient Skin Dose (PSD, Unfors) dosimeters on the surface of an anthropomorphic phantom (PBU-60, KYOTOKAGAKU $^{\circledR}$ ). CTDI measurements were made using a PMMA body phantom and a pencil ionizing chamber. A thorax scanning protocol was selected with half-fan acquisition mode. For organ doses calculation, a male voxel phantom ("Golem") was implemented in the CBCT computational model. The organ dose distribution in the thorax, $\mathrm{CTDI}_{W}$ and cumulative dose $\left(f_{100}(150)\right.$ and $\left.\mathrm{CTDI}_{\infty}\right)$ concepts we compared.

\section{Results}

The CBCT model was successfully validated due to the good agreement between MCNPX simulations and CTDI measurements (relative differences up to 8.05\%). The CTDI measured could be quantitatively indicative for the target organ dose. The determination of $f_{100}(150)$ seems to be a good practical dosimetric approach to define areas where this dose concept can explain absorbed doses inside the primary radiation field.

\section{Conclusions}

This study contributes for the on-going effort in developing a standard dose metric for CBCT. However, direct comparisons among different machines and scanning protocols are needed. This work also highlights the importance of improving awareness regarding the increased radiological risk arising from repeated exposures in CBCT. 


\title{
CT Radiation Dose Optimization Strategies - Clinical Practice Approach
}

\author{
Filipa Borlinhas $^{1,2}$, José Afonso ${ }^{3}$, Ana Cristina Vicente ${ }^{3}$, José Venâncio ${ }^{3}$ \\ ${ }^{1}$ Instituto Biofísica e Engenharia Biomédica (IBEB), Faculdade de Ciências da Universidade de \\ Lisboa. Campo Grande - 1749-016 Lisboa, Portugal \\ ${ }^{2}$ Escola Superior de Tecnologia da Saúde de Lisboa, EPE. Av. D. João II, Lote 4.69.01. 1990 - 096 \\ Lisboa, Portugal \\ ${ }^{3}$ Instituto Português de Oncologia de Lisboa Francisco Gentil, EPE. R. Prof. Lima Basto, 1099- \\ 023 Lisboa, Portugal
}

Corresponding author: filipaborlinhas@gmail.com

In medical radiation exposures, namely in Computed Tomography (CT), there is an inverse relation between the image noise and radiation dose. Radiographers need to recognize the situations that require optimization and to apply optimization strategies, without compromise patient diagnosis.

The purpose of this work, based on a literature review and on the analysis of routine CT procedures, is to provide an overview of CT optimization techniques feasible to implement in routine practice.

The key parameters and the main situations that affect image quality and patient dose will be discussed. Several CT parameters can be adjusted such as: potential and tube current, rotation time, Automatic Exposure Control (AEC), detectors configuration, slice thickness, Pitch, table speed, post processing with the filter kernels, and so on. These parameters vary with patient anatomical region of interest, examination length, positioning, clinical information, and acquisition phases. Furthermore, there are new reconstruction algorithms developed by manufacturers that also help to optimize dose by reducing artifacts and image noise, and many studies state their superior results.

Also, the knowledge on the CT parameters trade-offs between radiation dose and image quality is essential for dose optimization, so this will also be highlighted and described in this work.

The solution for the excess of radiation dose problem is not only to reduce radiation dose in general but also to adequate and personalize this optimization to each patient and clinical situation. The literature points out some solutions to handle this problem and is very important that the Radiographers are familiar with those when performing CT examinations in practice. 


\title{
The HESE Radiotherapy Methods for Pretreatment Patient Quality Assurance (QA) using Intensity Modulated Techniques
}

\author{
Marcelino, C. ${ }^{1,2}$; Pereira, A. ${ }^{1,2}$; Barreiros, M. ${ }^{1,2}$; Bernardo, A. ${ }^{1,2}$; Marques, S. $^{1,2}$; \\ Farinha, G. ${ }^{1,2}$; Chinita, P. ${ }^{1}$ \\ ${ }^{1}$ Espírito Santo's Hospital (Évora) Radiotherapy Department - Lenicare \\ ${ }^{2}$ Mercurius Health SA
}

Corresponding author: cj.marcelino@gmail.com

\section{Objective}

The use of intensity modulated techniques is rapidly increasing since it became available, in order to achieve high degree of conformation to the target volume, while protecting the organs at risks. We retrospectively analyzed patient-specific quality assurance (QA) results obtained with different methods over more than 1200 patients treated with IMRT and VMAT.

\section{Methods}

Since March 2011, a specific patient QA was conducted prior to treatment, using different measurements: ion chamber (1D absolute), film dosimetry (2D absolute and relative), ion chamber array (2D absolute) and portal dosimetry (2D relative).

PTW chambers and Seven29 were used for 1D and 2D array absolute dosimetry. Portal dosimetry was conducted with Varian EPID and for film dosimetry a flatbed RGB scanner was used to digitize films prior to analysis in RIT software.

All validation plans were previously projected on PTW Octavius phantom and the dose distribution was calculated. All measurements were compared to the treatment planning system (TPS) dose calculation with $\gamma$ analysis (3\%, 3mm distance-to-agreement criteria) or absolute point dose comparison.

\section{Results}

All methods showed good agreement between the measured dose and the pre-planned dose using TPS: 1D ion chamber (average deviation 1.2\%, range $-1.7 \%$ to $4.4 \%, n=445$ patients); film 2D absolute (average deviation 97.7\%, SD 2.6\%, $n=1052$ patients) and 2D ion chamber array (average deviation 99.5\%, SD 1.2\%, $\mathrm{n}=1357$ patients).

Relative 2D measurements with film also showed good agreement (average deviation 98.7\%, SD $2.0 \%, n=1092$ patients), while EPID dosimetry has recent implantation and the results are not compiled yet.

\section{Conclusion}

The analysis of the VMAT/IMRT QA process performed with different methods was satisfactory, although all methods showed distinct advantages and drawbacks. The most important drawbacks are the calibration process for film absolute dosimetry and understand the deviations causes between predicted and measured doses. 


\title{
From Image-Guided to Adaptive Radiotherapy in Helical Tomotherapy
}

\author{
Josefina Mateus $^{1}$, Tiago Ventura ${ }^{1}$, Maria do Carmo Lopes ${ }^{1}$
}

${ }^{1}$ Medical Physics Department, IPOCFG, E.P.E.

Corresponding author:imateus@ipocoimbra.min-saude.pt

\section{Introduction}

Helical Tomotherapy is a treatment modality that is specially designed to deliver intensitymodulated radiation therapy treatments. It has been used to treat a wide variety of pathologies, allowing for extended treatment volumes and simultaneous treatment of multiple lesions. Image guidance is done in Tomotherapy through megavoltage CT (MVCT) previously to every treatment fraction in order to verify and correct patient positioning. MVCT images can also be used to evaluate the dosimetric consequences of patient's eventual anatomy changes, which are the bases of the so called - Adaptive Radiotherapy. The purpose of this work is to present the adaptive radiotherapy workflow procedure taking advantage of the available software tools.

\section{Methods}

The first step is done in Plan Adaptive module where the rigid registration of daily MVCT with the planning $\mathrm{CT}$ is accepted or refined. Then a synthetic $\mathrm{CT}$, composed by planning $\mathrm{CT}$ and $\mathrm{MVCT}$, is generated. The delivered dose is calculated and exported to Velocity Al software where the planning target volumes (PTV) and organs at risk (OAR) are automatically generated by applying a deformable registration with the planned volumes. After clinical structures validation, the planned dose is compared with the daily fraction dose through DVHs analysis and isodose visual inspection. The cumulative dose for all fractions can also be estimated.

\section{Results}

This work presents the adaptive workflow for a lung and a head \& neck cases. In lung cases mostly changes in the tumor are considered whereas in head \& neck cases often the weight loss lead to dose changes in surrounding OARs.

\section{Conclusions}

The whole procedure allows the radiation oncologist to evaluate the need for replanning. MVCT in a daily basis opens the door for adaptive therapy and promises a better daily dose delivery accuracy for intensity-modulated radiation therapy. 


\title{
lodine-125 brachytherapy in choroidal melanoma
}

\author{
Paulo César Simões ${ }^{1}$, Ana Cavaco ${ }^{1}$, Tânia Teixeira ${ }^{1}$, João Casalta Lopes ${ }^{1}$, Cristina \\ Fonseca $^{2}$, Júlia Veríssimo ${ }^{2}$, Rui Proença ${ }^{2}$, Margarida Borrego ${ }^{1}$ \\ ${ }^{1}$ Serviço de Radioterapia, Centro Hospitalar e Universitário de Coimbra \\ ${ }^{2}$ Serviço de Oftalmologia, Centro Hospitalar e Universitário de Coimbra
}

*invited talk

\section{Corresponding author: cesar@chuc.min-saude.pt}

Choroidal melanoma arises from the blood-vessel layer beneath the retina. Uveal melanoma is a rare tumor: the incidence rate is less than one new case per 100,000 persons per year. Enucleation was the standard treatment until the 1980s, when radiotherapy was found to offer an equally effective therapeutic alternative for more than $90 \%$ of the patients. The management of this disease has evolved towards a more conservative, organ- and visionpreserving treatment.

A temporary ocular implant with radioactive sources of iodine 125 is the brachytherapy technique selected by our department, its implementation and daily practice since 2013 is presented.

Episcleral brachytherapy makes use of an applicator allowing for millimetric radioactive sources to be placed in tumor close contact minimizing radiation to healthy tissues with a low percentage of adverse effects depending on tumor localization and size. The dosimetric study determines activity and number of iodine sources required for each patient and calculates tumor and ocular structures at risk dose distribution. The dosimetric study selected plaque and radioactive seeds are assembled in aseptic conditions.

In the operating room the radioactive plaque is sutured to the scleral outer surface. The plaque remains attached to the eye and the patient is kept in a properly prepared room during the time needed to fully irradiate the tumor. The entire plaque is removed at the end of the treatment, which varies from 4 to 7 days, and is disassembled. After proper cleaning and inspection the parts can be re-used.

The use of radioactive sources, the complexity of the technique and the need to have precise data makes essential the cooperation of different health professionals such as the radiation oncologist, the ophthalmologist, the nurse, the anaesthetist and the medical physicist.

The medical physicist prepares the treatment and secures the quality assurance of the process. Although used sources energy and intensity are low evaluate and control the received doses during the procedure is necessary. 


\title{
Target Definition: the Weakest Link in (Single dose) RT?*
}

\author{
Joep Stroom ${ }^{1}, \underline{\text { Sandra Vieira }}$ \\ ${ }^{1}$ Champalimaud Centre for the Unknown, Lisbon, Portugal
}

*invited talk

\section{Corresponding author: sandra.vieira@fundacaochampalimaud.pt}

Since the official introduction of the planning volumes GTV (Gross Tumour Volume), CTV (Clinical Target Volume), and PTV (Planning Target Volume) by the ICRU 50 report in 1993, they are routinely used in the planning process of basically all radiation treatments. With the increasing attention to intra-fraction tumour motions, ICRU introduced the ITV (Internal Target Volume) concept in their follow-up report 62 in 1999. Finally, in 2010 ICRU report 83 appeared on the same subjects, which centred on the consequences of intensity modulated radiotherapy (IMRT) on the dose prescription and reporting. Since then image guided radiotherapy (IGRT) has become the latest trend in RT.

In the late nineties, PTV margin recipes to accommodate for uncertainties during radiotherapy have been proposed and are widely used in the radiotherapy community. In this paper, the most common margin recipes and the difference between systematic and random uncertainties will be explained. Also, remaining issues regarding the ICRU volumes will be discussed, like, what is the biggest geometrical uncertainty and are we taking care of it correctly? Have we validated existing margin recipes sufficiently? In what cases do these recipes apply and in what cases do they not? Should we maybe even combine CTV and PTV margins?

Finally, we will try to clarify the consequences of the introduction of IGRT on the different planning volumes. For instance, should the nomenclature or the margin recipes be altered or adjusted due to IGRT? Should ITV and PTV be combined? And if so, how exactly should we do that? 



\title{
Occupational radiation exposure from C-Arm Fluoroscopy during hip surgeries
}

\author{
Oksana Lesyuk ${ }^{1}$, António Fernando Abrantes ${ }^{1,2}$, Sónia Isabel do Espirito Santo \\ Rodrigues ${ }^{1}$, Patrick Emmanuel Sousa ${ }^{1}$, Rui Pedro Pereira de Almeida ${ }^{1,2,3}$, João Pedro \\ Pinheiro $^{1,4}$, Kevin Barros Azevedo ${ }^{1,2}$, Luís Pedro Vieira Ribeiro ${ }^{1}$ \\ ${ }^{1}$ Department of Medical Imaging and Radiotherapy of the Escola Superior de Saúde da \\ Universidade do Algarve (ESSUAlg), Faro, Portugal \\ ${ }^{2}$ CICS.NOVA - Pólo de Évora, Portugal \\ ${ }^{3}$ Universidad de Murcia, Murcia, Spain \\ ${ }^{4}$ Universidade de Coimbra, Coimbra, Portugal \\ Corresponding author: oksanalesyuk@gmail.com
}

\section{Introduction}

Fluoroscopy and interventional radiology is a major source of ionizing radiation in medical diagnostic context and due to technological development it has expanded to surgical specialties and operating rooms.

Considering proximity of the surgeons and surgical team to the C-arm X-ray system and large exposition time, occupational radiation exposure in professionals can assume considerable values and increased risk to develop deterministic or stochastic effects.

\section{Methods}

In order to study the distribution of scattered radiation in the operating room a fluoroscopyassisted hip surgery was simulated. An anthropomorphic whole-body phantom were used and the radiation exposure was quantified by $\mathrm{X}$-ray-specific detector.

Radiographs were obtained with a mobile $C$-arm X-ray system, with the tube at $0^{\circ}$ or $90^{\circ}$. The operating parameters employed $(\mathrm{mA}$, time, $\mathrm{kV}$ ) were determined by a statistical analysis based on the observation of orthopedic surgical procedures of the hip.

Measurements were made as function of height above the operating room floor, of distance and variation in the dose rate around the phantom.

\section{Results}

For all measurements, higher exposures were observed at $90 \circ$. In the measurements obtained as a function of height, the maximum dose rates observed were $1.167( \pm 0.023) \mu \mathrm{Sv} / \mathrm{s}$ and $2.278( \pm 0.023) \mu \mathrm{Sv} / \mathrm{s}$ at 0 o and 90 o respectively, corresponding to the chest level of main surgeon.

The data showed that an increase in distance from the table from 20 to $35 \mathrm{~cm}$ corresponded to a decrease in radiation dose by a half in both configurations.

During observational study we note that most healthcare professionals do use lead aprons and thyroid collars, although eye protection was rarely used.

\section{Conclusions}

We can conclude that, in the scenario under study, healthcare professionals are exposed to low levels of radiation. However, it is advisable to wear lead aprons, thyroid collars and protective goggles to reduce radiation exposure during such procedures. 


\title{
Feasibility for Implantation of a Patient Dosage Management System for Patients Submitted to Procedures in Interventional Cardiology
}

\section{Luciana Aparecida Salgado Rodrigues ${ }^{1}$, George Cesar Ximenes Meireles ${ }^{1}$, Letícia Lucente Campos Rodrigues ${ }^{2}$}

\author{
${ }^{1}$ Institute of Assistance to the State Public Servant - IAMSPE - SP \\ ${ }^{2}$ Instituto de Pesquisas Energéticas e Nucleares - IPEN - SP
}

Corresponding author: luarodrys@gmail.com

\section{Introduction}

Interventional procedures expose patients and professionals to high doses of $\mathrm{X}$ radiation, which ionizes the tissue cells that make up the human body, with the potential to cause biological effects by interacting indirectly with the atoms of our DNA cells. The risk is cumulative for patients and professionals. In Brazil, we do not yet have a regulation aimed at the control and management of doses delivered to patients, only for occupationally exposed individuals.

\section{Objective}

To develop a system for the management of doses of patients and occupationally exposed individuals to be used in the area of interventional cardiology.

\section{Methods}

The data were acquired at the Institute of Assistance to the State Public Servant - IAMSPE - SP in the Interventional Vascular Service, based on examinations of coronary angiography and percutaneous ad hoc and elective coronary interventions from August 2016 to April 2017. A multiprofessional group (physicians, nurse and radiology technologist) was organized to establish and evaluate the actions developed and the feasibility of the proposed models. Information materials were developed; Forms were restrained to contain fluoroscopy time; Product kerma area (Pka), incident air kerma (kai); And protocol of follow-up of patients with doses that exceed the levels of international recommendations suggested (International Atomic Energy Agency - IAEA, Report no 59).

\section{Results}

In the period from August 2016 to April 2017, 1516 were performed: 674 catheterizations (kai 1,3 \pm 1,2 Gy, Pka 58,3 \pm 41,3 Gy cm2), 65 AD HOC angioplasties (kai 2,6 \pm 1.4 Gy, Pka $141.7 \pm$

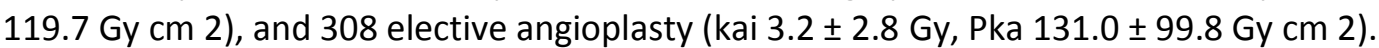

\section{Conclusion}

The project is feasible of extreme importance and requires great interaction of the team due to the proportion of actions and stages to be developed. 

Oral Presentations - Methodologies and systems of dose assessment (patient and personnel) 


\title{
Development of home-made primary standards for ionizing radiation: a cavity chamber for the measurement of air-kerma
}

\author{
Margarida Caldeira $^{1,2}$, Jean-Marc Bordy ${ }^{3}$, Carlos Oliveira ${ }^{1,2}$ \\ ${ }^{1}$ Centro de Ciências e Tecnologias Nucleares, Instituto Superior Técnico, Universidade de \\ Lisboa, Estrada Nacional 10, Km 139, 7, 2695-066 Bobadela, Portugal \\ ${ }^{2}$ Laboratório de Proteção e Segurança Radiológica, Instituto Superior Técnico, Universidade de \\ Lisboa, Estrada Nacional 10, km 139,7, 2986-066 Bobadela, Portugal \\ ${ }^{3}$ CEA-LIST Laboratoire National Henri Becquerel, CEA Saclay, 91191 Gif sur Yvette Cedex, \\ France
}

Corresponding author: margarida.caldeira@ctn.tecnico.ulisboa.pt

Ionization chambers are commonly used for measurements at radiotherapy facilities. In this field, primary standards are usually graphite cavity chambers characterized in terms of airkerma in ${ }^{60} \mathrm{Co}$ beams, since this is still the reference radiation for the calibration of radiotherapy detectors. Nowadays, several primary laboratories across Europe are involved in a joint effort to develop their own primary standards, and the LMRI follows this trend. The topic is important because the construction of home-made chambers provides knowledge that contributes to the improvement of the accuracy of measurement.

After the definition of the chamber's geometry, its components were machined at the workshops of LIP-Coimbra and IST. Prior to the assembling of the chamber, its collecting volume was measured using gravimetric and interferometric methods, at the primary laboratories for Volume and Length, at IPQ. The experimental measurements for the characterization of the cavity chamber were made at the LMRI, under the Eldorado $6{ }^{60} \mathrm{Co}$ beam. We also ran Monte Carlo simulations using EGSnrc, a crucial element for the calculation of the wall correction factor. After characterizing the chamber, a comparison with the LMRI's primary standard was held.

The air-kerma contributions were determined with uncertainties comparable to those of primary standards. However, the comparison with the LMRI primary standard showed a difference in the order of $1 \%$, which is a high value if we are considering primary standards. This is most likely due to electric field distortions near the edgy surfaces at the guard electrode level, suggesting readjustments in this critical region.

This work described the first effort for the development of home-made primary standards at the LMRI. The results indicated that improvements are needed to achieve metrological quality for primary standards. Regardless of the less satisfactory outcome, this is still a major primary standard candidate for the measurement of air-kerma. Its reexamination, along with the construction of new standards, will contribute to the establishment of a more accurate metrological basis for quantities related to the safe use of ionizing radiations. 


\title{
Metrological comparison of two thermoluminescent dosimeters (TLD) types using a linear accelerator and a new methodology for beam heterogeneity correction in the clinical dose range
}

\author{
$\underline{\text { Andreia Cristina Maia Oliveira }}{ }^{1,2}$, Anabela Gregório Dias ${ }^{1}$, João Miranda dos Santos ${ }^{2,3}$ \\ ${ }^{1}$ Departamento de Física e Astronomia da Faculdade de Ciências da Universidade do Porto \\ ${ }^{2}$ Centro de Investigação do Instituto Português de Oncologia do Porto Francisco Gentil, EPE \\ ${ }^{3}$ Instituto de Ciências Biomédicas Abel Salazar da Universidade do Porto \\ Corresponding author: up201203561@fc.up.pt
}

\section{Introduction}

Two TLD (LiF: Mg, Ti) batches (100 units each) from different manufactures were compared: Radcard (MTS-100) and Thermo Scientific ${ }^{\mathrm{TM}}$ (TLD-100) using a linear accelerator and a novel beam heterogeneities correction.

The purpose was to compare the TLD physical characteristics leading to a reliable clinical dosimetry (0.1 Gy to $5 \mathrm{~Gy}$ ) and to establish a calibration procedure approaching the ISO 28057:2014 standard.

\section{Methods}

Glow curves of all TLD irradiated by a Varian ${ }^{\mathrm{TM}}$ TrueBeam $^{\mathrm{TM}}$ linac using reference conditions were obtained using a HARSHAW TLD ${ }^{\text {TM }}$ Model 3500 Manual Reader. A fixed annealing protocol was established.

For each irradiation, 25 dosimeter were irradiated. Since the field is not homogeneous, it was necessary to apply a geometric correction factor. For this purpose were used the dose values obtained with the matrix - OCTAVIUS $1500^{\mathrm{XDR}}$ - placed during the irradiation just below the TLD plane. To accomplish the calibration of the TLDs, the efficiency of each detector, the Element Correction Coefficient (ECC) was determined for each dosimeter.

To test the validity of the calculated ECC, 9 dosimeters were randomly selected. Each TLD was individually submitted to the same anneal-irradiation-readout procedure, with a fixed dose (1.36 Gy).

Linearity, reproducibility, sensibility and batch heterogeneity were determined.

\section{Results}

Under the same conditions, the average counts obtained for TLD-100 was $69 \%$ of the MTS-100. The standard deviation for the first batch was $2.8 \%$ and for the second batch was $3.6 \%$.

The mean of variability between two consecutive cycles in the ECC value was $0.93 \%$ for the MTS-100, while the value obtained for the TLD-100 was $2.23 \%$.

The standard deviation of the first set of 9 dosimeters was initially $2.19 \%$ and after application of all correction factors was reduced to $1.28 \%$.

For the linearity, the coefficient of determination obtained was $R^{2}=0,9997$.

\section{Conclusions}

The Radcard dosimeters show higher sensitivity, better uniformity and lower variability. 


\title{
Dosimetry of kV Cone Beam CT with scintillation dosimeter
}

\author{
J. Machado ${ }^{1}$, L. Peralta ${ }^{1,2}$, E. Poli ${ }^{3}$ \\ ${ }^{1}$ Faculdade de Ciências da Universidade de Lisboa \\ ${ }^{2}$ Laboratório de Instrumentação e Física Experimental de Partículas \\ ${ }^{3}$ Centro Hospitalar Lisboa Norte \\ Corresponding author: luis@lip.pt
}

\section{Introduction}

Radiotherapy image guided (IGRT) arose from the need for greater precision in patient positioning. The IGRT uses the kV-CBCT imaging technique which allows a complete threedimensional representation of the region of interest in the patient's body that can be matched with the CT simulator images. The volume reconstructed in 3D is used to check and correct the patient's position on the treatment couch of the linear accelerator relative to his position in the CT simulator. This technique allows corrections regarding patient setup during treatment session and towards the tumour movement between treatment sessions. However, to obtain $\mathrm{kV}-\mathrm{CBCT}$ images it is used ionizing radiation which is not recorded in terms of dose to the patient, and therefore it is important a monitoring of the imaging dose in order to assess the total dose delivered to the patient.

\section{Methods}

In this study, various types of dosimeters are used: MOSFETs, ionization chambers, and plastic scintillation dosimeters (PSD). According to the literature PSD have several advantages, such as good linearity and sensitivity in the range of energies to be used (100-120 keV) and are (almost) transparent in radiographic images. The PSD could be an asset to quantify the kVCBCT dose. The main aim of this work was to build a prototype of a PSD and get its validation in $\mathrm{kV}$-CBCT beams. To validate the PSD, the results of dose measurement obtained by this device were compared with those obtained by an ionization chamber and a MOSFET.

\section{Results}

An approach to determine absorbed dose to water for $120 \mathrm{kVp}$ cone-beam (8.03 mm Al HVL) was performed by measurements in a standard PMMA phantom using three types of dosimeters in five different methods: a farmer ionization chamber were the dose was determined according to IAEA TRS-398 (a) and AAPM TG-61 (b), a MOSFET on standard (c) and high bias (d) setting and the plastic scintillator dosimeter (e). The obtained results were respectively: (a) 6.59+-0.04 mGy, (b) 6.70+-0.04 mGy, (c) 5.57+-0.04 mGy, (d) 5.24+-0.07 mGy and (e) 6.28+-0.01 mGy for the PSD.

\section{Conclusions}

Plastic scintillation dosimeters are an effective low-cost solution for patient dose control. They can be built with a number of sizes and shapes. In this work it was shown that they are a competitive alternative for $\mathrm{kV}-\mathrm{CBCT}$ for beam of $120 \mathrm{kVp}$. 


\title{
Online monitoring of Nuclear Medicine services
}

\author{
Maria do Carmo Baptista ${ }^{1}$, Margarida Prozil $^{1}$ \\ ${ }^{1}$ Consultório de Tomografia Computorizada - Dr. Campos Costa S.A. \\ Corresponding author: mcvb@drcamposcosta.pt
}

\section{Introduction}

Based on protocols between Dr. Campos Costa and some universities in our country, separate projects were developed and combine in an unique platform for monitoring and recording ionizing radiation, both in the radiology and nuclear medicine area.

This work consists in the development of on software and is based on a web platform, which allows, in real time, access to dose rates registered simultaneously in various nuclear medicine services, as well as sending alerts via e-mail in case of possible contamination of areas and periodically made a report of its readings and occurrences, to be added to the annual report of activities to be presented to the competent entities in the periodicity pre-defined by law.

\section{Methods}

Geiger detectors strategically installed in a nuclear medicine service register dose rates and through RS232 communication protocol store their records in mysql database. These data are subsequently treated and presented in an appealing and practical visual way for the day-to-day radiological management in the respective service.

The same method is replicated in all nuclear medicine services being managed by the same person. This RPR receives by e-mail messages of occurrences registered in each service, properly identified the service, detector position, dose rate and time of the respective registration, in order to be able to act in accordance with the occurrence.

\section{Results}

The system is tested and validated and is currently being used in services in the north of the country.

\section{Conclusions}

This system allows an immediate response to possible incident / accident situations reducing the impact of radiation exposure on both professionals and patients. It assists the RPR in a first analysis of the occurrence and stores all the information in database for later treatment. 


\title{
Acridine-Orange derivates as DNA-targeted radiopharmaceuticals for Auger therapy
}

\author{
Edgar Pereira ${ }^{1}$, Leticia Quental ${ }^{1}$, Elisa Palma ${ }^{1,2}$, Maria Cristina Oliveira ${ }^{1}$, Filipa \\ Mendes ${ }^{1}$, Paula Raposinho ${ }^{1}$, Isabel Correia ${ }^{2}$, João Lavrado ${ }^{3}$, Salvatore di Maria ${ }^{1}$, Ana \\ Belchior ${ }^{1}$, Pedro Vaz ${ }^{1}$, Isabel Santos ${ }^{1}$, António Paulo ${ }^{1}$
}

\begin{abstract}
${ }^{1}$ Centro de Ciências e Tecnologias Nucleares, Instituto Superior Técnico, Universidade de Lisboa, Estrada Nacional 10, km 139,7, Bobadela LRS 2695-066, Portugal

${ }^{2}$ Centro de Química Estrutural, Instituto Superior Técnico, Universidade de Lisboa, Av. Rovisco Pais 1049-001 Lisboa, Portugal

${ }^{3}$ iMed ULisboa, Faculdade de Farmácia, Universidade de Lisboa, Av. Prof. Gama Pinto, 1649003 Lisboa, Portugal
\end{abstract}

Corresponding author: anabelchior@tecnico.ulisboa.pt

\section{Introduction}

The aim of this study was to evaluate the influence of the distance to DNA in the radiationinduced biological effects promoted by AO-containing ${ }^{99 \mathrm{~m}} \mathrm{Tc}(\mathrm{I})$ tricarbonyl complexes. We focused on the comparison of pyrazolyl-diamine ${ }^{99 \mathrm{~m}} \mathrm{Tc}(\mathrm{I})$ tricarbonyl complexes containing alkyl linkers of different lengths between the $\mathrm{AO}$ unit and the bifunctional chelator with ${ }^{125}$ I-labelled structurally congeners.

\section{Methods}

This work encompassed a detailed and multidisciplinary investigation of the radiation-induced effects of ${ }^{99 \mathrm{~m}} \mathrm{Tc}$-complexes and structurally related ${ }^{125}$-labelled derivatives, which included spectroscopic characterization of DNA interaction, assessment of DNA damage in vitro and in living cells, cellular and nuclear internalization in tumoral cells and computational studies.

\section{Results}

Characterization of the DNA interaction, performed with the non-radioactive $\operatorname{Re}$ and ${ }^{127}$ I congeners, confirmed that all compounds act as DNA intercalators. Both classes of compounds induce double strand breaks (DSB) in plasmid DNA but the extent of DNA damage is strongly dependent on the linker between the Auger emitter $\left({ }^{99 \mathrm{~m}} \mathrm{Tc}\right.$ or $\left.{ }^{125} \mathrm{I}\right)$ and the AO moiety. The in vitro evaluation was complemented with molecular docking studies and Monte Carlo simulations of the energy deposited at the nanometric scale, which corroborated the experimental data. Two of the tested compounds, ${ }^{125} \mathrm{I}-\mathrm{C}_{5}$ and ${ }^{99 \mathrm{~m}} \mathrm{Tc}-\mathrm{C}_{3}$, place the corresponding radionuclide at similar distances to DNA and produce comparable DSB yields in plasmid and cellular DNA.

\section{Conclusions}

These results provided the first evidence that ${ }^{99 \mathrm{~m}} \mathrm{Tc}$ can induce DNA damage with similar efficiency to that of ${ }^{125} \mathrm{I}$, when both are positioned at comparable distances to the double helix. Furthermore, the high nuclear retention of ${ }^{99 \mathrm{~m}} \mathrm{Tc}-\mathrm{C}_{3}$ in tumoral cells suggests that ${ }^{99 \mathrm{~m}} \mathrm{Tc}$ labelled AO derivatives are more promising for the design of Auger-emitting radiopharmaceuticals than the ${ }^{125}$ I-labelled congeners. 


\title{
${ }^{131}$ I therapy in Thyroid Cancer and Benign Thyroid Diseases: Personal Dose Equivalent $H_{p}(10)$ Assessment in Patient's Close Family Members
}

\author{
Maria Raminhas Carapinha ${ }^{1,2,6}$, Gracinda Costa ${ }^{3}$, Teresa C. Ferreira ${ }^{4}$, Lucília Salgado ${ }^{4}$, \\ Sofia Vaz $^{4}$, Rui Ferreira ${ }^{3}$, Jorge Isidoro ${ }^{3}$, Teresa Rézio ${ }^{4}$, Carla Nunes ${ }^{2,7}$, António Barata \\ Tavares $^{2}$, Pedro Vaz ${ }^{5}$
}

\author{
${ }^{1}$ Área Científica de Medicina Nuclear, Departamento das Ciências e Tecnologias das Radiações \\ e Biossinais, Escola Superior de Tecnologia da Saúde de Lisboa, Instituto Politécnico de Lisboa, \\ Portugal \\ ${ }^{2}$ Escola Nacional de Saúde Publica, Universidade Nova de Lisboa, Av. Padre Cruz, 1649-016, \\ Lisboa, Portugal \\ ${ }^{3}$ Serviço de Medicina Nuclear, Centro Hospitalar e Universitário de Coimbra, EPE, Portugal \\ ${ }^{4}$ Serviço de Medicina Nuclear, Instituto Português de Oncologia de Lisboa, Francisco Gentil, \\ EPE, Portugal \\ ${ }^{5}$ Centro de Ciências e Tecnologias Nucleares, Instituto Superior Técnico Universidade de \\ Lisboa, Portugal \\ ${ }^{6}$ Grupo de Investigação em Radiações e Saúde, Escola Superior de Tecnologia da Saúde de \\ Lisboa, Instituto Politécnico de Lisboa, Portugal \\ ${ }^{7}$ Centro de Investigação em Saúde Pública, Av. Padre Cruz, 1649-016, Lisboa, Portugal
}

Corresponding author: maria.carapinha@estesl.ipl.pt

\section{Introduction}

The aim is to quantify the personal dose equivalent $H_{P}(10)$ in the family members (FMs) of the patients (PATs) undergoing iodine-131 thyroid cancer (TC) therapy and benign thyroid diseases (BTD) and to compare the $H_{P}(10)$ values of children and adults.

Methods

An observational study with convenience sampling was performed, including $83 \mathrm{FMs}(59 \%$ of 48 PATs $(72.9 \%$ + ). All FMs wore a whole body TLD during 21 days and received instructions on radiation protection, based on Euratom recommendations. All FMs were provided with relevant instructions for TLD use and answered a questionnaire. Two groups were defined: Group-TC, included 65 FMs (5 children below the age of 10) of 37 PATs treated for TC with average $(\bar{\alpha})$ activity of $3434 \mathrm{MBq}$ (range $1110-5920 \mathrm{MBq}$ ); Group-BTD included $18 \mathrm{FMs}$ adults of 11 PATs treated for BTD with $\bar{\alpha}$ activity of $336.4 \mathrm{MBq}$ (range $185-555 \mathrm{MBq}$ ). The in-PATs of Group-TC were discharged $48 \mathrm{~h}$ after therapy. All ethical principles of the investigation were respected.

Results

When the PATs of Group-TC were discharged the $\bar{\alpha}$ effective dose rate measured at 1 metre distance was $10.4 \mu \mathrm{Sv} / \mathrm{h}$ (range $2-28 \mu \mathrm{Sv} / \mathrm{h}$ ). The $\bar{\alpha}$ value of $H_{P}(10)$ in FMs were: $0.14 \mathrm{mSv}$ (range $0.00-3.37 \mathrm{mSv}$ ) for Group-TC and $0.37 \mathrm{mSv}$ (range $0.01-2.40 \mathrm{mSv}$ ) for Group-BTD. The $H_{P}(10)$ value depended on the degree of relationship $(p=0.008)$ and the age of the FMs $(p=0.007)$. $H_{P}(10)$ of the FMs were moderately associated to administered activity $\left(\rho_{s p}=-0.319 ; p=0.010\right)$ in Group-TC. No association was found between $H_{p}(10)$ FMs and the administered activity in Group-BTD $\left(\rho_{s p}=0.139 ; p=0.583\right)$.

Conclusions

The FMs of the PATs submitted ${ }^{131}$ I therapy for BTD received higher doses when compared to FMs of TC PATs. The $H_{P}(10)$ of the FMs depended to the degree of relationship and the age of the FMs. In the PATs submitted ${ }^{131}$ I therapy for BTD, the $H_{P}(10)$ of the FMs is not associated to the administered activity. The personal dose equivalent in these FMs does not reach the dose limits recommended by ICRP 97 and ICRP 94. 


\title{
Assessment of lodine-131 in the Urine of the Patient's Family Members after Differentiated Thyroid Carcinoma Therapy
}

\author{
Maria Raminhas Carapinha ${ }^{1,2,6}$, Gracinda Costa ${ }^{3}$, Teresa C. Ferreira ${ }^{4}$, Lucília Salgado ${ }^{4}$, \\ Inês Carvalho ${ }^{4}$, Monica Sofia ${ }^{3}$, Jorge Isidoro ${ }^{3}$, Teresa Rézio ${ }^{4}$, Lidia Silva ${ }^{5}$, Mário Reis ${ }^{5}$, \\ Marta Santos ${ }^{5}$, Carla Nunes ${ }^{2,7}$, António Barata Tavares ${ }^{2}$, Pedro Vaz ${ }^{5}$
}

\author{
${ }^{1}$ Área Científica de Medicina Nuclear, Departamento das Ciências e Tecnologias das Radiações \\ e Biossinais, Escola Superior de Tecnologia da Saúde de Lisboa, Instituto Politécnico de Lisboa, \\ Portugal \\ ${ }^{2}$ Escola Nacional de Saúde Publica, Universidade Nova de Lisboa, Av. Padre Cruz, 1649-016, \\ Lisboa, Portugal \\ ${ }^{3}$ Serviço de Medicina Nuclear, Centro Hospitalar e Universitário de Coimbra, EPE, Portugal \\ ${ }^{4}$ Serviço de Medicina Nuclear, Instituto Português de Oncologia de Lisboa, Francisco Gentil, \\ EPE, Portugal \\ ${ }^{5}$ Centro de Ciências e Tecnologias Nucleares, Instituto Superior Técnico Universidade de \\ Lisboa, Portugal \\ ${ }^{6}$ Grupo de Investigação em Radiações e Saúde, Escola Superior de Tecnologia da Saúde de \\ Lisboa, Instituto Politécnico de Lisboa, Portugal \\ ${ }^{7}$ Centro de Investigação em Saúde Pública, Av. Padre Cruz, 1649-016, Lisboa, Portugal
}

Corresponding author: maria.carapinha@estesl.ipl.pt

\section{Introduction}

The aim is to evaluate the internal exposure of the family members (FMs) of the patients (PATs) undergoing iodine-131 $\left({ }^{131} \mathrm{I}\right)$ thyroid cancer (TC) therapy and quantify the amount of ${ }^{131} \mathrm{I}$ in the FMs, excreted through the urinary.

Methods

An observational study with convenience sampling was performed, including 25 PATs and 34 FMs. The PATs, who were underwent ${ }^{131}$ I treatments for TC, were discharged from hospital $48 \mathrm{~h}$ after therapy. All FMs received instructions on radiation protection, based on Euratom recommendations use and submitted to a questionnaire. A urine sample was collected from every FMs about 70h after discharge of the PAT. Samples of urine were analyzed by gamma spectrometry and counted for $24 \mathrm{~h}$. All ethical principles of the investigation were respected.

\section{Results}

The average activity of ${ }^{131}$ I given to the PATs $(52.9 \%$ q) was $3266.4 \pm 1120.2 \mathrm{MBq}$. When the PATs were discharged the average $(\bar{\alpha})$ effective dose rate measured at 1 metre distance was $7.9 \pm 5.8 \mu \mathrm{Sv} / \mathrm{hr}$ (range $1-25 \mu \mathrm{Sv} / \mathrm{hr}$ ). In the $34 \mathrm{FMs}\left(52.9 \% \widehat{\partial}^{\lambda}\right.$ ) with $\bar{\alpha}$ of $48.1 \pm 18.6$ years, only in $3 F M s^{131}$ I wasn't detected in the urine. In the other 31 samples urines the specific activities of ${ }^{131}$ I has $\bar{\alpha}$ of $97.4 \mathrm{~Bq} / \mathrm{L}$ (range $0.0-1146 \mathrm{~Bq} / \mathrm{L}$ ). The specific activity of ${ }^{131}$ I in urine: it is not the same among the classes of the administered activity $(p=0.019)$; don't is the same on the different classes of FMs ages $(p=0.470)$ and the different degree of relationship $(p=0.744)$. We observed a moderate correlation between the specific activity of ${ }^{131} 1$ in the urine and the activity administered to the PATs $\left(\rho_{s p}=0.540 ; p=0.001\right)$ and also between the effective dose rate in the PATs $\left(\rho_{s p}=0.730 ; p<0.001\right)$. With a $\mathrm{Cl}$ of $95 \%$.

\section{Conclusions}

The PATs are a radioactive source that can cause exposure of the FMs to ionizing radiation. The specific activity of ${ }^{131} \mathrm{I}$ in the urines of the FMs is related to the activity administered to the PAT. It is clear that FMs of PATs submitted to radioiodine therapy can be subject to internal contamination. 


\title{
Deposited energies distribution comparison between ${ }^{125} \mathrm{I},{ }^{99 \mathrm{~m}} \mathrm{Tc},{ }^{161} \mathrm{~Tb}$, ${ }^{111}$ In and ${ }^{177} \mathrm{Lu}$ at micro and nano-scale
}

\author{
S. Di Maria ${ }^{1}$, A. Belchior ${ }^{1}$, Y. Romanets ${ }^{1}$, A. Paulo ${ }^{1}$, P. Vaz $^{1}$ \\ ${ }^{1}$ Centro de Ciências e Tecnologias Nucleares, Instituto Superior Técnico, Campus Tecnológico e \\ Nuclear, Estrada Nacional 10, km 139,7, 2695-066 Bobadela LRS, Portugal
}

Corresponding author: salvatore@ctn.tecnico.ulisboa.pt

\section{Introduction}

Molecular targeted radiotherapy is considering nowadays appealing, given the very short range (micrometers to few nanometers) of several radionuclides emitting Auger $(A)$, CosterKronig (CK), internal conversion (IC) electrons and $\beta$-radiation. ${ }^{125} \mathrm{I}\left(\mathrm{T}_{1 / 2}=59\right.$ days, 23 Auger electrons per decay) and ${ }^{99 \mathrm{~m}} \mathrm{Tc}\left(\mathrm{T}_{1 / 2}=6 \mathrm{~h}, 4.4\right.$ Auger electrons per decay) are two Auger-emitting radionuclides that have beenstudied for their potential use in theranostic, even if the effectiveness of the ${ }^{99 \mathrm{~m}} \mathrm{Tc}$ Auger emissions in inducing DNA double strand break is still controversial. However in the last years, ${ }^{111} \operatorname{In}\left(T_{1 / 2}=2.8 \mathrm{~h}, 7.43\right.$ Auger electrons per decay) and ${ }^{161} \mathrm{~Tb}\left(\mathrm{~T}_{1 / 2}=6.9\right.$ days, 10.96 Auger electrons per decay) raised also interest, because, apart their imaging capabilities, some studies showed their ability to induce cytotoxic effects when associated to radiolabeled compounds taken-up by tumor cells. In this context, the evaluation of the energy deposition pattern near the radionuclide decay site is important when Auger radiotherapy planning is contemplated, particularly when compared with radiotherapeutic procedures using T] emitters that are already in clinical use. For this reason, the ? emitter ${ }^{177} \mathrm{Lu}$ $\left(T_{1 / 2}=6.64 \mathrm{~d}, 1.11\right.$ Auger electrons per decay) was also included in this study, as ${ }^{177}$ Lu-labeled peptides had recently showed very positive results in Peptide Receptor Radionuclide Therapy (PRRT) of neuroendocrine tumors.

\section{Methods}

The state-of-the-art Monte Carlo (MC) radiation transport program MCNP6 was used. A simplified geometry for DNA segment, cytoplasm and cell composed of liquid water was considered and irradiated with an isotropic-like source. Emission data (photons were neglected) were obtained from the International Commission on Radiological Protection (ICRP) publication ICRP-107.

\section{Results}

This study intended to provide a quantitative approach for the variation of the deposited energy distribution for ${ }^{125} \mathrm{I},{ }^{99 \mathrm{~m}} \mathrm{Tc},{ }^{161} \mathrm{~Tb},{ }^{111} \mathrm{In}$ and ${ }^{177} \mathrm{Lu}$ when several spectra qualities are considered. The deposited energy distribution was assessed (also in terms of S-values in MIRD formalism) for each radionuclide studied and for each radiation type (Auger, IC and B radiation).

\section{Conclusions}

For these radionuclides $\left({ }^{161} \mathrm{~Tb},{ }^{111} \mathrm{In},{ }^{177} \mathrm{Lu},{ }^{125} \mathrm{I}\right.$ and $\left.{ }^{99 \mathrm{~m}} \mathrm{Tc}\right)$ an exact assessment of the energy deposition pattern near the radionuclide decay site, as well as the energy variation due to radionuclide-DNA distance, is of paramount importance to better design therapeutic strategies based on radionuclides that emit Auger electrons and/or $\beta$ radiation. 


\title{
Patient-personalized Voxel-based Dosimetry Planning for Liver Tumor Radioembolization
}

\author{
Paulo Ferreira $^{1,3},{ }^{\text {Rui Parafita }}{ }^{2}$, Ana Canudo ${ }^{2}$, Carla Oliveira ${ }^{1}$, Pedro S. Girão ${ }^{3}$, Paulo L. \\ Correia $^{3}$, Durval C. Costa ${ }^{1}$
}

\begin{abstract}
${ }^{1}$ Champalimaud Centre for the Unknown, Champalimaud Foundation, Nuclear MedicineRadiopharmacology Department, Lisboa, Portugal

${ }^{2}$ Mercurius Health at the Champalimaud Centre for the Unknown, Champalimaud Foundation, Nuclear Medicine-Radiopharmacology Department, Lisboa, Portugal

${ }^{3}$ Instituto de Telecomunicações, Instituto Superior Técnico - Universidade de Lisboa, Lisboa, Portugal
\end{abstract}

Corresponding author: paulo.ferreira@fundacaochampalimaud.pt

\section{Introduction}

Liver tumors are often inoperable because they are too large, too numerous or have grown into vital structures. Liver radioembolization (RE) is a clinical practice to treat primary and metastatic tumors via injecting Yttrium-90 $\left({ }^{90} \mathrm{Y}\right)$ microspheres (MS) into the hepatic artery.

Tecnetium-99m ( $\left.{ }^{99 \mathrm{~m}} \mathrm{Tc}\right)$ Macroaggregated Albumin (MAA) pre-treatment Single Photon Emission Computed Tomography (SPECT) and ${ }^{90} \mathrm{Y}$ post-treatment Positron Emission Tomography (PET) imaging are performed as part of the planning and treatment RE procedures.

\section{Methods}

In order to evaluate the predictive power of MAA in comparison with MS, we investigated 13 RE treatments, i.e., 154 planning target volumes (PTV) and 26 normal liver volumes (NLV), to correlate pre-treatment MAA SPECT with post-treatment MS PET maps for patientpersonalized voxel-dosimetry.

Dose-Volume histograms (DVH) of PTV and NLV have been used for dose comparison purposes. A Coverage Index $(\mathrm{Cl})$ and a Homogeneity Index ( $\mathrm{HI}$ ) are introduced to better characterize dose distributions, where $\mathrm{Cl}$ expresses the relationship between irradiated and non-irradiated targets $\left(\mathrm{Cl}_{\mathrm{PTV}}=\mathrm{TV} / \mathrm{PTV}\right.$ and $\left.\mathrm{Cl}_{\mathrm{NLV}}=\mathrm{TV} / \mathrm{NLV}\right)$, and $\mathrm{HI}$ dose homogeneity in PTV and $\mathrm{NLV}$ (HI=Mean/Max.Dose) for several isodose values (200\%, 125\%, 100\%, 50\% and 25\%).

\section{Results}

The best $\mathrm{Cl}$ (PTV: $0.74 \pm 0.16 / \mathrm{MAA}, 0.75 \pm 0.13 / \mathrm{MS}$ and NLV: $0.56 \pm 0.19 / \mathrm{MAA}, 0.56 \pm 0.18 / \mathrm{MS}$ ) was obtained when using the $50 \%$ (60Gy) reference isodose. Under these reference conditions, the HI was $0.55 \pm 0.15$ and $0.45 \pm 0.10$ in PTV vs. $0.25 \pm 0.06$ and $0.22 \pm 0.05$ in NLV, respectively for the MAA and MS distributions.

The mean $\mathrm{Cl}$ deviations between MS and MAA was -2\% in PTV and $-6 \%$ in NLV, revealing higher uptake of MAA in NLV and MS in PTV. The mean HI deviations was $-20 \%$ in PTV and $-18 \%$ in NLV, revealing the heterogeneous characteristic of the irradiations (MAA and MS).

\section{Conclusions}

Considering the $50 \%$ reference isodose (PTV and NLV) there is a good matching of the MAA and MS dose distributions. Further research is underway to prove the use of MAA as a predictor for MS dose distribution. 


\title{
Validation and Functional Characterization of Biomarkers for Cancer Theranostics with ${ }^{64} \mathrm{CuCl}_{2}$
}

\author{
Joana F. Guerreiro ${ }^{1}$, Vítor Alves ${ }^{2}$, Antero J. Abrunhosa ${ }^{2}$, Octávia Monteiro Gil ${ }^{1}$, Filipa \\ Mendes ${ }^{1}$
}

${ }^{1}$ Centro de Ciências e Tecnologias Nucleares, Instituto Superior Técnico, Universidade de Lisboa, Estrada Nacional 10 (km 139,7), 2695-066 Bobadela LRS, Portugal

${ }^{2}$ ICNAS - Instituto de Ciências Nucleares Aplicadas à Saúde, Universidade de Coimbra, Pólo da Saúde, Az, Sta Comba, Celas, 3000-548 Coimbra, Portugal

Corresponding author: joanaquerreiro@ctn.tecnico.ulisboa.pt

\section{Introduction}

Applications using radioisotopes are of major importance for cancer medicine. Currently, the cyclotron-produced ${ }^{64} \mathrm{Cu}$ stands out as one of the few known radionuclides to simultaneously emit positron, as well as beta particles and Auger electrons, thus having the potential to be used for both diagnosis and therapeutics (theranostics). Findings from preclinical studies demonstrated that the simple ionic copper chloride $\left({ }^{64} \mathrm{CuCl}_{2}\right)$ exhibits increased tumor uptake in human copper transporter 1 (hCTR1)-expressing tumor cell lines and tumor xenografts, having potential for the treatment of malignancies expressing high levels of this copper transporter.

\section{Methods}

In this work, the biological effects of exposure to ${ }^{64} \mathrm{CuCl}_{2}$ were assessed through cellular studies in a large panel of prostate cancer and melanoma cell lines, namely by characterizing ${ }^{64} \mathrm{CuCl}_{2}$ uptake and determining the proteins levels of different copper transporters. In addition, genotoxicity studies of the effects induced by different doses of ${ }^{64} \mathrm{CuCl}_{2}$ (using micronucleus and $\gamma-\mathrm{H} 2 \mathrm{AX}$ assays) were also performed.

\section{Results}

In most cell lines under study, ${ }^{64} \mathrm{CuCl}_{2}$ uptake increased as a function of incubation time. However, cellular uptake was dependent on the cell line used, being higher in prostate cancer than melanoma cell lines in most of the cases. The protein levels of hCtr1, and the efflux copper transporters Atp7A and Atp7B, were also assessed and correlated with ${ }^{64} \mathrm{CuCl}_{2}$ cellular uptake. The genotoxicity assays used allowed the assessment of DNA damage and repairing capacity.

\section{Conclusions}

In agreement with previous reports, we observed significant ${ }^{64} \mathrm{CuCl}_{2}$ cellular uptake in different prostate cancer and melanoma cell lines. In addition, it was possible to evaluate the radiosensitivity to ${ }^{64} \mathrm{CuCl}_{2}$ in the different cancer cell lines, something which deserves to be further evaluated in the context of the use of this radiopharmaceutical for cancer theranostics. 


\title{
Skin Contamination Survey on the Daily Practice of Nuclear Medicine Staff
}

\author{
Fernandes, N. ${ }^{1}$, Neves, D. ${ }^{1,2}$, Ferrer, A. ${ }^{2}$, Pires, L. ${ }^{2}$, Antunes, H. $^{2}$, João, M.F. ${ }^{2}$, Araújo, \\ A. ${ }^{3}$, Pereira, J. ${ }^{3}$, Metello, L.F. ${ }^{1,4}$ \\ ${ }^{1}$ ESS - IPP, ATC \& Curso Med. Nuclear, Rua Dr. António Bernardino de Almeida, 400, 4200 - \\ 072, Porto. Portugal \\ ${ }^{2}$ Diaton S.A. - Dept. de Med. Nuclear, Leiria, Coimbra, Viseu. Portugal \\ ${ }^{3}$ Serviço de Medicina Nuclear - Hospital de S. João, Porto, Alameda Prof. Hernâni Monteiro, \\ 4200 Porto. Portugal \\ ${ }^{4}$ IsoPor-Azores, Dept. de Med. Nuclear e Imagiologia Molecular, Angra do Heroísmo, I. \\ Terceira - Azores. Portugal \\ Corresponding author:Ifm@ess.ipp.pt
}

\section{Introduction}

Skin contamination of Nuclear Medicine (NM) staff may occur, essentially when dealing with liquid radioactive sources, a most common situation in daily practice. The aim of this study is to analyze frequency, sources and professional profiles involved on skin contamination occurring in NM daily practice.

\section{Methods}

In 3 months, 263 inspections were held on the hands of NM technologists (121), nurses (57), and NM technologists trainees (85), after a work shift with a minimal duration of 4 hours. The same Geiger-Müller detector was used for contamination detection and localization issues. Contamination threshold was established at $\geq 1 \mu \mathrm{Sv} / \mathrm{h}$ and all contaminations were confirmed by another detector (camera-gamma or proportional counter).

\section{Results}

Hand inspections were carried out in two distinct NM Departments (D1=145, D2=118). Hand contaminations were found in 26 cases $(9,9 \%)$. In $73 \%$ of the cases, the worker was unaware of it. Dose rates ranged from 1-150 $\mu \mathrm{Sv} / \mathrm{h}$. The vast majority of contaminations were focal (25 cases, 96.2\%), with main contamination sources identified as radiopharmaceutical administration (38.5\%) and radiopharmacy procedures (34.6\%). Most frequent contamination sites $(23.1 \%)$ were the tip of the index and the ring finger of the non-dominant hand and contamination was found in all professional profiles: $14.0 \%$ (8 out of 57 ) in nurses, $9.9 \%$ (12 out of 121 ) in NM technologists and $7.1 \%$ ( 6 out of 85 ) in technologist trainees.

\section{Conclusions}

Preliminary results obtained revealed that hands skin contamination may occur with nonnegligible frequency, suggesting that a hand/skin contamination monitoring program should be considered on NM daily practice. Further studies are needed, to correlate and assess work practices, the frequency and magnitude of skin contamination and its contribution to extremities effective dose, in order to better access the real situation and to sustain eventual improvement measures in conventional NM Departments daily practice. 


\title{
Minimisation of acquisition time in a TOF PET/CT scanner without compromising image quality
}

\author{
$\underline{\text { Joana Oliveira }}{ }^{1}$, Rui Parafita ${ }^{2}$, Susana Branco ${ }^{1}$ \\ ${ }^{1}$ Escola Superior de Tecnologia da Saúde de Lisboa, Instituto Politécnico de Lisboa, Portugal \\ ${ }^{2}$ Champalimaud Foundation, Portugal
}

Corresponding author: joanafonsecaoliveira@gmail.com

\section{Introduction}

Significant improvements have been made in Positron Emission Tomography/Computed Tomography (PET/CT) to enhance the image quality, namely, the development of time-of-flight (TOF) technology. This technique is useful to localize the emission point of the beta plusemitter $\left(\beta^{+}\right)$radiopharmaceutical inside the body, allowing better lesion contrast, especially for large patients, improving structural details and leading to a short scan time.

The main goal of this study is to verify the shortest acquisition time per bed position, in a TOF PET scanner, without compromising the image quality, in both phantom and clinical imaging.

\section{Methods}

For that purpose, images of a torso NEMA phantom were acquired with different acquisition times per bed position (30, 45, 60, 80 and $120 \mathrm{~s}$ ) in a TOF PET/CT scanner (GEMINI TF 16, Philips), using Gallium-68 ( $\left.{ }^{68} \mathrm{Ga}\right)$ citrate. Clinical images were also acquired of an aleatory patient (male, $64 \mathrm{y}$ ) with ${ }^{68} \mathrm{Ga}$-prostate specific membrane antigen $\left({ }^{68} \mathrm{Ga}-\mathrm{PSMA}\right)$. Image quality parameters, such as signal-to-noise ratio (SNR), noise, contrast, contrast-to-noise ratio (CNR), contrast recovery coefficient $(C R C)$ and quantification in terms of standardized uptake value (SUV) were acquired.

\section{Results}

The increased contrast and CRC in larger spheres and with longer acquisition times produces an increase on the noise, leading to a decrease in SNR and CNR. In phantom imaging, SUV max $_{\max }$ varied between 1.1 and 1.6 for background (normal uptake) and between 2.1 and 8.0 for spheres (abnormal uptake). A strong correlation was found for both SUV $\mathrm{max}_{\text {ax }}$ and SUV $\mathrm{V}_{\text {mean }}$ between the different acquisition times ( $\mathrm{R}>0.7)$. In patient imaging, spleen showed higher SNR, contrast, noise and CNR than liver. Median SUV $\max$ was 7.1 for liver, 9.8 for spleen and 1.8 for bone.

\section{Conclusions}

A time between 45 and $60 \mathrm{~s}$ per bed position is proposed for future clinical practices, allowing schedule more scans per day, contributing to an optimization of protocols without compromising the image quality. 


\title{
Relationship between cervical/abdomino-pelvic activity and effective dose at 1 meter (ED1M) in patients with differentiated thyroid carcinoma submitted to lodine-131 therapy
}

\author{
M. Rio Carvalho $^{1}$; M. Silvestre ${ }^{1}$; F. Norton Brandão ${ }^{1}$; I. P. Carvalho ${ }^{1}$; R. Sousa ${ }^{1}$; P. \\ Ratão ${ }^{1}$; T. C. Ferreira ${ }^{1}$; L. Salgado ${ }^{1}$.
}

${ }^{1}$ Serviço de Medicina Nuclear do Instituto Português de Oncologia de Lisboa Francisco Gentil E.P.E.

Corresponding author: manuelriocarvalho@gmail.com

Introduction

Patients diagnosed with differentiated thyroid carcinoma who need lodine-131 therapy require hospitalization and are subject to radioprotection measures according to the dose rate at 1 meter (ED1M). The retained activity in the patient is a function of several factors, including the administered activity, residual thyroid tissue remnant and patient physiologic status.

The patients perform a post-therapy whole body scintigraphy (WBS) for localizing the extent of thyroid remnant and detecting previously occult lesions. Through WBS, it is possible to observe the distribution of radiopharmaceutical in the body.

The purpose of this study was to investigate the correlation between ED1M and the cervical and abdominopelvic lodine-131 uptake in WBS.

\section{Methods}

From January 1st 2017 to March 31st 2017, 94 patients were treated, with lodine-131 at our ward. Only the patients with no metastases or contaminations were included $(n=75)$.

Data used includes ED1M, WBS counts, cervical region counts and abdomino-pelvic region counts obtained after drawing the respective regions of interest. Linear regression was used between these variables.

\section{Results}

The regression between total counts and ED1M $\left(y=3.10^{*} 10^{-6} x+2.99\right)$ shows $R^{2} 85 \%(p<0.001)$. The regression between abdomino-pelvic counts and ED1M $\left(y=9.11^{*} 10^{-6} x+2.66\right)$ shows $R^{2} 82 \%$ $(p<0.001)$. The regression between cervical counts and ED1M $\left(y=2.74 * 10^{-5} x+6.16\right)$ presented $R^{2}$ $17 \%(p<0.001)$.

\section{Conclusions}

As expected, the variables that have a stronger relationship are the total counts and ED1M. A stronger relationship between abdomino-pelvic activity and ED1M than between cervical activity and ED1M was also found.

The patient should be considered as a whole because the thyroid remnant is important from a radiation point of view but it is not the most important factor. 


\title{
Radionuclide Therapy Dosimetry under the New EU BSS*
}

\author{
$\underline{\text { João A.M. Santos }}{ }^{1,2,3}$ \\ ${ }^{1}$ Instituto Português de Oncologia do Porto Francisco Gentil, EPE (IPOPFG E.P.E.), Serviço de \\ Física Médica, Rua Dr. António Bernardino de Almeida, 4200-072 Porto, Portugal \\ ${ }^{2}$ IPOPFG E.P.E., Centro de Investigação, Porto, Portugal \\ ${ }^{3}$ Instituto de Ciências Biomédicas Abel Salazar da Universidade do Porto, Rua J Viterbo Ferreira \\ 228, 4050-313 Porto, Portugal
}

*invited talk

Corresponding author: joao.santos@ipoporto.min-saude.pt

\section{Introduction}

Radionuclide therapy (RT) dosimetry is wide-ranging, sometimes complex, and always needs resource allocation. From lodine-131 (e.g. hyperthyroidism) to Lutetium-177 (e.g. neuroendocrine cancers) or Itrium-90 (e.g. radioembolization), there is a broad range of radionuclides and activities for therapeutic use. Since each patient is unique, a personalized dosimetry approach can therefore be recommended.

\section{Methods}

New developments in the field, and the new EU BSS Directive, are approaching dosimetry in RT to dosimetry in External Radiotherapy. However, there is a price to attain this goal and it needs to be justified. Beauchamp and Childress beneficence principle is evoked to justify dosimetry in almost every patient subjected to RT, although the cost of such procedures can be onerous for the majority of the already overloaded health care systems. This fact, together with necessarily limited available funding, can conflict with the principle of justice, stated by these authors, when allocating resources, leading to the need of rationing and ethical reasoning.

\section{Results}

Dosimetry implementation according to the EU BSS Directive must be carefully considered for each particular patient and pathology. The same Directive also strongly reinforces the medical physics expert (MPE) as part of the therapeutic team for RT. This implies that MPE are fundamental elements in the process of decision whether dosimetry should or not be performed in each particular circumstance.

\section{Conclusions}

MPE should be aware of the vast range of ethical values and reasoning behind clinical decision making, and a formal education in Bioethics should be pursued by these professionals. 


\title{
Radionuclides in Waste Discharges from Health Establishments
}

\author{
$\underline{\text { N. Soares }}{ }^{1}$, I. Paiva ${ }^{2}$, L. Amaral ${ }^{3}$, P. Monteiro ${ }^{4}$, L. Salgado ${ }^{5}$, M. T. Rézio ${ }^{5}$, A. Baptista ${ }^{2}$ \\ ${ }^{1}$ Ambimed, Lda., Stericycle Portugal, Rua Fernando Pessoa, 8C, 2560-241 Torres Vedras \\ ${ }^{2}$ Centro de Ciências e Tecnologias Nucleares (C2TN), Instituto Superior Técnico, Universidade \\ de Lisboa, Estrada Nacional 10, km 139,7, 2695-066 Bobadela Loures \\ ${ }^{3}$ CENSE, Center for Environmental and Sustainability Research, Departamento de Ciências e \\ Engenharia do Ambiente, Faculdade de Ciências e Tecnologia, Universidade NOVA de Lisboa, \\ Campus da Caparica, 2829-516 Caparica, Portugal \\ ${ }^{4}$ Divisão do Ambiente e Energia, Direção Municipal da Estrutura Verde, Ambiente e Energia, \\ Câmara Municipal de Lisboa, Praça José Queirós, no1-Piso 3 (Edifício do Entreposto), 1800-237 \\ Lisboa \\ ${ }^{5}$ Serviço de Medicina Nuclear, Instituto Português de Oncologia de Lisboa Francisco Gentil, Rua \\ Prof. Lima Basto, 1099-023 Lisboa
}

Corresponding author: nsoares@ambimed.pt

Nuclear medicines (NM) use radiopharmaceuticals both in diagnostic and therapy which originate solid, liquid and gaseous radioactive wastes. Radioactive liquid wastes that result mainly from the patient's excreta are discharged as wastewaters. Depending on the radioisotopes activities administered and the type of medical examination, NM can discharge the effluents directly into the sewer system or storage them in retention tanks for decay prior to discharge in the sewer. The Lisbon Borough Council (CML) in collaboration with the IST/CTN, has in place since 1989, a monitoring programs to monitor the discharged radioactive liquid wastes produced by nuclear medicines both in state and private health establishments across Lisbon. Samples of the discharged effluent are collected from the sewer, outside the nuclear medicines and sent to IST/CTN for radiological analysis by gamma spectrometry. In this work, a first analysis of the available 10 years historical data from previous monitoring programs are analyzed and compared with literature data. From the analysis of the data, I-131 and Tc-99m are the main radionuclides detected in the discharged waters as expected from their wide uses both in therapy and diagnostic. Samples collected at Lisbon wastewater treatment plans (ETAR) were also analyzed for radionuclides assessing its presence and quantification of the specific activity by gamma spectrometry. The effects of the changes in the treatment system in place in the largest health establishment carrying out both diagnostic and therapy exams in Lisbon, on the monitoring results are discussed as well as other countries treatment options. Preliminary conclusions are positive in the way that monitoring programs have shown to be effective in controlling radioactive discharges providing treatment procedures are in place but more data is needed to evaluate the radiological situation in the ETAR and its connection with the nuclear medicines across the city. Future monitoring programs could be improved in order to start collecting data that could be adequate not only to legal monitoring but also to evaluate the overall radiological impact in the environment of the discharges as well as to allow evaluation of doses to critical groups such as the sewage treatment workers. 

Conference "Proteção Radiológica na Saúde 2017"

Oral Presentations - Optimization 


\title{
Dose and Image Quality in Computed Tomography: an overview of Portuguese Data
}

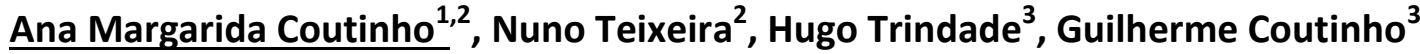 \\ ${ }^{1}$ Instituto Superior de Engenharia de Lisboa: ISEL-IPL (Rua Conselheiro Emídio Navarro 1, 1959- \\ 007 Lisboa) \\ ${ }^{2}$ Escola Superior de Tenologia da Saúde de Lisboa: ESTeSL-IPL (Avenida Dom João II Lote \\ 4.69.01, 1990-096 Lisboa) \\ ${ }^{3}$ MedicalConsult - Grupo Stericycle Portugal (Rua Fernando Pessoa - 8C, 2560-241 Torres \\ Vedras)
}

Corresponding author: ana.m.coutinho93@gmail.com

Computed Tomography exams expose patients to higher dose levels than most exams in radiology and the number of CT exams is increasing year after year in Portugal. In 2009 were performed 1.1 million CT exams and later in 2014 there were 1.6 million.

This study aims to analyze dose and image quality data gathered from 180 distinct computed tomography systems, which represents 350 quality assurance interventions done in Portuguese national health units (mainland and islands) between 2014 and 2017. In the quality assurance interventions, a Catphan ${ }^{\circledR} 500$ phantom was aligned in the center of the gantry and irradiated, for analysis of six parameters: CT numbers, slice thickness, low and high contrast resolution, uniformity and noise. Afterwards, an ionization chamber (Raysafe Xi CT sensor) was placed in the interior of a PMMA (polymethylmethacrylate) phantom and the Computed Tomography Dose Index (CTDI) was measured. Data analysis was performed using IBM SPSS v.22.0.

In order to verify the CT numbers, four materials with different densities were analyzed and the mean CT numbers obtained were: $-980 \mathrm{HU}$ (Air), $-943 \mathrm{HU}$ (Teflon), -115 HU (Acrylic) and $99 \mathrm{HU}$ (LDPE). The high contrast resolution values were determined for X-ray energies in a range of $80 \mathrm{kV}$ to $100 \mathrm{kV}$ at $200 \mathrm{~mA}$ and the mean spatial resolution obtained was $8 \mathrm{lp} / \mathrm{cm}$ with a gap size of $0,063 \mathrm{~cm}$. When increasing the voltage to $130-140 \mathrm{kV}$ the mean spatial resolution was $9 \mathrm{lp} / \mathrm{cm}$ with a gap size of $0,056 \mathrm{~cm}$. Dose measured in head and body scan techniques, with a voltage between $80 \mathrm{kV}$ and $100 \mathrm{kV}$ at $100 \mathrm{~mA}$ and $10 \mathrm{~mm}$ slice thickness was $6 \mathrm{mGy}$ and $3 \mathrm{mGy}$, respectively. When increasing the voltage to $130-140 \mathrm{kV}$ the mean values obtained were $23 \mathrm{mGy}$ (head) and $12 \mathrm{mGy}$ (body).

These results show that with lower voltage the CTDI is four times lower, while keeping an adequate spatial resolution. Adequate CT protocols are very important to ensure safety to all patients, and specific designed pediatric protocols should be used, once children are more sensitive to the effects of ionizing radiation. It is important to adapt CT exams in order to minimize exposure while providing good diagnostic quality. In this study a comparison between adults and children protocols is made (using international publications like the ones form AAPM - American Association of Physicists in Medicine), using dose and resolution data from the Portuguese equipment. 


\title{
A Portuguese approach regarding dose assessment and image quality in intraoral radiology
}

\author{
Guilherme Coutinho ${ }^{1}$, Hugo Trindade ${ }^{1}$, Mariana Trincão ${ }^{1}$, Cláudia Xavier ${ }^{1}$, Cláudia \\ Mota $^{1}$
}

${ }^{1}$ MedicalConsult - Grupo Stericyle Portugal, Rua Fernando Pessoa 8C, 2560-241, Torres Vedras

Corresponding author: quilherme.coutinho@medicalconsult.pt

Intraoral imaging is the most common X-ray diagnostic method in dentistry and is an important tool for the clinician, providing information that is impossible to obtain by clinical examination alone.

Studies have shown that doses from intraoral radiology are smaller than in other radiographic techniques, although the collective dose could be significant. Every year, it is observed an increasing number of intraoral X-rays units. In the beginning of 2016, the Portuguese Health General Directorate (DGS) have licensed 5344 intraoral equipment. It is also estimated that there is about $15-25 \%$ of non-licensed X-rays units, which could increase the number of intraoral units to nearly 6500. On the other hand, according to Portuguese Dental Association (OMD - Ordem dos Médicos Dentistas), in 2012, there was a doctor per 1153 inhabitants. In the end of 2016, OMD was expecting to have 9338 dentists and the Portuguese Medical Association (OM - Ordem dos Médicos) indicates that there are 601 stomatologists. This numbers indicate that there is a significant number of dental practitioners that use radiology procedures regularly. It is estimated between 2 and 12 million radiographs performed each year, in Portugal.

This study aims to give an overview of the Portuguese intraoral X-Rays units; to compare doses in digital and film intraoral radiography; to characterize the general state in terms of quality assurance parameters (kilovoltage peak, type of generators (pulsed or continuous), brand and nominal parameters) of the intraoral equipment used in Portugal; and to evaluate the image quality of digital sensors in terms of high contrast resolution (spatial resolution).

The data used was gathered from measurements performed in 1200 intraoral X-ray equipment on Portuguese dental practices distributed throughout the mainland and islands, between September 2016 and April 2017. The measurements are part of the annual quality assurance program of each equipment, based on the requirements of Decree-Law 180/2002 and European Commission Report RP162. Entrance Surface Air Kerma (ESAK) was measured with a Raysafe X2 R/F Sensor. The image quality of 760 digital sensors was evaluated in terms of spatial resolution. It was used the Pro-Dent gamma phantom from Pro-Project and the protocol described by the manufacturer. Statistical analysis was done with IBM SPSS v.22.

Result analysis have shown that digital radiography is the technique adopted in the majority of tested equipment (around 84\%) and confirms the lower doses (mean ESAK: 0,9 mGy) compared to non-digital radiography (mean ESAK: $2,3 \mathrm{mGy}$ ). About $40 \%$ of units have generators with continuous wave forms. It was verified lower doses in continuous generators (mean ESAK: 0,9 mGy) compared to pulsed generators (mean ESAK: 1,3 mGy). Spatial resolution is $8 \mathrm{lp} / \mathrm{mm}$ in $55 \%$ of radiovisiography (RVG) sensors and 7,1 $\mathrm{lp} / \mathrm{mm}$ in $28 \%$. There were not found any relation between dose and spatial resolution. Neither, brands and models of the sensors are associated with higher resolutions.

In conclusion, the lowest dose examination that will answer the clinical question should always be undertaken and every effort should be made to perform the radiography at minimum dose to the patient. Regarding the amount of intraoral units, the increasing number of dental practitioners and clinical facilities, the resulting collective dose could not be discarded and should be estimated in further studies. Considering the diversity of brands (48 in this study) 
and equipment (117 models tested) it is also important to develop Diagnostic Reference Levels and consistent specialized programs of formation to promote staff safety culture and consequently health care best practice. 


\title{
Influence of the axial scan orientation angle and gantry tilt in Head CT dose exposure
}

\author{
Pereira, Rui Miguel $^{1,2}$; Ribeiro, Ana Beatriz ${ }^{1}$; Ferreira, Ana Isabel ${ }^{1}$; Pinto, Humberto ${ }^{1}$; \\ Carvalho, Salomé ${ }^{1}$; Santos, Milton Rodrigues ${ }^{1}$
}

${ }^{1}$ Escola Superior de Saúde da Universidade de Aveiro, Campus de Santiago, 3810 - Aveiro

${ }^{2}$ Serviço de Imagiologia, Centro Hospitalar do Baixo Vouga, EPE, Av. Artur Ravara, 3810 - Aveiro

Corresponding author: ruimpereira@ua.pt

\section{Introduction}

Radiation exposure due to Head Computed Tomography (CT) scans has been a growing concern, leading to an increasing interest in CT protocol optimization ${ }^{1,2}$, due to its significant use in clinical practice and eye lens exposure ${ }^{3}$, and where optimization for gantry tilt has shown good results ${ }^{2}$.

The present study aims to analyze the axial scan acquisition variability and its repercussion in the radiation dose in the scope of Head CT studies.

\section{Methods}

Initially, an anthropomorphic phantom was submitted to head CT scans using routine protocol, with different axial scan angles orientation.

Secondly, a retrospective study was conducted on routine Head CT studies from a mediumsized health instituition. Demographic anonymized patient data, scan protocol and dose report data were colleted.

Scan angle was measured using sagittal reformation and supraorbitomeatal line (SOML) as reference. Data analysis was performed using Microsoft Excel and SPSS 24.

\section{Results}

Data from 115 adult patients routine Head CT studies $\left(56{ }^{\lambda}\right.$; 59 ; ; between 18 and 94 years old) were collected.

DLP average value was $1109.82 \pm 98.22 \mathrm{mGy} . \mathrm{cm}$, for scan angle was $-9.87 \pm 6.70$ 을 for gantry tilt angle was $13.14 \pm 9.53 \%$.

DLP and scan angle shown statistical significant correlation with negative trend lines on linear regression model ( $R^{2}$ : up to 0.31 in patients and $>0.85$ in phantom). Gantry tilt and scan angle presented significant correlation with positive trend line, but no correlation between gantry tilt and DLP were observed.

DLP shown lower value for -4.99 o to 0 o interval $(1027.53 \pm 74.05 \mathrm{mGy} . \mathrm{cm})$ and a growth trend further away from this interval.

\section{Conclusions}

The methodology used allowed to identify a significant variability in the patient positioning as well as in the scan angle. A normalization of the positioning as well as the scan angle, closer to the SOML, is recommended for a decrease in exposure. No relationship between gantry tilt and dose was observed, contrary to what happens with phantom study.

\section{References:}

1. Trattner S, Pearson GDN, Chin C, et al. Standardization and Optimization of \{CT\} Protocols to Achieve Low Dose. J Am Coll Radiol. 2014;11(3):271-278. doi:http://doi.org/10.1016/j.jacr.2013.10.016.

2. Nikupaavo U, Kaasalainen T, Reijonen V, Ahonen S-M, Kortesniemi M. Lens Dose in Routine Head CT: Comparison of Different Optimization Methods With Anthropomorphic Phantoms. Am J Roentgenol. 2014;204(1):117-123. doi:10.2214/AJR.14.12763.

3. Figueira, C; Vieira, C; Santos, D; Santos, D.; Vale, J; Santos MR. Reference dose levels in head computed tomography: a pilot study performed during traineeship in three Portuguese health institutions. Insights Imaging. 2014;5(1):271. doi:10.1007/s13244-014-0317-5. 


\title{
Dose values in interventional computed tomography procedures: a multicenter study
}

\author{
Ilda Gomes ${ }^{1}$, Ana Costa ${ }^{1}$, Andrea Pimenta ${ }^{2}$, Carla Fonseca ${ }^{3}$, Crsitina Almeida ${ }^{4}$, \\ Graciano Paulo ${ }^{1}$, Joana Santos ${ }^{1}$
}

\author{
${ }^{1}$ ESTES - Coimbra Health School; Sanfil \\ ${ }^{2} \mathrm{CHSJ}$ - Centro Hospitalar de São João \\ ${ }^{3} \mathrm{CHUC}$ - Centro Hospitalar e Universitário de Coimbra \\ ${ }^{4} \mathrm{CHLC}$ - Centro Hospitalar Lisboa Central;
}

Corresponding author: joanasantos@estescoimbra.pt

\section{Introduction}

Computed tomography (CT) is a valuable medical tool to plan and guide interventional or therapeutic procedures. The interventional procedures can be performed based in 2 dimensions images (2D), image reconstructions (3D) or using CT fluoroscopy. The applications CT fluoroscopy is the high radiation exposure procedure and radiation protection safety measures must apply. The use of fluoroscopy $\mathrm{CT}$ is controversial and interventional procedures are regularly performed based on $2 \mathrm{D}$ images.

\section{Methods}

This study was developed in three Portuguese centers of excellence in interventional CT. Retrospective analysis of exposure parameters and CT dose values in terms of CT Dose Index (CTDIvol - mGy) and Dose Length Product (DLP - mGy.cm) were directly collected from the Digital Imaging Archiving and Communication System (DICOM) headers, available on Picture Archiving and Communication System (PACS). Local DRL's were calculated for chest, abdomen and skeletal biopsies, drainages and ablation therapy.

\section{Results}

Local DRLs were obtained for the most common interventional CT procedures per each center. Lung biopsy revealed to be the most frequent procedure. The exposure parameters and dose values varies across the centers. The found acquisition modes for intervention $C T$ are $2 D$ in (axial and helical mode) and CT fluoroscopy. The highest interventional acquisition dose values were found for CT fluoroscopy. The majority of the obtained dose values are similar to other studies.

\section{Conclusions}

The first national approach of interventional CT dose values was performed. Different approaches to these procedures were verified. A lack of standardisation of practice was identified justifying further research in order to protect the staff and decrease the risk of patient's over exposure and procedures complications. 


\title{
Effective dose to patients from PET/CT procedures
}

\author{
$\underline{\text { Sara Russo }^{1}}$, Pedro Almeida $^{2,3}$, Ana Sofia Matos ${ }^{4}$, Luís Oliveira ${ }^{3}$, Isabel Conde ${ }^{3}$, Teresa \\ Lúcio ${ }^{3}$
}

${ }^{1}$ Faculdade de Ciências e Tecnologia da Universidade Nova de Lisboa, Campus de Caparica 2829-516 Caparica, Portugal

${ }^{2}$ Instituto de Biofísica e Engenharia Biomédica, Faculdade de Ciências, Universidade de Lisboa, Campo Grande, 1749-016 Lisboa, Portugal

${ }^{3}$ Joaquim Chaves Saúde, Clínica Quadrantes, 1495-148 Algés

${ }^{4}$ UNIDEMI, Faculdade de Ciências e Tecnologia da Universidade Nova de Lisboa, Campus de Caparica 2829-516 Caparica, Portugal

Corresponding author: $\underline{\text { s.russo@campus.fct.unl.pt }}$

\section{Introduction}

Clinical PET/CT results from the fusion of anatomical (CT) and functional (PET) images. PET/CT allows precise diagnosis, nevertheless, the radiation doses associated with these exams need to be optimized due to the potential biological consequences resulting from the interaction of the radiation with tissues. Therefore, national and international organizations - such as the International Commission on Radiological Protection (ICRP) - took on the responsibility to recommend the optimization of the exposure to ionising radiation due to medical examinations, which should be as low as reasonably achievable (ALARA).

\section{Methods}

A novel methodology based on short run (Quesenberry Q-statistics) and normalized with non constant sample size (Z-chart) control charts was developed to establish simultaneous intra and inter daily control of administered activity. To illustrate the proposed methodology, 498 patients (243 female and 255 male) were selected from a set of PET-CT 18F-FDG exams (6-7 beds) performed between 2015 and 2016. These exams were performed on a PET-CT Siemens True-Vue. For these exams we have evaluated the ratio between the injected activity and the body mass. The results are expressed as mean \pm standard deviation. Differences were considered significant at a $p$-value $<0.05$.

\section{Results}

For the PET component of the PET/CT exam the mean injected 18F-FDG activity was $346.63 \pm 65.5 \mathrm{MBq}$ which correspond to an effective dose of $6.59 \pm 1.2 \mathrm{mSv}$. Through the combined control charts approach we were able verify a decresase in the ratio between the injected activity and the body mass from $5.17 \pm 0.77$ to $5.15 \pm 0.56$ during this period. This resulted in an efective dose optimization for 18F-FDG exams.

\section{Conclusions}

The use of joint control charts, based on the Quesenberry Q-statistics and Z-charts, revealed to be a suitable tool not only for detecting possible maladministration but also for monitoring the injected activity and the correspondent effective dose delivered to patients in PET-CT. 


\title{
Image quality in digital mammography- evaluation of protocols and guides for routine quality control
}

\author{
$\underline{\text { Hugo Trindade }}{ }^{1}$, Cláudia Xavier $^{1}$, Guilherme Coutinho $^{1}$ \\ ${ }^{1}$ MedicalConsult (Rua Fernando Pessoa - 8C, 2560-241 Torres Vedras) \\ Corresponding author: hugo.trindade@medicalconsult.pt
}

In Portugal there is a clear urgency for the update of the legislation in quality control of radiological equipment, especially in mammography. The latest official document (DL 180/2002) only covers screen-film mammography and is totally unfit for the technical advances in this field - Computed Radiography (CR) and direct radiography (DR). Given the existence of three main international protocols (EUREF, IAEA and EFOMP) with different philosophies and methodologies for image evaluation, our concern, and the goal of this study, is the implementation of a methodology for routine quality control, simpler but assuring a high level of image quality, based on acquired data. EUREF Guidelines has published acceptable and achievable levels for the maximum average glandular dose (AGD) in mammographic exams and those are taken as the standard values to use. However, evaluations of radiation dose at the patient organ should be accompanied by a method to quantify image quality. Signal difference to noise ratio (SDNR), is the only common parameter, used to the evaluation of image quality, in the 3 different protocols. According to the EUREF protocol, image quality is evaluated in terms of the threshold contrast visibility at a standard simulated breast thickness, from observations made from images of the CDMAM (Contrast Detail Mammography Phantom) for $50 \mathrm{~mm}$ PMMA, and quality for different breast thickness is estimated from this value using SDNR. EFOMP establishes SDNR limits for different thickness estimated from measured SDNR for $45 \mathrm{~mm}$ of PMMA as AEC acceptance criteria. IAEA establishes reference acceptable and achievable SDNR levels which vary with the image acquisition system. In this study we evaluate over 30 digital mammography systems, from different manufactures, over the years 2011 to 2017, resulting in more than 330 quality control tests. AGD is compared with EUREF limits for PMMA thickness varying from $20 \mathrm{~mm}$ to $70 \mathrm{~mm}$. We also study SDNR for such thicknesses and compare it to the limits from IAEA, EUREF and EFOMP, in terms of acceptable and achievable levels of image quality. Threshold contrast visibility for $50 \mathrm{~mm}$ PMMA thickness is also evaluated. Preliminary data indicates that $47 \%$ of the equipment uses DR technology (53\% are CR). In DR systems, AGD for $50 \mathrm{~mm}$ PMMA is $1.2 \pm 0.4 \mathrm{mGy}$, below the acceptable level of $3 \mathrm{mGy}$. For SDNR, $96 \%$ of the equipment complies with the IAEA and EUREF acceptable values. $85 \%$ of the equipment complies with IAEA achievable limits. For CR systems, AGD for $50 \mathrm{~mm}$ PMMA is $2.4 \pm 0.7 \mathrm{mGy}$. For SDNR, all equipment complies with the IAEA acceptable values and $74 \%$ with the achievable limits. Only $34 \%$ of the equipment complies with EUREF acceptable criteria. 


\title{
Cancer incidence after low dose radiation exposure: the Portuguese tinea capitis $\mathrm{X}$-irradiated cohort*
}

\author{
Luís Antunes ${ }^{1}$, Maria José Bento ${ }^{1}$, Manuel Sobrinho-Simões ${ }^{2,3,4,5}$, Paula Soares ${ }^{2,3,4}$, \\ Paula Boaventura ${ }^{2,3}$
}

\footnotetext{
${ }^{1}$ North Region Cancer Registry of Portugal, Department of Epidemiology, Portuguese Oncology Institute of Porto (IPO Porto), Porto, Portugal

${ }^{2}$ IPATIMUP - Institute of Molecular Pathology and Immunology of the University of Porto, 4200-465 Porto, Portugal

${ }^{3}$ i3S - Instituto de Investigação e Inovação em Saúde, Universidade do Porto, Rua Alfredo Allen, 208, 4200-135 Porto, Portugal

${ }^{4}$ Faculty of Medicine, University of Porto, 4200 - 319 Porto, Portugal

${ }^{5}$ Department of Pathology, Centro Hospitalar de S. João, 4200 - 319 Porto, Portugal
}

$*_{\text {invited talk }}$

\section{Corresponding author: mboaventura@ipatimup.pt}

\section{Introduction}

Exposure to ionizing radiation has been largely associated with cancer development, particularly for childhood exposure and for high doses of radiation, but at very low radiation doses the situation is much less clear. Having had access to a cohort of individuals submitted in childhood to low dose radiation (tinea capitis Portuguese cohort) our aim in the present study was to compare the incidence of cancer in the cohort with the incidence one would expect if the cohort had the same age- and gender-specific rates as the general population.

\section{Methods}

3357 individuals were matched with the RORENO database to determine which members of the cohort had developed cancer and, if so, to determine its site and date of diagnosis. The association between X-ray epilation treatment and all cancer types combined and specific types of cancer individually was evaluated using standardized incidence ratios (SIR).

\section{Results}

Over the full follow-up period (20 years), 310 (13.7\%) individuals were identified with cancer. The risk for an irradiated individual to develop a malignant non-skin tumour in the period 1991-2010 was 1.41 higher $(95 \% \mathrm{Cl}: 1.27-1.59)$ than the general population. We observed a higher cancer risk in males comparing with females $(S I R=1.60,95 \% \mathrm{Cl}: 1.36-1.87$ vs $\mathrm{SIR}=1.27$, $\mathrm{Cl}=1.08-1.49)$. Apart from breast cancer, increased risks were observed for all cancer types evaluated. For thyroid cancer, individuals irradiated at younger age ( $<5$ year-old) presented higher SIRs (SIR=4.53; 95\% CI: $2.17-8.33$ ) than individuals irradiated at older age ( $\geq 5$ year-old) (SIR=2.27; 95\%Cl: 1.47-3.35).

\section{Conclusions}

In the present study we have confirmed an association between tinea capitis X-ray epilation in childhood and later increased risk of overall cancer, with a 1.4 fold increased risk. An increased risk for cancers not located in the irradiated area was observed, not previously described in the tinea capitis irradiated cohorts. 


\title{
Clinical Diagnostic Reference Levels in Pediatric CT
}

\author{
$\underline{\text { João Casimiro }}^{1}$; Joana Coimbra ${ }^{2}$ Carla Conceição $^{1}$ \\ ${ }^{1}$ Centro Hospitalar Lisboa Central - Hospital D. Estefânia \\ ${ }^{2}$ Centro Hospitalar Lisboa Central - Hospital S. António dos Capuchos \\ Corresponding author: casimiro.1983@gmail.com
}

\section{Introduction}

DRL's are one of the tools used in the optimization of protocols in Radiology, with the objective to ensure minimal exposure to individuals, within certain groups, and obtain the diagnostic value intended for each type of exam or treatment.

With the upcoming deadline of February 2018, limit to transposition of the European Basic Safety Standards (Directive 2013/59/EURATOM) regarding the establishment of DRL's for radiologic examinations, one should start to look ahead, and understand where we can act leading to the development of DRL's. First steps were taken by the use of weight groups rather than age groups but the use of adapted protocols of examination for specific clinical situations will bring a benefit to patients in relation to dose savings.

\section{Methods}

Establishing DRL's in Pediatric CT represents a challenge because of the width range of ages, groups and clinical conditions. After the establishment of local DRL's the radiology staff should evaluate which are (the most representative clinical conditions. Then, in agreement with the referring physicians radiology staff must analyze which are the diagnostic questions for a given exam in a specific condition and try to manage existing DRL's in order to obtain a lower exposure to patient but preserving the answers needed for the prescribed exam.

\section{Results}

In our center we currently use several protocols based in clinical DRL's that we have developed in our department with the physicians that usually prescribe those selected group of exams. Some of the most used protocols, customized for clinical propose, include clinical conditions such as hydrocephalus, sinusitis, leg alignment measurements and pectus escavatum. Some of technical parameters adjusted included kVp, mA, slice thickness and scan coverage.

\section{Conclusions}

Clinical DRL's represent the next step towards patient safety and will push radiology to the new trend that is personalized medicine. 


\section{ALARA - a concept to maintain or to abandon? Recent controversies*}

\section{Carla Conceição $^{1}$}

${ }^{1}$ Hospital Dona Estefânia, Centro Hospitalar Lisboa Central

*invited talk

\section{Corresponding author: c.ribeiroconceicao@gmail.com}

\section{Introduction}

The development and generalization of multidetector CT imaging has led to an increase in accuracy and applications, resulting in an exponential growth in the number of examinations carried out in children and a consequent increase of ionizing radiation exposure in pediatric population.

Several strategies of radiation protection have been developed, mainly based on justification and optimization of the exams, namely the ALARA concept. However, ALARA and its usefulness has recently been called into question.

\section{Methods}

A review of the recent literature regarding the debate "Should the ALARA concept and the Image Gently campaign be terminated?" is done.

\section{Results}

The arguments favorable and unfavorable to the application of this concept are presented.

\section{Conclusions}

There is currently an intense debate about the usefulness of the ALARA concept, with different experts arguing divergent opinions. This debate is therefore still open and probably with a long way to go. 


\title{
Non-Accidental Injury (NAI) Paediatric Radiography - an optimisation study
}

\author{
J Hampel $^{1}, \underline{\text { A Pascoal }^{2}}$ \\ ${ }^{1}$ Barking, Havering and Redbridge University Hospitals NHS Trust, UK \\ 'Guy's and St Thomas' NHS Foundation Trust, London, UK
}

Corresponding author: jodie.schultz@nhs.net

\section{Introduction}

This study compares radiography protocols in cli nical use at four London hospitals for NonAccidental Imaging (NAI) skeletal surveys. Further investigation was undertaken to identify the higher radiography views and explore the potential for optimising patient exposure with a digital radiography (DR) system.

\section{Methods}

The clinical protocols at each site were reviewed and compared with existing guidance (RCR, $\mathrm{RCPCH}, 2008)$. Retrospective data collection was carried out to obtain exposure data for a sample of NAI skeletal surveys performed at each site. The abdomen AP view was selected for optimisation.

An anthropomorphic paediatric phantom (CIRS, 2013) was imaged at two sites using a radiography/fluoroscopy (R/F) system (Axiom Luminos dRF, Siemens) and a DR system (Ysio, Siemens).

On the DR system additional abdominal AP views were acquired at a range of $k V$ (40-117), with and without additional copper filtration $(0.1 \mathrm{~mm})$ for matched effective dose (ED).

ED and skin dose was calculated using software (PCXMC V2, STUK). Contrast-to-Noise Ratio (CNR) measurements were performed in anatomical regions of interest in the images.

\section{Results}

The protocols in use varied significant between sites namely in the number of standard views. Of the four participating sites, three different types of imaging technologies were used for NAI imaging (direct digital system, Radiography/Fluoroscopy system, and Computed Radiography (CR)). Organ doses and effective dose varied depending on the technology and protocol in use. The ED obtained were $90 \pm 4 \mu \mathrm{Sv}$, and $57 \pm 3 \mu \mathrm{Sv}$ for the NAl skeletal survey performed using the phantom with the $R / F$ and the $D R$ system, respectively.

The optimisation study for the abdomen AP projection (DR) showed that $0.1 \mathrm{~mm}$ Cu reduced the skin dose by an average of $13 \%$ over the $\mathrm{kV}$ range (40-117 kV) compared with no copper. An improved CNR was observed at 55kV compared with current clinical settings (64 kV) for the same ED.

\section{Conclusion}

This study showed a wide range of technologies and protocols in use for NAl imaging. Additionally, improved CNR of the abdomen AP projection may be obtained for the same ED by reducing the $\mathrm{kV}$ compared with the current technique. 



\title{
Hospital Survey on Patient Safety Culture - The Radiology Department
}

\author{
$\underline{\text { Kevin Barros Azevedo }}^{1,2}$, Carlos Alberto da Silva ${ }^{2,3,4}$, António Fernando Abrantes ${ }^{1,2}$, \\ Luís Pedro Vieira Ribeiro ${ }^{1}$, Anabela Magalhães Ribeiro', Rui Pedro Pereira de \\ Almeida $^{1,2,5}$, Oksana Lesyuk ${ }^{1}$, Mónica Vanessa Canha Reis ${ }^{1}$ \\ ${ }^{1}$ Department of Medical Imaging and Radiotherapy of the Escola Superior de Saúde da \\ Universidade do Algarve (ESSUAlg), Faro, Portugal \\ ${ }^{2}$ CICS.NOVA - Pólo de Évora, Évora, Portugal \\ ${ }^{3}$ CICTS - Centro de Investigação em Ciências e Tecnologias da Saúde, Pólo de Évora, Évora, \\ Portugal \\ ${ }^{4}$ CISAAS - Centro de Investigação em Sociologia e Antropologia Augusto da Silva, Pólo de Évora, \\ Évora, Portugal \\ ${ }^{5}$ Universidad de Murcia, Murcia, Spain
}

Corresponding author: kbazevedo@ualq.pt

\section{Introduction}

The Radiographer is a key element in the Radiology Department. To perform the examinations, from their planning, to their execution and evaluation, there are several factors that may influence patient safety, not only at the department level, but also at the healthcare facility level.

It is clear that the main goal is to diagnose and treat the patient, but at the same time do no unnecessary harm. Incidents or accidents, more commonly seen as errors, are one of the most assessed measurements when the topic is patient safety.

\section{Methods}

Cross-sectional survey developed in three different Radiology Departments, using the HSOPSC survey comprising a total of 80 radiographers. The questionnaire consists of 42 questions measured on a five-points Likert scale grouped into 12 dimensions of patient safety culture. Confirmatory factor analysis (CFA) was used to examine the applicability of the HSOPSC factor structure in imaging department settings, performed psychometric analysis for internal consistency and construct validity.

\section{Results}

CFA yielded satisfactory results with an internal consistency value of 0.89 in the application of the HSPSC in the imaging departments. "Teamwork" scored the highest positive value (87\%) followed by "Perceptions of Safety" (85\%). Gender, age-group, shifts and professional experience have shown significant statistical differences on some dimensions of the HSOPSC $(p<0.05)$.

\section{Conclusions}

To maximize patient safety, the first step is to make it a cultural issue in the department and in the institution. Only if every healthcare worker understands the importance of this subject and feels like a link in the chain of safety, it becomes possible to achieve higher levels of safety.

The professional responsibility in safety starts even before the first contact with the patient and ends after the last contact with the patient. It is always important to check the progress in patient safety, by looking at indicators and to the healthcare worker perceptions. 


\title{
Working with ionization radiation: what do you know about it? Risk perception when working with radiation
}

\author{
Ana Sofia Lourenço Oliveira Pinheiro ${ }^{1}$, Bianca Silva Campos Conceição ${ }^{1}$, Catarina \\ Teixeira ${ }^{1}$, Daniel Filipe Dias Figueiredo ${ }^{1}$, João Baptista Casademont Braadell Schiappa \\ de Azevedo ${ }^{1}{ }_{\text {L }}$ Luís Miguel Barreto Pereira de Sousa ${ }^{1}{ }_{2}$ Maria José Pereira Rodrigues ${ }^{1}$ \\ Mariana Santos Portela Trincão ${ }_{L}^{1}$ Marisa Silva Barreira ${ }_{L}^{1}$ Pêro Miguel Paquete \\ Pedroso $^{1}$, Victoria Corregidor ${ }^{1}$ \\ ${ }^{1}$ Master Degree: Radiation Protection and Safety, Instituto Superior Técnico, Lisboa, Portugal \\ Corresponding author: anaoliveirapinheiro@tecnico.ulisboa.pt
}

\section{Introduction}

Radiation was discovered more than a century ago, with a profound effect on both Industry and Medicine sectors. The benefits of using radiation are vastly and certainly exceed the associated risks. Furthermore, the increased sophistication and clinical efficacy of imaging and treatments have resulted in its dramatic growth over the last years and thereby, the tendency is to develop machines more "dose-efficient", to research new radionuclides etc.

The goal is to reduce the effects of radiation in both, patients and staff. But, in this sense, the best protection is knowledge.

\section{Methods}

The level of knowledge of the professionals exposed to radiation should be as high as possible, in order to improve the protection available as apron, glasses or other personal protective items.

The methodology of this work included the development of a questionnaire with different questions about radiation and its effects, and it was distributed to different Portuguese hospitals, to be answered by the professionals that spend most of the time working with ionizing radiation.

\section{Results}

Primarily results show a good level of knowledge in general. Although more efforts should be done in universities in order to include more subjects about radiation for the non-specialists, who in a primary query refers to practices which involve radiation as conventional radiography, $\mathrm{CT}$, etc.

The preliminary results will be presented and discussed during the conference.

\section{Conclusions}

The number of procedures with the radiation use has been growing, although not accompanied also by increasing knowledge of its adverse effects, as verified in part of the professionals involved. The effects of radiation on the professionals health has been developing some problems that could often be avoided.

It is necessary to support physicians with training and awareness actions for the risks associated with excess radiation exposure. A better knowledge of imaging techniques that are constantly evolving should be promoted.

Regular training should be done not only focusing in the professionals who are working with radiation, but also to responsible for, human resources and administrative boards. 


\title{
Preliminary Results of a Multidisciplinary Approach for Clinical Auditing in Radiology Departments - The Primary Care Experience in the Algarve
}

\author{
$\underline{\text { Paula Simãozinho }}{ }^{1}$, Margarida Faria $^{1}$, Filipe Figueiredo ${ }^{1}$ \\ ${ }^{1}$ Administração Regional de Saúde do Algarve I.P. \\ Corresponding author: psimaozinho@arsalgarve.min-saude.pt
}

\section{Introduction}

The Portuguese legal framework imposes a set of norms that endeavor to protect people's health and wellbeing in those instances when ionizing radiation is used within a medical context. As a consequence, every healthcare provider must adhere to a broad range of mandatory criteria in order to be able to offer medical imaging services. However - when considering the present knowledge, the prevailing circumstances and its ultimate intention this current framework seems to contain a few inconsistencies; moreover, healthcare providers often fail to comply with the strict legal criteria arising from the EURATOM directives. So as to discuss and strengthen the current approach and its legal aspects, our main purpose is to clarify these inconsistencies as well as to single out the most common nonconformities found in healthcare institutions providing radiology services in the Algarve region.

\section{Methods}

Inspections were carried out at several radiology facilities located throughout the Algarve region, in southern Portugal. These assessments have been performed by ARS Algarve's radiological monitoring committee during the last quarter of 2016 and the first quarter of 2017. The inspections revealed a series of non-compliances that have been positively established and subsequently reported to higher authority. At the onset, the data was assembled using simple qualitative methods in order to define a comprehensive list of nonconformities; this data was then quantitatively examined using statistical tools with the intention of drawing actionable conclusions.

\section{Results}

The criterion most often found to be non-compliant to directives was the pervasive lack of knowledge, by radiological facility employees, regarding the Radiological Protection Program (PPR) of the institution where they were working. Within the scope of the inspection, $100 \%$ of the questioned workers did not know what was included in the PPR. Two of the inspected radiological facilities also employed unqualified workers: these employees, which were operating radiological equipment, have been unable to prove their mandatory credentials as qualified technicians. 'Category B' employees operating without individual dose monitoring were found in about $50 \%$ of the inspected facilities.

\section{Conclusions}

The auditing and inspection uncovered a number of serious non-compliances across different radiological facilities throughout the Algarve; it has also exposed a string of inconsistencies between what is compulsory by the current legislation and the operational scenario found in the various locations. This state of affairs seems to arise from the widespread inoperability of the public institutions that seek to provide both the licenses and the inspections for these radiological facilities. 


\title{
Radiation Protection and Safety at Portuguese Institute of Oncology of Coimbra: 15 years of experience
}

\author{
Maria Carmen de Sousa ${ }^{1}$, Maria do Carmo Lopes ${ }^{1}$, Catarina Barros ${ }^{1}$, Carla Alves ${ }^{1}$, Ana \\ Roda $^{1}$
}

${ }^{1}$ Instituto Português de Oncologia de Coimbra Francisco Gentil, EPE, Av. Bissaya Barreto 98, 3000-075 Coimbra, Portugal

Corresponding author: carmen.sousa@ipocoimbra.min-saude.pt

Portuguese Institute of Oncology of Coimbra (IPOC) is a Cancer Center with around 240 beds and different radiation practices in External Radiation Therapy ( 2 linacs and 1 tomotherapy), Brachytherapy ( 1 high dose rate afterloading system and prostate seeds with iodine-125), Nuclear Medicine (2 therapy rooms and diagnostic exams), Radiation Imaging (mammography, $\mathrm{CT}$, radiography \& fluoroscopy and orthopantomography units) and others (blood product irradiator, IRMA/RIA techniques with iodine-125 and examinations performed outside the Imaging Department) but with no interventional procedures nor radiopediatric examinations. The purpose of this work is to present the key elements of the extended radiation protection and safety program (RPSP) that has been implemented during the last 15 years, since the creation of the Medical Physics Department which includes administrative, procedural and engineer controls. We will discuss the benefits reached with the organizational and structural model adopted for the radiation protection and safety responsibilities and duties at IPOC but also the pathways that need to be pointed out to improve the RPSP whose some directions are 1) a more regular radiation and safety training of all relevant staff, 2) auditing the application of the radiation safety procedures and 3 ) the team work for analyzing and improving the radiation procedures in the scope of the optimization of protection process in medical exposures for instance. 



\title{
Low doses of ionizing radiation induce angiogenesis: benefits, concerns and challenges to health and science*
}

\author{
$\underline{\text { Susana Constantino }}{ }^{1}$ \\ ${ }^{1}$ Centro Cardiovascular da Universidade de Lisboa, Faculdade de Medicina, Universidade de \\ Lisboa. Avenida Prof. Egas Moniz, 1649-028 Lisbon, Portugal
}

*invited talk

\section{Corresponding author: sconstantino@medicina.ulisboa.pt}

\section{Introduction}

Radiotherapy is a standard cancer treatment. However, the healthy tissues near the tumor target volume are also exposed to daily sub-therapeutic doses of ionizing radiation (SDIR). We and others demonstrate that SDIR comprise a wide range of doses which induce different biological and health effects. High to moderate SDIR are described as promoting human cardiotoxicity and radiation pneumonitis after breast cancer radiotherapy. Strikingly, we showed that the exposure of healthy tissues to moderate to low SDIR promote metastases development. Now, we are validating these findings in humans. Interestingly, by using a model of experimentally induced hindlimb ischemia, our data supports the use of low doses of ionizing radiation in enhancing ischemia-induced neovascularization in vivo. We currently have an ongoing exploratory clinical trial to determine the clinical and molecular effects in "nonoption" CLI patients.

Although our published results are focused on endothelial cells (ECs), the effect of SDIR in other cells is still unknown.

\section{Methods}

Peritoneal biopsies exposed or not to moderate to low SDIR from patients with rectal cancer that received neoadjuvant radiotherapy were collected followed by ECs isolation by laser capture microscopy and qRT-PCR analysis.

Confluent 3T3-L1 pre-adipocytes were exposed or not to LDIR and induced to differentiate. The conditioned medium was analysed by ELISA and Zymography and used for in vitro (woundhealing) and in vivo (chick chorioallantoic membrane) angiogenic assays.

\section{Results}

Moderate to low SDIR significantly activate ECs of peritumoral tissues and increase microvascular density.

Moreover, the conditioned medium of adipocytes upon SDIR exposure presents higher levels of angiogenic factors and potentiates an angiogenic response both in vitro and in vivo.

\section{Conclusions}

Overall, these results provide new insights into the cellular effects of LDIR and a new rationale basis to improve current radiation oncology protocols. 


\title{
Radiopharmacy - Radiobiological concerns regarding radiopharmaceuticals applications*
}

\author{
$\underline{\text { Lurdes Gano }}{ }^{1}$ \\ ${ }^{1}$ Centro de Ciências e Tecnologias Nucleares, Instituto Superior Técnico, Estrada Nacional 10 \\ (km 139,7), 2695-066 Bobadela LRS \\ *invited talk \\ Corresponding author: Igano@ctn.tecnico.ulisboa.pt

\section{Introduction} \\ Radiopharmaceuticals are radioactive medicinal products used for diagnostic or therapeutic \\ purposes. Even though the medical use of any form of ionising radiation is critically considered \\ in terms of benefit for patients, the presence of radionuclides may induce a potential biological \\ risk attributable to the dose of radiation released in main organs and cells. Thus, within \\ radiopharmacy procedures to prepare individual patient's doses must be optimized regarding \\ radiation safety of patients, public and also technical staff.
}

\section{Methods}

In this overview, relevant internal dosimetric aspects and radiobiological effects related to the most commonly used radiopharmaceuticals applicable to diagnosis and especially to radionuclide therapy will be outlined.

\section{Results}

In this context, important aspects regarding the selection of the radionuclide, the biodistribution, pharmacokinetics, metabolism and excretion pathways of the radiopharmaceuticals will be discussed. Radiobiology in normal tissues versus in tumors will be considered. Furthermore, considerations on pediatric applications will also be summarized taking into account the fact that rapidly growing tissues are generally more sensitive to ionizing radiation. Accordingly, optimization of radiation safety procedures within radiopharmacy will be reviewed.

\section{Conclusions}

Knowledge of the radiobiology of normal and injured tissues, the pharmacokinetics and dosimetry of each radiopharmaceutical are core prerequisites for a safe radiopharmacy practice both for the patients and the related professionals. 


\title{
Low doses of ionizing radiation induce angiogenesis: therapeutic implications
}

\section{Filipa G. Marques ${ }^{1}$, Joana Ferreira ${ }^{1}$, Carolina Cardina ${ }^{1}$, Esmeralda Poli ${ }^{2}$, João Malaquias ${ }^{2}$, Filomena Pina ${ }^{2}$, José C. Mendes de Almeida ${ }^{3}$, Marc Mareel ${ }^{4}$ and Susana Constantino Rosa Santos ${ }^{1}$}

\author{
${ }^{1}$ Centro Cardiovascular da Universidade de Lisboa, Faculdade de Medicina, Universidade de \\ Lisboa \\ ${ }^{2}$ Hospital de Santa Maria, Centro Hospitalar Lisboa Norte \\ ${ }^{3}$ Hospital de Santa Maria, Centro Hospitalar Lisboa Norte. Faculdade de Medicina, \\ Universidade de Lisboa \\ ${ }^{4}$ University Hospital Ghent, Belgium \\ Corresponding author:fmarques@medicina.ulisboa.pt
}

\section{Introduction}

During radiotherapy, healthy tissues located in the peritumoral area are exposed to low doses of ionizing radiation (LDIR). The term LDIR includes a wide range of values and our attention will be focused in the range of doses that induce neovascularization. Understanding the effect of LDIR on promoting vascularization is a crucial step since radiotherapy is a treatment of election in cancer and a proangiogenic effect, even in the peritumoral tissue, would be counterproductive.

Recently, we demonstrated that LDIR enhance in vitro and in vivo angiogenesis and consequently promote tumor growth and metastasis development. Now, we are interested in validating these findings in humans, our first goal. Although our published results are focused on endothelial cells (ECs), the effect of LDIR in other cells is still unknown, our second goal.

\section{Methods}

Peritoneal biopsies exposed or not to LDIR from patients with rectal cancer that received neoadjuvant radiotherapy were collected followed by ECs isolation by laser capture microscopy and qRT-PCR analysis. Furthermore, confluent 3T3-L1 pre-adipocytes were exposed or not to LDIR and induced to differentiate. The number of mature adipocytes was determined by Oil Red staining and extracellular levels of angiogenic factors analyzed by ELISA and Zymography. In addition, the conditioned medium was used for in vitro (wound-healing) and in vivo (chick chorioallantoic membrane) angiogenic assays.

\section{Results}

Our data show that LDIR significantly activate ECs of peritumoral tissues and increase microvascular density. Moreover, LDIR significantly decrease the number of mature adipocytes. Interestingly, significantly higher levels of VEGF are produced by this lower number of adipocytes upon LDIR exposure. Consistently, their conditioned medium potentiates an angiogenic response both in vitro and in vivo conditions.

\section{Conclusions}

Overall, these results provide new insights into the cellular effects of LDIR and a new rationale basis to improve current radiation oncology protocols. 


\title{
Genetic damage induced in exfoliated buccal cells after orthopantomography
}

\author{
Octávia Monteiro Gil ${ }^{1}$, Daniel Esteves ${ }^{1}$, Ana Catarina Antunes ${ }^{1}$, Paula Madeira ${ }^{2}$, \\ Francisco Proença ${ }^{2}$, Pedro Vaz ${ }^{1}$
}

\author{
${ }^{1}$ Centro de Ciências e Tecnologias Nucleares, Instituto Superior Técnico, Universidade de \\ Lisboa, Estrada Nacional 10 ao km 139,7, 2695-066 Bobadela LRS, Portugal \\ ${ }^{2}$ Centro Hospitalar Lisboa Central, EPE, Hospital São José, Rua José António Serrano, 1150-199 \\ Lisboa
}

Corresponding author: ogil@ctn.tecnico.ulisboa.pt

\section{Introduction}

Orthopantomography is the most widespread radiographic imaging technique of the dental, maxillary and mandibular arches, being a radiologic examination that allows to accurately plan orthodontic treatments. Orthopantomography uses low doses of ionizing radiation (IR) in comparison to other diagnostic radiology methods. Therefore, because of the commonalty of this method, it seemed rational to estimate the damage induced by these doses. The evaluation of micronuclei formation in the oral mucosa exfoliated cells is a non-invasive procedure that can give an idea of the damage induced by the exposure to the low dose from the exam. Micronuclei are biomarkers of genotoxic events and chromosomal instability.

In buccal mucosa cells, the damage that leads to the formation of micronuclei takes place in the basal layer of the epithelial tissue where cells undergo mitosis. The turnover of epithelial tissues brings the cells to the surface where they are exfoliated, being the maximal rate of micronuclei formation observed 1 to 3 weeks after the exposure to the genotoxic agent.

The present study was undertaken to investigate the frequency of micronuclei in mononucleated cells in the oral mucosa from individuals submitted to orthopantomography.

\section{Methods}

The micronucleus test in the buccal exfoliated mononucleated cells was performed in 20 individuals that undergo ortopantomography examination. Samples were collected before and 10 days after the exam to study the possible damage induced by the exposure to IR. The Student's t-test was used to compare the frequency of micronuclei before and 10 days after $\mathrm{x}$ ray exposure.

\section{Results}

After orthopantomography the mean frequency of micronuclei in mononucleated cells was higher when compared with the samples collected before the exam being the difference statistically significant.

\section{Conclusions}

From the results of our study we can infer that orthopantomography induces genetic damage. 


\title{
Low-dose ionizing radiation induces therapeutic neovascularization in a pre-clinical model of hindlimb ischemia
}

\author{
Paula de Oliveira ${ }^{1+}$, Augusto Ministro ${ }^{2 \dagger}$, Raquel J. Nunes ${ }^{1}$, André Rocha ${ }^{1}$, Adriana \\ Correia $^{1}$, Tânia Carvalho ${ }^{3}$, José Rino ${ }^{3}$, Pedro Faísca ${ }^{4}$, Jorg D. Becker ${ }^{5}$, J. Goyri-O'Neill ${ }^{6}$, \\ Filomena Pina ${ }^{7}$, Esmeralda Poli ${ }^{7}$, Bruno Silva-Santos ${ }^{3}$, Fausto Pinto ${ }^{2}$, Marc Mareel ${ }^{8}$, \\ Karine Serre ${ }^{3}$ and Susana Constantino Rosa Santos ${ }^{1}$
}

\author{
${ }^{1}$ Centro Cardiovascular da Universidade de Lisboa, Faculdade de Medicina, Universidade de \\ Lisboa. Avenida Prof. Egas Moniz, 1649-028 Lisboa, Portugal \\ ${ }^{2}$ Hospital de Santa Maria, Centro Hospitalar Lisboa Norte. Avenida Prof. Egas Moniz, 1649-035 \\ Lisboa, Portugal; Centro Cardiovascular da Universidade de Lisboa, Faculdade de Medicina, \\ Universidade de Lisboa. Avenida Prof. Egas Moniz, 1649-028 Lisboa, Portugal \\ ${ }^{3}$ Instituto de Medicina Molecular, Faculdade de Medicina, Universidade de Lisboa. Avenida \\ Prof. Egas Moniz, 1649-028 Lisboa, Portugal \\ ${ }^{4}$ Faculdade de Medicina Veterinária, Universidade Lusófona de Humanidades e Tecnologias. \\ Campo Grande 376, 1749-024 Lisboa, Portugal \\ ${ }^{5}$ Instituto Gulbenkian de Ciência. Rua Quinta Grande 6, 2780-156 Oeiras, Portugal \\ ${ }^{6}$ Nova Medical School/Faculdade de Ciências Médicas, Universidade Nova de Lisboa. Campo \\ Mártires da Pátria 130, 1169-056 Lisboa, Portugal \\ ${ }^{7}$ Hospital de Santa Maria, Centro Hospitalar Lisboa Norte. Avenida Prof. Egas Moniz, 1649-035 \\ Lisboa, Portugal \\ ${ }^{8}$ University Hospital Ghent, De Pintelaan, 185, B-9000 Ghent, Belgium \\ + Equal first authorship
}

\section{Corresponding author: paulaoliveira@medicina.ulisboa.pt}

\section{Introduction}

We have shown that low doses of ionizing radiation (LDIR) induce angiogenesis; there is no evidence that they induce neovascularization in the setting of peripheral arterial disease. Here, we investigated the use of LDIR as an innovative and non-invasive strategy to stimulate therapeutic neovascularization using a model of experimentally induced hindlimb ischemia (HLI).

Methods

After surgical induction of $\mathrm{HLI}$, both hindlimbs of $\mathrm{C} 57 \mathrm{BL} / 6$ mice were sham-irradiated or irradiated with0.3 Gy, in 4 consecutive days and allowed to recovered. Blood flow, capillary and collateral densities were assessed by laser Doppler perfusion imaging, immunohistochemistry and diaphonization, respectively. Capillaries were microdissected followed by RNA extraction, cDNA synthesis and qRT-PCR analysis. The immune cell infiltrate and endothelial progenitor cells (EPCS) were assessed by FACS. Plasma cytokines were assessed by ELISA. After 52 wk post-HLI, body weights, urine, blood and different organs were collected and analyzed.

Results

We demonstrate that LDIR, significantly improved blood perfusion in the ischemic limb by stimulating capillary and collateral densities. LDIR significantly increased the circulating levels of VEGF, PIGF and G-CSF, and the number of circulating EPCS mediating their incorporation to ischemic muscles. These effects were dependent upon LDIR exposition on the ischemic niche but independent of the recruitment of monocytes and macrophages. LDIR induced a durable and simultaneous up-regulation of a repertoire of pro-angiogenic factors and their receptors in endothelial cells via vascular endothelial growth factor receptor signaling. The vasculature in 
an irradiated non-ischemic bed was not affected and after 52-wk of LDIR exposure no differences in the incidence of morbidity and mortality were seen.

Conclusion

These findings disclose an innovative, non-invasive strategy to induce therapeutic neovascularization emerging as a novel approach in the treatment of critical limb ischemia patients. 


\title{
Genotoxicity Biomarkers: applications and challenges in Radiobiology*
}

\author{
$\underline{\text { Nuno G. Oliveira }}{ }^{1}$ \\ ${ }^{1}$ Research Institute for Medicines (iMed.ULisboa), Faculty of Pharmacy, Universidade de \\ Lisboa, Av. Professor Gama Pinto, 1649-003 Lisbon, Portugal \\ *invited talk \\ Corresponding author: ngoliveira@ff.ulisboa.pt

\section{Introduction} \\ Biomarkers are extensively used in several clinical contexts and in the Toxicology field to assess \\ exposure, effects or susceptibility to chemical and physical agents. Biomarkers have been \\ particularly relevant to address different issues in Radiobiology including to assess the risk in \\ populations exposed occupationally, environmentally or accidentally to ionizing radiation (IR).
}

\section{Methods}

Among the different types of biomarkers, genotoxicity biomarkers clearly play a crucial role in radiation research. These biomarkers, particularly the cytogenetic biomarkers, can be used either to estimate exposure or to assess the effects induced by different types of IR (e.g. low and high LET radiation).

\section{Results}

Dicentric chromosomes have been widely used for a long time in biological dosimetry in view of their specificity to IR. The lower limit for dose detection by dicentrics is 0.1-0.2 Gy (IAEA). Micronuclei induction has also been used in several biological dosimetry studies. In addition, there are also genotoxicity biomarkers determinant to evaluate retrospective exposures (e.g. stable translocations) while other biomarkers can be considered emergent, particularly the ?H2AX. Regarding the latter it has a lower detection sensitivity limit (>0.01 Gy) and its usefulness is the radiation field is increasing.

\section{Conclusions}

Biomarkers have a determinant role in modern Radiobiology. The association of susceptibility biomarkers with classical/emergent genotoxicity biomarkers represent an important challenge that may give some additional insights on the variability of responses found in IR-exposed populations. 


\title{
Temporal variability of gamma radiation at the Eastern North Atlantic (ENA) site (Azores)
}

\section{Susana M. Barbosa ${ }^{1}$, Eduardo Brito Azevedo ${ }^{1}$, Pedro Miranda ${ }^{1}$, Diana Guimarães ${ }^{1}$, Catarina Monteiro ${ }^{1}$}

\author{
${ }^{1}$ INESC TEC - INESC Technology and Science \\ Corresponding author: susana.a.barbosa@inesctec.pt
}

\section{Introduction}

The concentration of radon in the natural environment exhibits significant temporal variability on multiple time scales, from very short sub-daily fluctuations to seasonal oscillations and long-term trends. The temporal variability of gamma radiation at the Eastern North Atlantic (ENA) site in the Graciosa Island (Azores) is examined as a proxy of the variation of Rn-222 progeny in the atmosphere and as a tracer of dynamic surface-atmosphere interactions.

\section{Methods}

The campaign at the ENA site (https://www.arm.gov/research/campaigns/ena2015grm) was initiated in May 2015 and is expected to run until March 2018. Continuous monitoring of gamma radiation is performed with an $\mathrm{Nal}(\mathrm{TI})$ scintillation sensor of 3" $\times 3$ " (Scionix, Holland) equipped with an electronic total count Single Channel Analyzer (SCA) measuring gamma radiation from $475 \mathrm{KeV}$ to $3 \mathrm{MeV}$, at the height of about $1 \mathrm{~m}$ from the ground. The total count of gamma rays registered by the scintillator is recorded every 15 minutes.

\section{Results}

The time series of 15-minute gamma ray counts is characterized by sharp anomalies over a slowly-varying signal. All the data are freely available at https://rdm.inesctec.pt/dataset/cs2017-001. Sharp peaks are coincident with heavy precipitation and are, as expected, associated with the scavenging effect of precipitation bringing radon progeny from the upper levels of the atmosphere to the ground surface. Diurnal anomalies occur in occasional conditions of weak winds and thermal stability of the atmosphere enabling the build-up of radon near the surface during the night and before sunrise.

\section{Conclusions}

The temporal variability of radon gas concentration is heavily dependent on meteorological conditions, influencing both its exhalation from the porous medium and its transport by diffusion and advection. Meteorological effects need therefore to be considered in the assessment of radon exposure and corresponding health effects. 


\title{
The exposure to radon gas - causes and effects in human health
}

\author{
$\underline{\text { Maria de Lurdes Dinis }}^{1,2}$, Ana Sofia Silva ${ }^{1,2}$ \\ ${ }^{1}$ CERENA, FEUP/UP - Centre for Natural Resources and the Environment, Faculty of \\ Engineering, University of Porto \\ ${ }^{2}$ PROA/LABIOMEP - Research Laboratory on Prevention of Occupational and Environmental \\ Risk; Faculty of Engineering, University of Porto
}

$*_{\text {invited talk }}$

Corresponding author: $\underline{\text { mldinis@fe.up.pt }}$

\section{Introduction}

Most of the average annual dose to which the population is exposed to natural sources of ionizing radiation comes from radon inhalation and its radioactive progeny $(57 \%)$ and terrestrial gamma radiation (18\%). Radon can be found in varying amounts in all rocks, soil, air, and in different kinds of water like lakes, springs, wells and groundwater. Radon is currently recognized as the second cause of lung cancer in the general population, the first being smoking. The purpose of this work was to perform a review on the exposure to radon considering the factors that may lead to an increasing exposure and the consequents evidences on health effects.

\section{Methods}

A systematic review was conducted in multiple databases with Metalib tool. The methodology adopted in this work focused on a few issues: i) identify the possible sources of radon exposure; ii) identify the parameters affecting radon concentration iii) reflections on occupational exposure to radon - case study: thermal spring and hydrotherapy treatments and iv) conclusions based on the evidence of health effects of exposure to radon.

\section{Results}

Radon is well known as a radiation hazard being the main cause of lung cancer in underground miners; epidemiological studies revealed a strong correlation between lung cancer and exposure to radon. The evidence that radon exposure can result in similar effects in others environments rather than mining activities, started to be the focus of attention in the seventies. In particular, in thermal spring and hydrotherapy treatments rooms, high indoor radon concentrations were registered revealing concerning exposure levels. The short lived decay products of radon are responsible for most of the hazard by inhalation. The intake of radon through the water ingestion can give rise to an additional exposure dose to the stomach.

\section{Conclusions}

Prolonged exposure to radon can cause a negative effect on health (lung cancer and bronchial tissue damages). The results of some studies showed that radon concentrations in indoor air of hydrotherapy treatments establishments can lead to an intense exposure and consequently result in a short-term impact for users but in a long-term for workers who have longer and continuous exposure periods. In this way, this additional exposure may become extremely significant to this workers group and radon occupational exposure should, at least, be monitored. 


\title{
Radon Concentration Assessment in Water Sources of Public Drinking of Covilhã's County, Portugal
}

\author{
M.Inácio $^{1,2}$, S. Soares ${ }^{1,2,3}$, P. Almeida ${ }^{4}$ \\ ${ }^{1}$ Faculdade de Ciências da Universidade da Beira Interior, Covilhã, Portugal \\ ${ }^{2}$ Centro de Matemática e Aplicações da Universidade da Beira Interior, Covilhã, Portugal \\ ${ }^{3}$ Laboratório de Instrumentação e Física Experimental de Partículas, Lisboa, Portugal \\ ${ }^{4}$ Faculdade de Engenharia da Universidade da Beira Interior, Covilhã, Portugal
}

\section{Corresponding author: minacio@ubi.pt}

\section{Introduction}

Radon formed by radioactive desintegration of 226Ra. It's an odorless, tasteless and colorless radioactive gas, with on half-life of 3.8 days, that occurs naturally in the environment resulting that results from the natural radioactive decay of uranium, found in quantities in most rocks, soils and water. Exposure to radon occurs primarily through inhalation, resulting in radiation to the lung and to a lesser degree other organs through radon gas dissolved in blood.

\section{Methods}

Radon concentration measurements were performed on thirty three samples collected from water wells at different depths and types of aquifers, at Covilhã county, Portugal. In order to determine the radon concentration on water sample we used a Rad7 radon monitors equipment from the American manufactures Durridge. The RAD H2O accessory was developed specially to perform radon concentration measurements on water and is able to present results after a 30 minutes analysis.

\section{Results}

Our results for twenty three of the thirty three water samples show that the annual effective dose due to ingestion, are clearly over the reference limit value of $100 \mathrm{~Bq} / \mathrm{L}$. So, on this study, we obtain an average value of $2.575 \mathrm{mSv} / \mathrm{year}$, for adults, and $5.151 \mathrm{mSv} / \mathrm{year}$, for children, clearly above the aforementioned reference values.

The observed values of radon concentration in water from the collected samples is dependent not only of the geological setting on the geographic location of this study. The correlation between geology and radon concentration is clear when overlapping the geological information map where metamorphic terrains on the south tend to show smaller concentration on radon in water.

\section{Conclusions}

Uranium, parent material of radon daughter isotope, is widely distributed in rocks and soils of the Covilhã's county. From a health viewpoint, $222 \mathrm{Rn}$ is the most important radon isotope because its decay products, $218 \mathrm{Po}$ and $214 \mathrm{Po}$, can have a marked adverse effect in human tissues. We decided to measure radon in underground water because about $50 \%$ of population natural exposure is from this radioactive gas and, the highest percentage of radon enters the human body by breathing, during bath, and from drinking water. Based on the portable device rad7, radon was measured in water and the results shows that its concentration average value, in thirty three samples of water collected, are higher than the Council Directive 2013/51/EURATOM advised level of $100 \mathrm{~Bq} / \mathrm{L}$. Taking into account public health it is recommended that the measured water sources are considered not safe for drinking purposes, accordingly to those international limits, and will be advantageous boiling it if used for that purpose. 


\title{
Geogenic radon in Portugal: summary and contribution for the conception of risk maps
}

\author{
Pereira, A.J.S.C ${ }^{1}$, Neves, L.J.P.F. ${ }^{1}$ \\ ${ }^{1}$ Laboratório de Radioatividade Natural, Departamento de Ciências da Terra, Universidade de \\ Coimbra
}

*invited talk

\section{Corresponding author: apereira@dct.uc.pt}

Radon gas is known for its role as a natural environmental risk factor, particularly when it occurs in high concentrations in confined spaces, significantly increasing lung cancer risk. Consequently, several laws have been established with the purpose of minimizing radon gasassociated risk, such as the Council Directive 2013/59/Euratom of 5 December 2013. This law highlights that each Member State is responsible for preparing national action plans for radon. These plans should be based, among other things, on a set of parameters controlling the production and migration of radon gas in rocks and soils. Risk maps subsequentely developed at different scales should be based on these parameters.

The substrate in continental Portugal facilitates the occurrence of geological situations which can produce and transfer substantial quantities of radon gas. This has been known since the 1980 s, when the first studies were conducted. These studies focused particularly on indoor air of dwellings.

The Laboratory of Natural Radioactivity of the University of Coimbra has been collecting substantial data, through projects at a national level, in order to identify geological factors that control the distribution of radon in the several lithologies that make up the substrate of the Portuguese territory. So far, more than 600 samples representative of the different geological units have been gathered and prepared with the purpose of analyzing $U$, Th and $K$ concentrations, as well as gas exhalation potential, density and porosity. Simultaneously, over 2000 measurements of radon soil-gas concentrations were obtained. The purpose of this presentation is to give a summary of the current knowledge of this issue in the Portuguese territory, as well as to show how the experience gained contributes to define new methods of risk mapping in Europe, particularly regarding geogenic radon. 



\title{
The need for technological updating in Radiology - A case study in CT
}

\author{
Afonso, $\mathrm{J}^{1}$, Borlinhas, $\mathrm{F}^{1,2,3}$, Venâncio, $\mathrm{J}^{1}$ \\ ${ }^{1}$ Instituto Português de Oncologia de Lisboa Francisco Gentil, EPE. R. Prof. Lima Basto, 1099- \\ 023 Lisboa, Portugal \\ ${ }^{2}$ Escola Superior de Tecnologia da Saúde de Lisboa (ESTeSL), Instituto Politécnico de Lisboa \\ (IPL). Av. D. João II, Lote 4.69.01. 1990 - 096 Lisboa, Portugal \\ ${ }^{3}$ Instituto Engenharia Biomédica e Biofísica (IBEB), Faculdade de Ciências da Universidade de \\ Lisboa (FCUL). Campo Grande - 1749-016 Lisboa, Portugal \\ Corresponding author:jafonso@ipolisboa.min-saude.pt
}

\section{Introduction}

The exposure of population to ionizing radiation following radiologic exams has become a topic of special concern due to its growing importance. Computed Tomography (CT) tecnhology is well-known to be the main accountable for the significant increase verified.

In this context and derived from the concerns of health personnel, as well as media highlight on this topic, manufacturers have been developing solutions that improve their scanners performance on radiation dose, being, therefore, a strong sales argument.

\section{Methods}

Radiation dose measurements were obtained in similar technical conditions of real CT exams at the Radiology Department of IPOLFG, EPE, with a $32 \mathrm{~cm}$ circular Polymethylmethacrylate phantom, simulating an adult's chest, abdomen and pelvis. Comparisons were made between the performance of a CT scanner, developed and manufactured in 2002, equipped with the best technology available at the time, and similar measurements, gathered in the same circumstances were obtained with another CT scanner of the same manufacturer, but developed and manufactured in 2014

Both devices have16 rows of detectors, but differ in hardware and software, as well as other characteristics related to their construction.

The data collected using a Unfords dosimeter, model $\mathrm{Xi}$ with processing according to international guidelines, allows the dose comparison between these two devices that can be due, for example, to the dose optimization technology inherent to each equipment.

Results

The dose/dose indicators comparison in devices supplied with the best available at the moment of their manufacture in 2002 and 2014 highlights the importance of the progress achieved in 12 years of technical evolution.

\section{Conclusions}

Dosage control in radiation received by the population as a result of CT exams, whose growth has been verified in the last few years, results not only from the increasing number of requests for exams due to trivialization and reduced cost of these devices, but also the celerity and commodity in performing them.

An increase in awareness of the negative impact of this matter, not only individually but also publicly, has been countered by the manufacturers with a strong investment in technological development to keep their devices at the same level has the competition's, which results in a shorter lifespan for the CT devices. Nowadays, a top-level device gets exceeded and obsolete in a decade.

Therefore, has to be proven by this study, a frequent evaluation and analysis of the technology available, in addition to its impact in control and decrease of the dosage to which the patients are submitted during exams, is crucial. 
Poster Presentations - Education, training, qualification and certification in radiological protection 


\title{
Occupational Exposure to lonizing Radiations: Knowledge, Attitudes and Practices of Health Students
}

\author{
B. Sousa ${ }^{1}$, J. Canhoto ${ }^{1}$, M. Raminhas Carapinha ${ }^{4,5}$, A. Grilo $^{2,4,5}$, C. Silva ${ }^{3,6}$, A. Ferreira ${ }^{4,5}$, \\ M. Caetano ${ }^{4,5}$, V. Fonseca ${ }^{4,5}$
}

${ }^{1}$ Degree in Nuclear Medicine, Lisbon School of Health Technology - Polytechnic Institute of Lisbon, Portugal

${ }^{2}$ Department of Human and Social Sciences, Lisbon School of Health Technology - Polytechnic Institute of Lisbon, Portugal

${ }^{3}$ Department of Natural and Exact Sciences, Lisbon School of Health Technology - Polytechnic Institute of Lisbon, Portugal

${ }^{4}$ Department of Sciences and Technologies of Radiations and Health Biossins, Lisbon School of Health Technology - Polytechnic Institute of Lisbon, Portugal

${ }^{5}$ Research Group on Radiation and Health - GIReS - Lisbon School of Health Technology Polytechnic Institute of Lisbon, Portugal

${ }^{6}$ Center of Statistics and Applications of University of Lisbon

Corresponding author: maria.carapinha@estesl.ipl.pt

\section{Introduction}

Despite the regulation compelling the use of individual dosimeter, there are suspicious about dosimetric registry, particularly in occupational exposure of health students to ionizing radiations. These uncertainties influence behaviours. The aims are: Evaluate the level of confidence of the health students, exposed to ionizing radiations, in the dosimetric registry; Evaluate behaviours of these students; Outline an intervention plan to implement attitude changes to optimize behaviours in Radiation Protection and Safety (RPS).

\section{Methods}

An observational study (questionnaire) applied to $1284^{\text {th }}$ year students of Medical Imaging and Radiotherapy (MIRT), Nuclear Medicine (NM), Radiotherapy (RT) and Clinical Physiology (CP) of the Lisbon School of Health Technology of the Polytechnic Institute of Lisbon. The data were collected between December 2016 and January 2017. All ethical principles have been considered.

\section{Results}

Of the 91 respondents, 24(26.4\%) were enrolled in CP, 40(44\%) in MIRT, 23(25.3\%) in NM and $4(4.4 \%)$ in RT. The mean age was $21.6 \pm 1.2$ years. The response rate was $71.0 \%$. The confidence in the reading technique was $100 \%$ for all areas except CP (92\%), with the lowest confidence for direct reading dosimeters. Dosimeter use is higher in MIRT (57.8\%) and lower in CP (33.3\%). CP is the area that least knows how to use the dosimeter (26.1\%) and that more considers education in RPS as inadequate (92.9\%).

\section{Conclusions}

The confidence in the dosimetric registry is independent of the type of reading and superior in the whole body dosimeters. A frequency of use of dosimeters varies between the areas and with the knowledge about the legislation. RPS training for several degrees is different, so the conscience of the risks of exposure isn't the same. The location where the dosimeter is stored may be affected by the knowledge about its working mode. We suggest the adequacy of study plans to alert students to the risks and the implementation of monitoring norms 


\title{
Radiation survey around the $50 \mathrm{KVp}$ X-ray source of the Xoft Axxent Electronic Brachytherapy System
}

\author{
J. Vale $^{1}$; G. Campos ${ }^{1}$; F. Ponte ${ }^{1}$ \\ ${ }^{1}$ Julio Teixeira, S.A. Radioncologia \\ Corresponding author: joana.vale@gmail.com \\ Introduction \\ Xoft Axxent Intraoperative Electronic Brachytherapy System operates in a regular operating \\ room. \\ The objective of this work was to create the dose rate map around the $50 \mathrm{KVp} \mathrm{X}$-ray source in \\ order to visualize the safest locations in the room for radiation workers and other staff who \\ needs to stay in the room during irradiation treatment delivery and evaluate the efficiency of \\ the existing individual radiation shields like lead aprons.
}

\section{Methods and materials}

We simulated an intracavitary treatment using a Solid water phantom composed by a slab $2 \mathrm{~cm}$ thick with a hole for source positioning on top of 10 slabs $1 \mathrm{~cm}$ thick.

Axxent FlexiShield $0.45 \mathrm{~mm} \mathrm{~Pb}$ equivalent covered the phantom as in the real treatment.

We measured the dose rate at 34 points around the source with Atomtex Radiation Monitor AT117, in two situations: 1-without any additional protection, 2- behind a lead apron of $0.50 \mathrm{~mm} \mathrm{~Pb}$ equivalent.

Assuming 5 treatments a week of 15 minutes each and the public dose limit of $1 \mathrm{mSV}$ per year, for each situation we obtained a virtual dose rate map with MATLAB software.

\section{Results}

Behind the Axxent controller we measured the lowest radiation levels in both situations, and always stay below the public dose limit.

For the first situation, a safety zone of $145 \mathrm{~cm}$ around the source must be respected.

In the same above conditions, behind the lead apron, dose rates are reduced around 124 times and the safety zone decreases to $13 \mathrm{~cm}$.

\section{Conclusions}

Operator should always stay behind the controller during irradiation.

It is safe for non-controlled staff to stay in the room, if wearing individual lead aprons.

Individual exposures may still be reduced increasing the distance from source.

All staff involved should keep in mind ALARA principle at all times during treatment. 
Poster Presentations - Imaging in pregnancy and foetal exposure 


\title{
Risks of Fetal Exposure to lonizing Radiation
}

\author{
Cristina Patrício $^{1}$, Rita Chagas ${ }^{1}$, Sara Gonçalves ${ }^{1}$ \\ ${ }^{1}$ Escola Superior de Tecnologia da Saúde de Lisboa \\ Corresponding author: ritachagas96@hotmail.com
}

\section{Introduction}

Imaging diagnostic exams are often used during pregnancy. The most commonly used methods are those that do not pose a risk to the fetus, such as Ultrasound and Magnetic Resonance. Exams that involve the use of ionizing radiation are usually postponed or dismissed due to potential health risks to the fetus. However, a delayed diagnosis due to non-use of these exams may be more harmful to maternal and fetal health than the possible risks associated with the use of radiation.

\section{Methods}

In this work we propose to review the conclusions of the following articles:

1. Garcia TJ, Lara PHS, Kinjo CS, Bezerra EA, Higasiaraguti M, Oliveira NM, Sousa NC, Yonamine RY, Sales SMA, Morimoto TP, Zamboni JW, Sancovski M. Aspectos atuais em imagenologia na gestação. Arquivos Brasileiros de Ciências da Saúde. 2012 Dec; 47(3):143-148;

2. D'Ippolito G, Medeiros RB. Exames Radiológicos na Gestação. Radiologia Brasileira. 2005 Nov/Dec; 38(6):447-450 ;

3. Baptista E, Domingues AP, Duarte $H$, Vasco E, Moura P. Segurança dos exames imagiológicos na gravidez. Acta Obstétrica e Ginecológica Portuguesa. 2014; 8(2):176-185;

4. Videira Al, Nogueira A. Exposição às Radiações lonizantes na Gravidez: Efeitos Biológicos no Embrião e no Feto. Arquivos da Maternidade Dr. Alfredo da Costa. 2002 Dec;8(2):66-71.

We have analyzed them and compiled in a single document the conclusions reached by these authors. It's important to emphasize that none of the conclusions presented are of our authorship, we only refer the ideas of other authors.

Keywords: "fetal exposure"; "dose limits"; "pregnancy"; "nuclear medicine"; "radiological examinations"

\section{Results}

Exposure to fetal doses below $100 \mathrm{mGy}$ is not associated with increased deterministic effects, so this dose is not considered indicative of pregnancy discontinuation. However, this hypothesis should be considered when the radiation dose is greater than $250 \mathrm{mGy}$ (there is no exam that exposes the fetus to this level of radiation, but may occur in a combination of tests).

\section{Conclusions}

It's of utmost importance, before prescribing a radiological examination to a pregnant woman, to be sure that it's indispensable, that it cannot be postponed or if there is no other safer exam for the fetus that gives us the same information necessary for a correct diagnosis. If it cannot be avoided, before we submit a pregnant woman to ionizing radiation we must estimate the absorbed dose by the fetus, based on the protocol of the exam to be performed.

Therefore, the fear that diagnostic exams that use ionizing radiation may be harmful to the fetus is, in most cases, unjustified, because the fetal dose received after most procedures is well below the threshold dose for the occurrence of deterministic effects. 


\title{
Occupational radiation exposure in chemoembolizations: Evaluation of doses in different body regions of professionals with different roles in the procedure
}

\author{
Ana Monteiro ${ }^{1}$, Cláudia Machado ${ }^{1}$, Filomena Oliveira ${ }^{1}$, Ildefonso Pinto ${ }^{2}$, João \\ Schiappa ${ }^{2}$, Rui Barros ${ }^{3}$ \\ ${ }^{1}$ Centro Hospitalar do Porto \\ ${ }^{2}$ MedicalConsult, Unip. Lda \\ ${ }^{3}$ IQI - Instituto para a Qualidade em Imagem, S.A. \\ Corresponding author: anara.monteiro@gmail.com

\section{Introduction} \\ Every day worldwide ionizing radiation is used in patients in more than 10 million diagnostic \\ and therapeutic radiology procedures. The increasing use of ionizing radiation can be seen as \\ simply the growing volume of work done or as the change of the procedures performed. The \\ main objective of the radiation monitoring is to ensure that the doses received by \\ professionals do not exceed the values established by Decree No. 222/2008. The aim of this \\ study is to investigate radiation exposure profiles in medical staff during an interventional \\ radiologic procedure - chemoembolization.
}

\section{Methods}

This work intends to evaluate the radiation dose received by the professionals involved in the performance of chemoembolization procedures. This procedure was selected considering the potential high dose to medical staff. The study aims to overlook at least twelve interventional radiology procedures and six staff members proposed to participate in the study - two radiologists, one radiographer, one anesthetist, one circulating nurse and one anesthesia nurse. Several dosimeters expected to quantify the dose received in different organs will be placed in the professionals.

\section{Results}

With the results, we intend to get information on the amount of radiation exposure, per region of the body, received by the professionals involved in the procedure. The resulting data will help determine the maximum number of procedures per year allowed for both the primary interventionist and the assistant.

\section{Conclusions}

The dose management of health professionals can be used to access the various types of individual radiological protection in diagnostic and therapeutic procedures, considering different locations of the professionals in the room. The optimization of the individual protection as well as the optimization of the parameters of image acquisition can contribute to reduce the radiation dose to the professionals and to the patients. 
Poster Presentations - Methodologies and systems of dose assessment (patient and personnel) 


\title{
Adapting a Co-60 treatment room to a flattening filter-free dual energy medical linear accelerator: vault design and shielding calculations
}

\author{
$\underline{\text { Rita Figueira }}{ }^{1}$, Catarina Souto ${ }^{1}$, Mónica Sousa ${ }^{1}$, Teresa Reis ${ }^{1}$, Ana Luísa Carvalho ${ }^{1}$ \\ ${ }^{1}$ Serviço de Radioterapia, Centro Hospitalar de São João (CHSJ), Porto, Portugal \\ Corresponding author: fisica.medica@hsjoao.min-saude.pt
}

Introduction:

The installation of a new radiotherapy treatment equipment in a room originally designed to accommodate a Co-60 therapy unit resulted in different vault design and shielding considerations. Due to space restrictions, no layout modifications outside the original bunker were permitted, including the existent maze layout. Linac location, shielding thickness calculations and different shielding materials were analysed, in order to provide the required protection for professionals, patients and members of the public.

Methods:

Barrier thickness calculations were performed according to two different guidelines: the 1996 German Standard DIN-6847 (mandatory according to DL no 180/2002) and the more recent US NCRP Report 151 (2005). The calculations considered the different photon beam available energies for 3DCRT, IMRT and VMAT techniques and the foreseen workload of the new linac. Different shielding materials were also analysed.

Results:

Calculation results confirmed the need to reinforce both primary and secondary barriers, mainly for primary and leakage radiation attenuation, respectively. The use of new highdensity shielding materials makes possible to achieve the necessary shielding without major structural interventions and without compromising the interior space of the bunker or its functionality.

\section{Conclusions:}

Calculations demonstrated the major impact of high photon beam energies on structural shielding, with the need to reinforce all the existing bunker walls thicknesses.

Calculations also revealed differences in both formalisms, mainly due to the effect of beam quality changes during transmission across barriers on TVL data and, for photon scattered radiation, due to radiation scattering angles. For door thickness calculations, NCRP considers $x$ and gamma photons as well as neutrons, whereas DIN methodology includes only photon tertiary radiation and dispersed neutrons. 


\title{
Reproducibility of an optical surface scanning system used for patient positioning verification in external radiotherapy
}

\author{
Nichal Gentilal ${ }^{1}$, Sara Germano ${ }^{2}$, Sofia Faustino ${ }^{2}$, Ariana Rocha ${ }^{2}$, Carla Miguel $^{2}$, Carlos \\ Machado $^{2}$, Telma Antunes ${ }^{2}$, Francisco Mascarenhas ${ }^{2}$ \\ ${ }^{1}$ Instituto de Biofísica e Engenharia Biomédica, Faculdade de Ciências, Universidade de Lisboa, \\ 1749-016 Lisboa \\ ${ }^{2}$ Departamento de Radioterapia, Hospital da Luz, 1500-650 Lisboa
}

Corresponding author: nichal.gentilal95@gmail.com

\section{Introduction}

Monitoring of patient positioning during radiotherapy is one of the most common methods to reduce uncertainties. Some systems used for this purpose use ionizing radiation, increasing the dose received by the patient. However, there are other possibilities based on the information obtained through reflection after projecting a visible light pattern onto the patient's surface to monitor his position. Our purpose was to test the reproducibility of an optical surface (OS) scanning system and to establish a flowchart for clinical use.

\section{Methods}

Sentinel is used during planning CT (plCT), for acquiring a 3D OS image of the patient. A primary point of that surface is chosen to monitor respiratory motion. The same point is used at the treatment room, by catalyst, for the same purpose.

Using a phantom to simulate the patient, we performed several tests to verify the primary point's coordinates transformation when the treatment isocenter is different from CT's isocenter and to ensure that the same point of the phantom's surface is being monitored both during $\mathrm{PICT}$ and treatment.

\section{Results}

The results presented in figure 1 show the primary point's coordinates in catalyst for different couch angles and isocenter coordinates. The results obtained allowed us to create a flowchart which summarizes the way of working with these OS systems.

\section{Conclusions}

These systems are very helpful to monitor patient position during a radiotherapy treatment because they avoid to increase the radiation dose for the patient, have a high efficiency and are very simple to use. Furthermore, they have already proven to be a reliable solution for respiratory gated irradiation. This study confirmed that the primary point selected during surface scanning is accurately reproduced, enabling a precise monitoring of respiratory motion, during radiation treatment, even when the treatment couch is rotated. The authors believe that the tested OS scanning's systems can reduce the toxicity of the radiation treatment and increase safety of radiotherapy. 
A

\begin{tabular}{|c|c|c|c|c|}
\hline $\begin{array}{c}\text { CT's couch } \\
\text { coordinate /mm }\end{array}$ & $\begin{array}{c}\text { Primary point } \\
\text { Sentinel }(x, y) / m m\end{array}$ & LINAC's couch angle & $\begin{array}{l}\text { Beam isocenter } \\
(\mathbf{x}, \mathbf{y}, \mathbf{x}) \mathrm{mm}\end{array}$ & $\begin{array}{c}\text { Primary point } \\
\text { Catalyst }(x, y) \text { mm }\end{array}$ \\
\hline \multirow{15}{*}{0} & \multirow{15}{*}{$(-30,55)$} & 0 & $(0,0,-2)$ & $(-30,55)$ \\
\hline & & 0 & $(30,0,-2)$ & $(-60,55)$ \\
\hline & & $\overline{0}$ & $(-30,0,-2)$ & $(0,55)$ \\
\hline & & 0 & $(0,40,-2)$ & $(-30,15)$ \\
\hline & & 0 & $(0,-40,-2)$ & $(-30,95)$ \\
\hline & & 0 & $(-30,55,45)$ & $(0,0)$ \\
\hline & & 0 & $(-100,30,48)$ & $(70.25)$ \\
\hline & & 45 & $(-30,55,45)$ & $(0,0)$ \\
\hline & & 90 & $(-30,55,45)$ & $(0,0)$ \\
\hline & & 270 & $(-30,55,45)$ & $(0,0)$ \\
\hline & & 315 & $(-30,55,45)$ & $(0,0)$ \\
\hline & & 45 & $(30,0,-2)$ & $(-81,3,-3,5)$ \\
\hline & & 90 & $(30,0,-2)$ & $(-60,-55)$ \\
\hline & & 270 & $(30,0,-2)$ & $(60,55)$ \\
\hline & & 315 & $(30,0,-2)$ & $(-3,5,81.3)$ \\
\hline \multirow{2}{*}{157} & \multirow{2}{*}{$(-30,102)$} & 0 & $(0,0,-2)$ & $(-30,55)$ \\
\hline & & 0 & $(-30,55,-2)$ & $(0,0)$ \\
\hline
\end{tabular}

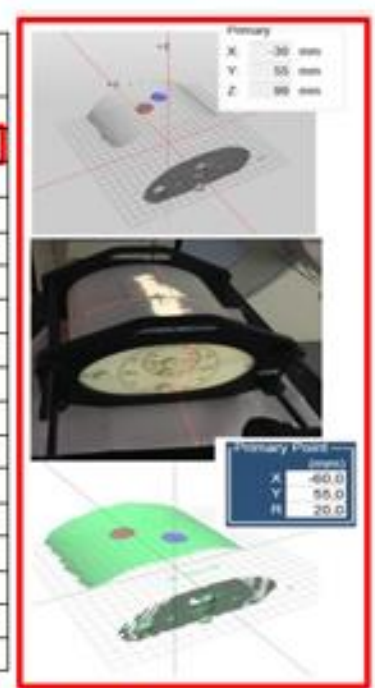

B

\section{CT Sentinel Catalyst}

$\begin{gathered}\text { Define slice zero in } \\ \text { Cr. If necessary } \\ \text { position the } \\ \text { move the table to } \\ \text { using the } \mathrm{CT} \\ \text { internal lasers }\end{gathered}$
the desired position
and register its
value

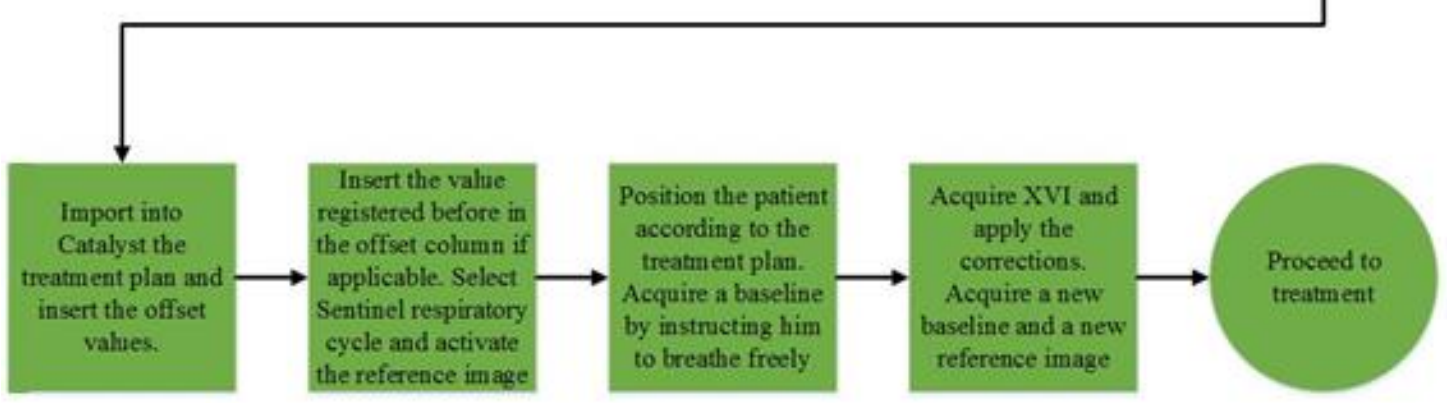

Figure1: A: Coordinates of primary point as function of beam's isocenter, where it is possible to see, at the right side: the image acquired by Sentinel (above), the phantom (middle) and by Catalyst (below). B: Flowchart that summarizes the correct way to work with Sentinel and Catalvst 


\section{Xófigo vs ${ }^{177}$ Lu- labelled anti-PSMA}

\section{Daniela Agostinho', Melissa Costa', Salomé Galaio'}

${ }^{1}$ Escola Superior de Tecnologia da Saúde de Lisboa - Instituto Politécnico de Lisboa, Av. D. João II, lote 4.69.01, Parque das Nações, 1990-096 Lisboa

\section{Corresponding author: mel 23 92@hotmail.com}

\section{Introduction}

PCa (Prostate Cancer) is a disease with a high incidence rate. Xofigo $\left({ }^{223}\right.$ Ra dichloride) is a medicine indicated for patients with this disease in the metastatic phase specifically, symptomatic bone metastases.

${ }^{177}$ Lu-anti-PSMA represents a set of promising molecules in radioimmunotherapy in PCa patients since they are able to recognize PSMA (prostate specific membrane antigen) which is highly expressed in PCa metastases.

The objective of this study is to highlight the advantages and disadvantages of both treatments in patients with advanced staged PCa as there are no comparative studies at this time.

\section{Methods}

The AISYMPCA study was one of the chosen to analyze since it was what allowed Xofigo to be approved. The phase II study of ${ }^{177}$ Lu labeled with anti-PSMA with $J 591$ was also analyzed reason being, it is one of the more recent studies with results.

\section{Results}

Xofigo is currently used in combination with chemotherapy, increasing the survival rate by 3.6 months. The adverse effects associated with this type of treatment are not severe and are reversible. On the other hand, ${ }^{177}$ Lu-anti-PSMA obtained promising results indicating that it could increase the survival rate up to 21.8 months. It allows simultaneously the acquisition of body images representative of the biodistribution / location of tumors / metastases by their gamma emission and therapeutics since it is also a $\beta^{-}$emitter.

\section{Conclusions}

The study of ${ }^{177}$ Lu-anti-PSMA molecules has emerged exponentially, being evident to the scientific community the potential in theranostics and radioimmunotherapy techniques, seeking the most appropriate treatment for each type of patient, with the ultimate goal of increasing the survival rate in patients with metastatic prostate cancer. 


\title{
The Impact of Patient-Specific Attenuation Correction on ${ }^{99 \mathrm{~m}}$ Tc-MAA SPECT Imaging for ${ }^{90} \mathrm{Y}$ Microspheres Liver Radioembolization Treatment Planning: A Preliminary Study on Phantom Models
}

\author{
Laura Demino $^{1}$, Paulo Ferreira ${ }^{2}$, Francisco P. M. Oliveira ${ }^{2}$, and \\ Durval C. Costa ${ }^{2}$
}

\footnotetext{
${ }^{1}$ Center of Physics and Engineering of Advanced Materials, CeFEMA, Instituto Superior Técnico, University of Lisbon, Lisbon, Portugal

${ }^{2}$ Nuclear Medicine-Radiopharmacology Department, Champalimaud Center for the Unknown, Lisbon, Portugal
}

Corresponding author: laura.demino@mail.polimi.it

\section{Introduction}

Yttryum-90 $\left({ }^{90} \mathrm{Y}\right)$ microspheres liver radioembolization represents an innovative oncologic procedure for unresectable primary and metastatic hepatic tumors. As a treatment planning method, Technetium-99m ( ${ }^{99 \mathrm{~m}} \mathrm{Tc}$ ) macroaggregated albumin (MAA) Single Photon Emission Computed Tomography (SPECT) provides an estimation of the metabolically active tumor and, hence, of the therapeutic microspheres distribution, through the evaluation of the tumor-toliver radiotracer uptake ratio. However, ${ }^{99 \mathrm{~m}} \mathrm{Tc} \gamma$-photons attenuation within human body compromises the accuracy of quantitative ${ }^{99 m}$ TC-MAA SPECT images. Therefore, the implementation of patient-specific attenuation corrections may be fundamental for the proper interpretation of ${ }^{99 \mathrm{~m}}$ Tc-MAA SPECT images, and, thus, the efficacy and safety of the radioembolization treatment.

\section{Methods}

This initial part of our study addresses the impact of Computed Tomography (CT)-based attenuation correction on ${ }^{99 m}$ TC SPECT simulated and/or acquired computational and physical phantom images, performed by incorporating the CT-derived attenuation maps into the process of iterative SPECT images reconstruction based on the Maximum Likehood Expectation Maximization (MLEM) algorithm.

\section{Results}

Preliminary results on the employed phantom models reveal that attenuation corrected ${ }^{99 \mathrm{~m}} \mathrm{Tc}$ SPECT images present higher count density profiles, up to $50 \%$. Increased counts uniformity of reconstructed ${ }^{99 \mathrm{~m}} \mathrm{TC}$ SPECT images is observed for homogeneous activity phantom, with maximum peak deviation of $7 \%$. Furthermore, images are qualitatively improved, with visually greater contrast.

\section{Conclusion}

Attenuation corrected ${ }^{99 \mathrm{~m}} \mathrm{Tc}-\mathrm{MAA}$ SPECT images may significantly improve the accuracy of ${ }^{90} \mathrm{Y}$ microspheres dose calculation for liver radioembolization, enhancing the therapeutic effects while minimizing the complications. For this reason, we firmly believe in further researching in this field, in order to quantitatively determine the dosimetric importance of patient-specific corrections for ${ }^{99 \mathrm{~m}} \mathrm{Tc}$ photons attenuation within human body. This will permit to clinically appraise the impact of attenuation corrected ${ }^{99 m}$ Tc-MAA SPECT images as liver radioembolization pre-treatment evaluation. 


\title{
Study of Bladder Emptying Impact on Exposition Dose Rates induced from the Patient in Conventional Nuclear Medicine
}

\author{
Cunha, A. ${ }^{1}$, Neves, D. ${ }^{1,2}$, Pires, $\mathrm{L}^{\prime 2}$. Antunes, $\mathrm{H}^{2}$. Oliveira, R. ${ }^{3}$, Nunes, $A .{ }^{4}$, Alves, $C .{ }^{4}$, \\ Ferreira, E. ${ }^{4}$, Metello, L.F. ${ }^{1,5}$ \\ ${ }^{1}$ ESS - IPP, ATC\&CMN, Rua Dr. António Bernardino de Almeida, 400, 4200 - 072 Porto. Portugal \\ ${ }^{2}$ DIATON S.A., Dept. de Med. Nuclear, Coimbra \& Leiria \& Viseu. Portugal \\ ${ }^{3}$ FEUP - UP, Dept de Estatistica, Rua Dr. Roberto Frias, 4200 - 465 Porto. Portugal \\ ${ }^{4}$ DCC - Dr. Campos Costa, Dept. de Med. Nuclear, Instituto CUF, Rua Fonte das Sete Bicas, 170, \\ 4460 - 188 Matosinhos. Portugal \\ ${ }^{5}$ IsoPor-Azores, Dept de Med. Nuclear e Imagiologia Molecular, Angra do Heroismo, I. Terceira, \\ Azores. Portugal
}

Corresponding author:Ifm@ess.ipp.pt

\section{Introduction}

Agents used in Nuclear Medicine (NM) are mostly excreted by urinary system. Patients subjected to NM procedures emit radiation isotropically, exposing themselves, professionals and public. However, when bladder emptying doesn't have image impact, requesting patients to void before positioning isn't a common practice. This fact can influence patient dose rate and therefore, occupational exposure. The present study aims to evaluate voiding impact on patient dose rate in common NM procedures, in distinct anatomic areas and different distances, in order to investigate relevancy of void before imaging.

\section{Methods}

85 patients were evaluated: 30 bone scintigraphy(BS), 15 thyroid scintigraphy(TS) and 40 myocardial perfusion scans (20 in rest (MPS-R), 20 under stress (MPS-S)). Dose rates were measured before and after voiding at different anatomic areas (head-vertex (HV), head lateral $(\mathrm{HL})$, pelvis $(\mathrm{P})$ and feet $(\mathrm{F}))$ and for different distances $(0,0.5$ and $1 \mathrm{~m})$. Geiger-Muller detectors were used.

\section{Results}

Higher patient dose rates were observed at P. Before voiding, at $0,0.5$ and $1 \mathrm{~m}$, the mean values for emitted patient dose rates were $797( \pm 174,43), 121( \pm 19,46)$ and $36( \pm 7,47) \mu \mathrm{Sv} / \mathrm{h}$ respectively. After voiding, values were $721( \pm 181,36), 102( \pm 21,00)$ and $29( \pm 5,60) \mu \mathrm{Sv} / \mathrm{h}$. Lower patient dose rates were measured at the $\mathrm{F}$. At $0 \mathrm{~m}$, the major reduction on dose rate was observed at the P for BS and TS (23\%); the minor was achieved at the HL in MPS-S (7\%). At $0.5 \mathrm{~m}$, the higher difference was observed at the $\mathrm{F}$, for TS (36\%); while the smaller was achieved at the HV, for MPS-S (8\%). At $1 \mathrm{~m}$, the major reduction was observed at the $\mathrm{F}$ for TS (44\%); the minor was observed at the $\mathrm{HL}$, also in TS, with the same value at the P for MPS-S $(18 \%)$.

\section{Conclusions}

Strategies for patient dose rate reduction are crucial for radioprotection matters. Obtained results seems to point that patients should be always encouraged to void before imaging to allow reducing exposition for all involved parts. 


\section{Evaluation of Dose Rates after performing 131I Therapy for Thyroid Cancer}

\section{Pires, Ricardo ${ }^{1}$; Jorge, Ricardo ${ }^{1}$; Alvernaz, Ana Paula ${ }^{1}$; Calado, Denise ${ }^{1}$; Rézio, M Teresa $^{1}$; Vieira, Maria do Rosario ${ }^{1}$}

${ }^{1}$ Departamento de Medicina Molecular do Hospital da Luz, Avenida Lusíada, 100, Lisboa

Corresponding author: ricardo.pires@hospitaldaluz.pt

\section{Introduction}

This work is a retrospective analysis of the dose rates on the day that patients undergoing 131 iodine therapies for thyroid carcinoma are discharged.

The aim of the study was to evaluate the implications of these therapies in the daily routine of these patients.

\section{Methods}

The results of 98 patients were evaluated. The population evaluated was divided according to the pre-treatment performed, the activity administered and the number of hospitalization days.

\section{Results}

As mentionned the population was divided into pre-treatment type, administered activity, and number of days of hospitalization.

The results obtained are shown in the following tables:

\begin{tabular}{|c|c|c|c|c|}
\cline { 3 - 5 } \multicolumn{2}{c|}{} & $\begin{array}{c}\text { Administered } \\
\text { activity } \mathbf{( m C i )}\end{array}$ & $\begin{array}{c}\text { Dose Rate after } \\
\text { treatment }(\mathbf{m S v} / \mathbf{h})\end{array}$ & $\begin{array}{c}\text { Days of restrictions } \\
\text { (d) }\end{array}$ \\
\hline \multirow{3}{*}{$\begin{array}{c}\text { Pre-treatment } \\
\text { with CYNOMEL }\end{array}$} & $\mathbf{2}$ days of hospitalization & 100 & 18,1 & 14 \\
\cline { 2 - 5 } & $\mathbf{3}$ days of hospitalization & 100 & 8,5 & 7 \\
\cline { 3 - 5 } & 150 & 10,9 & 7 \\
\hline
\end{tabular}

\begin{tabular}{|c|c|c|c|c|}
\hline & & $\begin{array}{l}\text { Administered } \\
\text { activity (mCi) }\end{array}$ & $\begin{array}{l}\text { Dose Rate after } \\
\text { treatment }(\mathrm{mSv} / \mathrm{h})\end{array}$ & $\begin{array}{l}\text { Days of restrictions } \\
\text { (d) }\end{array}$ \\
\hline \multirow{4}{*}{$\begin{array}{l}\text { Pre-treatment } \\
\text { with THYROGEN }\end{array}$} & \multirow{2}{*}{2 days of hospitalization } & 100 & 9,8 & 7 \\
\hline & & 150 & 11,3 & 7 \\
\hline & \multirow{2}{*}{3 days of hospitalization } & 100 & 4,0 & 4 \\
\hline & & 150 & 4,3 & 4 \\
\hline
\end{tabular}

\section{Conclusions}

From the analysis of the results it is possible to conclude that the type of pre-treatment is the most important factor to determine the number of days of restrictions after discharge. The therapies performed under THYROGEN, regardless of the activity administered and the dose rate on discharge, allow patients to return to their daily routine more quickly.

The number of hospitalization days is another important factor to return the daily routine quickly.

We performed a t student test with a $t=0,03$ which means that we reject null hypothesis, concluding that the two population evaluate are different.

This conclusion with less exposure to ionizing radiation is in favor of the pre-treatment with thyrogen in terms of radiological protection of the patient, relatives, and the public in general. 


\title{
Estimation of doses from patients undergoing Nuclear Medicine procedures
}

\author{
Sousa A. ${ }^{1}$, de Sousa V. ${ }^{2}$, Cardoso G. ${ }^{2}$, Santos A.I. ${ }^{2,3}$ \\ ${ }^{1}$ Faculdade de Ciências e Tecnologia - Universidade Nova de Lisboa, Lisboa, PORTUGAL \\ ${ }^{2}$ Hospital Garcia de Orta, Almada, PORTUGAL \\ ${ }^{3}$ Nova Medical School - Universidade Nova de Lisboa, Lisboa, PORTUGAL
}

Corresponding author: anaraquel64@hotmail.com

\section{Introduction}

The increasing number of Nuclear Medicine (NM) procedures performed reinforces the need to evaluate if the patient can be released from the department without compromising radiation protection of the public that may contact with him/her after the procedures. Therefore, the aim of this work was to estimate absorbed dose by the public, considering different procedures, administered activities and scenarios.

\section{Methods}

The study focused on 5 diagnostic procedures, all performed with Technetium-99m labelled radiopharmaceuticals: Renogram ( $\left.{ }^{99 \mathrm{~m}} \mathrm{Tc}-\mathrm{MAG} 3\right)$, Thyroid Scintigraphy $\left.{ }^{99 \mathrm{~m}} \mathrm{Tc}-\mathrm{NaTcO}_{4}\right)$, Myocardial Perfusion Scintigraphy - Rest and Stress ( ${ }^{99 \mathrm{~m}} \mathrm{Tc}$-Sestamibi), Whole Body Bone Scintigraphy $\left({ }^{99 \mathrm{~m}} \mathrm{Tc}-\mathrm{HMDP}\right)$ and Renal Scintigraphy $\left({ }^{99 \mathrm{~m}} \mathrm{TC}-\mathrm{DMSA}\right)$. The absorbed dose rates/minute were calculated, given the time interval that usually occurs between radiopharmaceutical administration and the patient release from the department, the different times in proximity with other people after leaving the department and the different time durations for each contact, at a distance of 1 meter. The dose rate values were compared to $0.58 \mathrm{mSv} / \mathrm{h}$, a recommended dose limit from U.S.NRC Regulatory Guide 8.39 for the release of a patient undergoing diagnostic NM procedures.

\section{Results}

Higher dose rate values were observed in Myocardial Perfusion Scintigraphy with $2.67 \times 10^{-7}$ $\mathrm{Gy} / \mathrm{min}$ (equivalent to $1.60 \times 10^{-2} \mathrm{mSv} / \mathrm{h}$ ), while the lowest dose rate values were observed in Renograms with $1.02 \times 10^{-7} \mathrm{~Gy} / \mathrm{min}$ (equivalent to $6.12 \times 10^{-3} \mathrm{mSv} / \mathrm{h}$ ), considering that the patient contacts with a person 5 minutes after leaving the department.

\section{Conclusions}

It was verified that none of the values measured before the patient left the department exceeded the limit established by U.S.NRC when considering a patient submitted to only one diagnostic NM procedure. As expected, it has been found that the dose rate decreases while increasing the time between administration and release of the patient. Also, absorbed dose increases with the permanence time near the injected patient. 


\title{
Radiologia Convencional DRL's in BASE units
}

\author{
Maria do Carmo Baptista ${ }^{1}$, Margarida Prozil $^{1}$
}

${ }^{1}$ Consultório de Tomografia Computorizada - Dr. Campos Costa S.A.

Corresponding author: mcvb@drcamposcosta.pt

\section{Introduction}

The existence of a common methodology for all European countries in the European DataMed 2 project, published in RP154 of the European Commission, has led to the elaboration at national level of a work plan for the evaluation of doses in the Portuguese population due to diagnostic radiology and nuclear medicine examinations.

\section{Methods}

The parameter of the yield of the tube measured in the $Q C$ tests is used. The equipment has its own characterization of its X-ray tube, reducing the error associated with the determination of DRL's. With the yield values measured at a normalized distance, by the firing parameters for each of the examinations considered and using the backscatter factor, $\mathrm{K}$, we obtain the ESD values in $m G y$, which depends on $K=f(k V p), f$, Dose ratio absorbed in the tissue by the absorbed dose in air and pfd, patient focus distance in $\mathrm{cm}$. The yield value is introduced not as constant but as a function which is assumed to have a linear dependence with $\mathrm{kVp}$. In order to guarantee the correct functioning of the sources of ionizing radiation, the parameter HVL in $\mathrm{mmAl}$ is validated. In this way, its correct and adjusted dose rate is verified, since according to Portuguese legislation the radiation source must have a filter system of the primary beam sufficient to obtain a semi-reducing effect of more than $3 \mathrm{mmAl}$ to $100 \mathrm{kVp}$.

\section{Results}

Distinctions and records between the two incidences are considered, as well as the separation of hip and pelvic exams, since the protocol used for acquisition is different, reflecting a high error in the subsequent treatment of data. We started to have the results in the segment TOP7, subdivided into two incidents.

\section{Conclusions}

36 conventional radiology devices are used and more than 50,000 results are recorded over a period of approximately 6 months. The discrepancy observed in results is attributed to the different technologies existing in the technological park, to the physiognomy of the patient by geographical area and protocols used. 


\title{
Arms up vs. Arms down - CT Dose Optimization
}

\author{
Filipa Borlinhas $^{1,2,3}$, Ana Cristina Vicente ${ }^{3}$, José Venâncio ${ }^{3}$ \\ ${ }^{1}$ Escola Superior de Tecnologia da Saúde de Lisboa, EPE. Av. D. João II, Lote 4.69.01. 1990 - 096 \\ Lisboa, Portugal \\ ${ }^{2}$ Instituto Biofísica e Engenharia Biomédica e (IBEB), Faculdade de Ciências da Universidade de \\ Lisboa. Campo Grande - 1749-016 Lisboa, Portugal \\ ${ }^{3}$ Instituto Português de Oncologia de Lisboa Francisco Gentil, EPE (IPOLFG, EPE). R. Prof. Lima \\ Basto, 1099-023 Lisboa, Portugal \\ Corresponding author: filipaborlinhas@gmail.com
}

\section{Introduction}

Computed Tomography (CT) technologies are evolving in terms radiation dose optimization. When a transition of $\mathrm{CT}$ technology takes place, every procedure should be revised and questioned in terms of radiation dose optimization. A procedure such as positioning a patient for a CT examination may be consider simple, but it may become radical concerning radiation dose. The CT examination of Neck+Thorax+Abdomen+Pelvis (NTAP) requires a large anatomical region to be irradiated and, in most of the cases, the patients have to be scanned regularly to evaluate oncologic disease. Radiographers gathered efforts in order to optimize the delivered radiation dose of this type of examinations, and positioning of the patient during the scout was found as a dose reduction parameter.

The aim of this work is to emphasize the need to constantly revise CT examination protocols and clinical practice.

\section{Methods}

Two different positioning to perform the NTAP CT examination scout were tested, one with patient with arms up and the other with arms down. In the past these examinations were performed with arms down so it was only necessary to do the new CT examination scouts with arms up. Dose estimations provided by the CT equipment were reported and compared between the two different positioning during the scout.

\section{Results}

The radiation dose for the entire NTAP examination was lower when the scout was performed with arms up. Considering AEC technology, contrast media phases, anatomical regions specificities, and patient comfort, these tests were performed without compromising the diagnosis of the patient, but significant changes had to be applied to the protocol.

\section{Conclusions}

The $\mathrm{CT}$ technology evolution implies changes in clinical practice and examination procedures. It is extremely important that the Radiology professionals revise their practices periodically in order to find procedures that can be optimized in terms of radiation dose. 


\title{
Study of the SEPOR BARITA RX as an alternative of radiological protection to Lead
}

\author{
$\underline{\text { Rui Jorge Poínhas Correia }}{ }^{1}$, João Cardoso ${ }^{2}$ \\ ${ }^{1}$ Tabal-Sepor, Areias e Argamassas, Lda - Rua de Serração, N ․o3, 2125-316, Muge, Salvaterra \\ de Magos, Portugal \\ ${ }^{2}$ Laboratório de Proteção e Segurança Radiológica - Estrada Nacional 10 (ao km 139,7), 2695- \\ 066 Bobadela, Loures, Portugal
}

Corresponding author: geral@tabalsepor.com

\section{Introduction}

Lead, like lead sheet, is used as a radiation attenuator. It is a solution with serious environmental and economic impacts. Although it is a solution where the advantage is essentially based on the thickness required for the need for attenuation, its replacement by SEPOR BARITA is a consequence of the advantages of this product. Barite is a mineral whose radiological properties are known. Although it is a mineral with a high density, difficult to apply, its incorporation in a mortar, in the appropriate proportions, results the SEPOR BARITA. A mortar with radiological protection properties, along with the workability and uniformity of a common mortar. In order to understand the correspondence between Radiation Sources Vs Attenuation Vs Application Thickness between Lead and SEPOR BARITA, an analysis / study was carried out at the Laboratory of Radiological Protection and Safety of Instituto Superior Técnico, whose method, results and conclusions are presented.

\section{Methods}

The experimental geometry used to determine the attenuation properties of this material is described in IEC 61331-1: 1994, called "narrow beam geometry". The radiation qualities used for this study are those described in ISO 4037-1, N-80, N-100, N-120 and N-150. For the measurements, a PTW M23331 ionization chamber with $1 \mathrm{~cm} 3$ of sensitive volume connected to an electrometer PTW UNITED E was used. The applied measurement methodology consisted in the accomplishment of five initial measurements without plate of attenuation and next five measurements with each one of the plates made available for test. In addition, measurements of the ambient conditions were made in order to standardize the measurements to the standard ambient conditions, namely: $20^{\circ} \mathrm{C}$ temperature, $1013.25 \mathrm{hPa}$ pressure and $50 \%$ relative humidity. From the experimental results, it was calculated the mass attenuation coefficient, $\mu / \rho$, of this SEPOR BARITA material, and the equivalent lead thickness of this material, for each of the radiation qualities used, using the data from the The mass attenuation coefficient of lead published by the National Institution of Standards and Technology (NIST).

\section{Results}

From the obtained results, the attenuation ratios $(1 / 10)$ of the different thicknesses of the attenuating material were obtained. These results are shown in the following figures: 


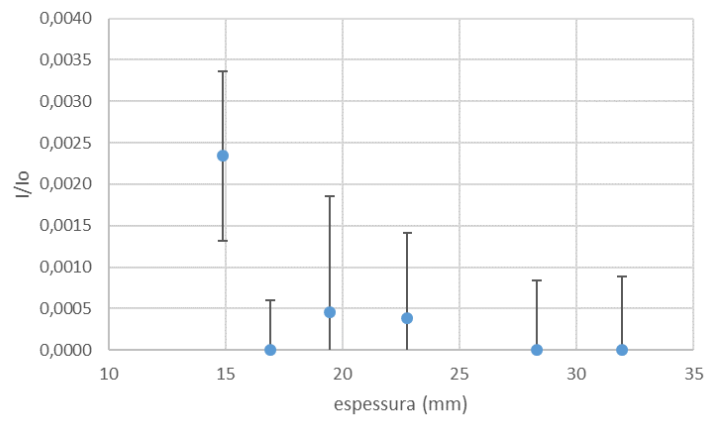

Figure 1: Results of the attenuation studies for the quality of $\mathrm{N}-80$ radiation.

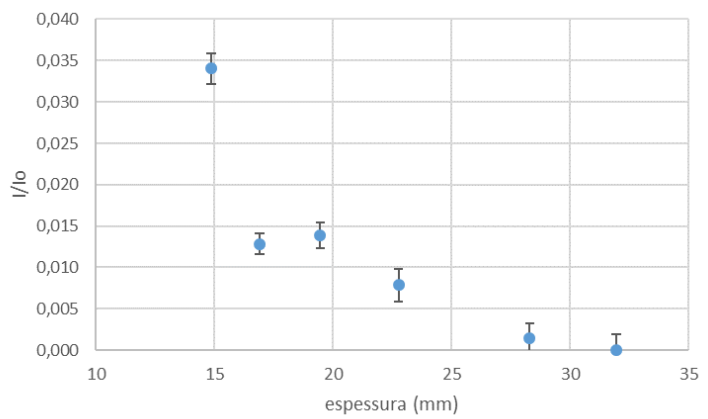

Figure 2: Results of the attenuation studies for the quality of $\mathrm{N}-100$ radiation.

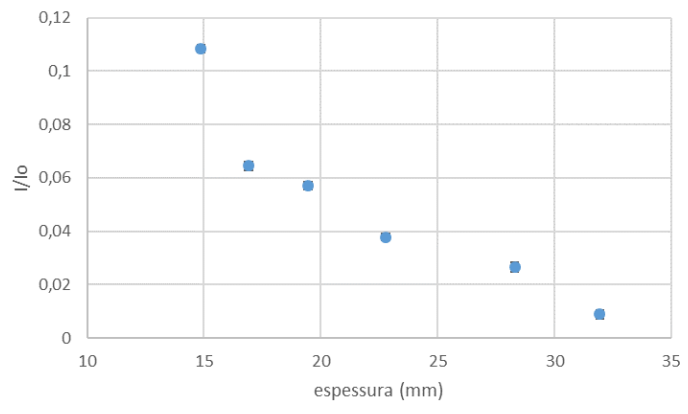

Figure 3: Results of the attenuation studies for the quality of $\mathrm{N}-120$ radiation.

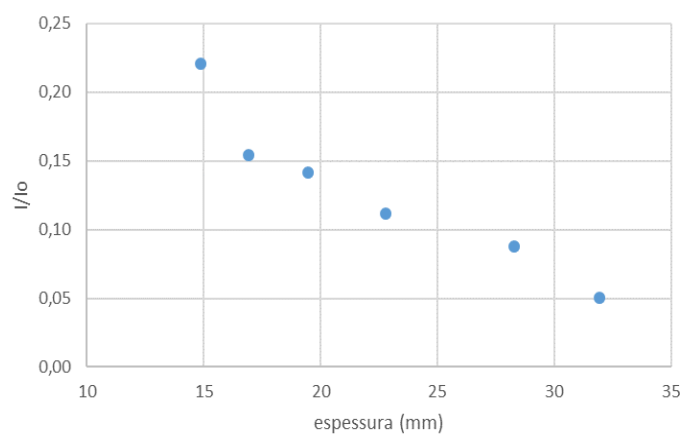

Figure 4: Results of attenuation studies for N-150 radiation quality.

\section{Conclusions}

According to the tests and results obtained, the SEPOR BARITA material is an excellent alternative to lead. In spite of the thickness required for the lead equivalent to be clearly superior - in lead we treat with $\mathrm{mm}$ and with this material with $\mathrm{cm} \mathrm{-,} \mathrm{With} \mathrm{a} \mathrm{theoretical}$ consumption of $21 \mathrm{~kg} / \mathrm{m}^{2} / \mathrm{cm}$, its easy application and the possibility of adjusting several thicknesses confers an optimal solution for radiological protection. For example: for a $\mathrm{x}$-ray tube of $100 \mathrm{kVp}$, with a $17 \mathrm{~mm}$ application of SEPOR BARITA, it is possible to achieve the same protection of $2 \mathrm{~mm}$ of Lead sheet. Two great assets of the SEPOR BARITA are: economic solution more favorable than lead, comes to have a cost 5 times smaller, and greater durability. 


\title{
A Portuguese overview of Panoramic Extraoral X-Ray Systems
}

\author{
Guilherme Coutinho $^{1}$, Hugo Trindade ${ }^{1}$, Mariana Trincão ${ }^{1}$, Cláudia Xavier ${ }^{1}$, Cláudia \\ Mota $^{1}$ \\ ${ }^{1}$ MedicalConsult - Grupo Stericyle Portugal (Rua Fernando Pessoa 8C, 2560-241, Torres \\ Vedras)
}

Corresponding author: guilherme.coutinho@medicalconsult.pt

Panoramic Extraoral X-ray is a radiological technique which generates a single tomographic image of facial structures that includes both the maxillary and mandibular dental arches and their supporting structures. These images are most useful clinically for diagnosis requiring broad jaws coverage. Regarding the advantages of this radiological technique, dental practitioners have increased the number of extraoral x-rays units and, in the beginning of 2016, there were 1228 licensed by the Portuguese Health General Directorate (Direção Geral da Saúde).

This study aims to give an overview of the Portuguese extraoral X-Rays units; to determine the dose in terms of Dose-Area Product (DAP) and the radiation output; to characterize the general state in terms of quality assurance parameters (kilovoltage peak, type of acquisition (digital, CR - computed radiography and film), filtration, brands and nominal parameters) of the extraoral X-Ray equipment used in Portugal; and to evaluate image quality in terms of high contrast resolution.

This study assessed the measurements performed on 270 extraoral panoramic X-ray equipment on Portuguese health units spread throughout the mainland and islands, between November 2016 and April 2017. The measurements are part of the annual quality assurance program of each equipment, based on the requirements of Decree-Law 180/2002 and European Commission Report RP162. Entrance Surface Air Kerma (ESAK) was measured with a Raysafe X2 R/F Sensor. The image quality of 210 units was evaluated in terms of spatial resolution. It was used the Pro-Dent gamma phantom from Pro-Project and the protocol described by the manufacturer. Statistical analysis was done with IBM SPSS v.22.

The obtained results showed that each unity undertakes in average 22 exposures per week (orthopantomography). Considering 1228 licensed equipment, around 1.4 million extraoral XRays are performed every year in Portugal. The majority of equipment found were from Gendex, Trophy-Kodak-Carestream and Owandy. Regarding the image systems: $78 \%$ uses digital sensors, $12 \%$ uses $C R$ and $10 \%$ uses films. The nominal parameters mean values for an average male adult were: $72 \mathrm{kV}, 9 \mathrm{~mA}, 13,5$ seconds. The mean radiation output was $35 \mu \mathrm{Gy} / \mathrm{mAs} @ 1 \mathrm{~m}$ for $80 \mathrm{kV}$. For typical clinical procedures, the mean DAP was $72 \mathrm{mGy} . \mathrm{cm}^{2}$ and the mean spatial resolution obtained was $3 \mathrm{lp} / \mathrm{mm}$. In $10 \%$ of the measurements the DAP was above $100 \mathrm{mGy} \cdot \mathrm{cm}^{2}$. In average, the difference between the time of exposure and the voltage to the nominal values are under $1 \%$.

It was evaluated the general state of the Portuguese extraoral panoramic X-Rays units. Regular radiation safety and performance surveys of $\mathrm{X}$-ray equipment must be performed to ensure the optimum level of protection for patients while maintaining the highest image quality. 


\title{
Measurement Uncertainty in Quality Control of Computed Tomography
}

\author{
Ana Rita Sousa ${ }^{1}$, Pedro A. Gomes ${ }^{1}$, Louis F. Branco ${ }^{1}$ \\ ${ }^{1}$ Unidade Técnica de Proteção Radiológica - Instituto de Soldadura e Qualidade (UTPR - ISQ) \\ Corresponding author: pagomes@isq.pt
}

\section{Introduction}

In the quality control ( $Q C$ ) of diagnostic radiology equipment, several parameters are evaluated in order to assure a good performance of the equipment. This evaluation involves the measurement of several quantities and, as in any measurement, the result obtained is affected by an uncertainty that includes several contributions. The analysis of measurement uncertainties is of increased importance given that QC measurements are paired with regulatory acceptability criteria, and the measurement uncertainties should not be neglected.

\section{Methods}

A correct analysis of measurement uncertainty should always involve in-depth analysis of the various sources of uncertainty affecting the measurement result, such as: poor repeatability of measurements (precision), measuring instrument's resolution limits and maximum permissible errors according to their manuals, specifications and standards to which detectors, phantoms and test objects are manufactured, including the influence of backscatter radiation and environmental conditions, among others.

As such, the expanded measurement uncertainties inherent to the various $Q C$ tests of a computed tomography (CT) equipment were estimated based on specifications and measurements carried out in-locu.

\section{Results}

In this work, the impact of accounting for measurement uncertainty in the context of conformity evaluation of a CT scanner was studied. For this purpose, the dominant sources of uncertainty for the expanded measurement uncertainties were identified and quantified.

The table below shows the estimated expanded measurement uncertainties for the CT QC tests foreseen in Decree-Law n.o 180/2002, of August 8 (transposition of the European Commission's Radiation Protection Publication № 91 [1997]), in comparison with the respective legal acceptability criteria.

\begin{tabular}{|c|c|c|c|}
\hline & Decree-Law n.o 180/2002, of August 8th & Expanded uncertainty, $U *(k=2)$ & Regulatory Acceptability Criteria \\
\hline \multirow{2}{*}{ 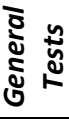 } & Tube voltage accuracy & $2,5 \%^{(1)}$ & $<10 \%$ \\
\hline & Total filtration & $0,3 \mathrm{~mm} \mathrm{Al}{ }^{(1)}$ & $\geq 2,5 \mathrm{~mm} \mathrm{Al}$ \\
\hline \multirow{6}{*}{ 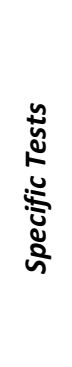 } & Computed Tomography Dose Index (CTDI) & $6,6 \%^{(2)}$ & $\leq 20 \%$ \\
\hline & Image slice width & $5,4 \%(1 \mathrm{~mm} \text { slice })^{(3)}$ & $\leq 20 \%$ \\
\hline & Image noise & $5,4 \%^{(3)}$ & $\leq 20 \%$ \\
\hline & CT number uniformity & $2,6 \%^{(3)}$ & $\leq 1,5 \%$ \\
\hline & CT number accuracy & $\begin{array}{l}1,5 \% \text {, or } \\
12 \mathrm{HU} \quad{\text { (water })^{(3)}}^{(3)}\end{array}$ & $\begin{array}{l}<5 \%, \text { or } \\
<20 \mathrm{HU}\end{array}$ \\
\hline & Spatial resolution & 0,2\%(@MTF 50\%) ${ }^{(3)}$ & $\leq 20 \%$ \\
\hline
\end{tabular}

*The value presented corresponds to a percentage (\%) of the measured value, or other, as specified.

\footnotetext{
${ }^{1}$ RaySafe X2 R/F sensor.

${ }^{2}$ RaySafe X2 CT sensor and Leeds Test Objects TO CTDI.

${ }^{3}$ Catphan 600 test object and Codonics software.
} 


\section{Conclusions}

This study identified and quantified the main sources of uncertainty of CT QC tests carried out in the field.

It was important to become aware of the difficulty and complexity inherent to the characterization and estimation process of certain measurement uncertainty sources not specified by the (documentation provided by) manufacturers.

It was verified that there are parameters whose calculated expanded uncertainty exceed $1 / 3$ of the established acceptability criteria, and, in some cases, even the totality thereof (e.g. CT number uniformity). It should be noted that when the expanded measurement uncertainty exceeds $1 / 3$ of its applicable acceptability criteria, the margin assigned to the measurement error for conformity analysis is significantly reduced: |Measurement Error| + |Expanded Uncertainty $|\leq|$ Acceptability Criteria $\mid$.

Accounting for the expanded measurement uncertainty in QC of medical equipment is notably relevant since it allows to evaluate the legal compliance of equipment with a coverage probability of $95,45 \%$, and consequently, the correct conclusion on acceptability for clinical use. 


\title{
Avaliação do efeito da proteção de bismuto na dose de radiação à superfície da mama e na qualidade de imagem, em TC do Tórax
}

\author{
Pimenta, Andrea $^{1}$; Santos, Joana ${ }^{2}$; Silva, Vitor ${ }^{1,3}$; Ramos, Isabel ${ }^{4}$ \\ ${ }^{1}$ Centro Hospitalar São João, EPE \\ ${ }^{2}$ Escola Superior de Tecnologia da Saúde de Coimbra \\ ${ }^{3}$ Escola Superior de Saúde do Porto \\ ${ }^{4}$ Faculdade de Medicina da Universidade do Porto \\ Corresponding author: aspimenta@gmail.com
}

\section{Introduction}

To evaluate surface breast radiation dose and image quality of different distances of bismuth shields to phantom surface, at CT Thorax High Resolution (HR).

\section{Methods}

An anthropomorphic phantom was scanned four times: without shield (reference scan) and with bismuth shield at distances of $1 \mathrm{~cm}, 3 \mathrm{~cm}$ and $4 \mathrm{~cm}$ of phantom surface. All acquisitions were done with the same parameters of $\mathrm{CT}$ Thorax HR with automatic tube current modulation switched on.

Surface breast radiation dose was measured with 5 MOSFETs. A quantitative assessment of image was performed by study of signal and image noise. These were obtained by measurement of mean value and standard deviation of Hounsfield Units (HU), respectively, in each of the six ROls placed in homogeneous areas of the phantom (two in breast, two in mediastinum and two in posterolateral chest wall), in the same image of each acquisition. Median and interquatil range were obtained for each of quantitative variables and a normality test was performed for each one of the samples.

To assess differences in radiation dose to the surface of breast, in signal and in image noise, by the use of bismuth shields, a non parametric Mann-Whitney test was performed, with adjustment for multiple comparisons.

A quality evaluation was performed in 50 clinic studies of CT Thoracic HR with the bismuth shield applied by a distance of $1 \mathrm{~cm}$ of the patient. Two radiologists evaluated images, in a blind way, to determinate the effect of bismuth shield on clinic diagnostic and inter-observer agreement proportion was calculated.

\section{Results}

Bismuth shields are useful because it reduces the radiation dose to the breast surface. Regarding to the reference scan (without bismuth) the dose to the breast was reduced $43,9 \%, 38,8 \%, 37,2 \%$ by using a breast shield for a distance of a $1 \mathrm{~cm}, 3 \mathrm{~cm}$ and $4 \mathrm{~cm}$ of the surface of the phantom, respectively. These differences were not statistically significant. Signal and image noise increased when protection was used. The maximum increase of signal and image noise occurred for a distance of $1 \mathrm{~cm}$. As the distance between the shield and phantom surface increased, signal value decreased. Image noise did not decrease linearly. This was greater at distance of $4 \mathrm{~cm}$ when compared with $3 \mathrm{~cm}$. These differences were not statistically significant.

The inter-observer agreement proportion of "bismuth shield doesn't affect the diagnostic evaluation" was $98 \%$.

\section{Conclusions}


The use of bismuth protection reduces dose to the breast surface. When the distance between protection and phantom increases, the dose reduction decreases. At a distance of $1 \mathrm{~cm}$, despite a greater increase in signal and image noise, bismuth protection does not affect the diagnostic evaluation in Thoracic CT. Bismuth protection should be used routinely, at a distance of $1 \mathrm{~cm}$, always considering the limitations in terms of absolute $\mathrm{HU}$. 


\title{
Optimisation of computed tomography practice - patient and phantom approach
}

\author{
Filipa Pires ${ }^{1}$, Francisco Alves ${ }^{2}, \underline{\text { Joana Santos }}{ }^{3}$ \\ ${ }^{1}$ ESTES-Coimbra Health School; CHUC - Centro Hospitalar e Universitário de Coimbra; Sanfil \\ ${ }^{2}$ ESTES-Coimbra Health School; ICNAS - Instituto de Ciências Nucleares Aplicadas à Saúde \\ ${ }^{3}$ ESTES-Coimbra Health School
}

Corresponding author: joanasantos@estescoimbra.pt

\section{Introduction}

Computed Tomography examinations are responsible for a large proportion of effective collective dose across the countries, and concern about potential effects increased in the last years. The aim of this study was to analyse the exposure parameters and dose levels of the most common CT procedures in order to audit and implement optimisation measures.

\section{Methods}

This study was carried out in four phases: (1) establishment of local Diagnostic Reference Levels (DRL's) base on the $75^{\text {th }}$ percentile dose value of the most common CT examinations; (2) analyse of the practice and literature comparison; (3) anthropomorphic phantom experimental tests with PBU-60; (4) subjective and objective image quality analysis, based on visual grading characteristic (VGC) of the radiologist opinion of the guideline criteria and on the standard deviation value of the Hounsfield Units in homogeneous Regions Of Interest, respectively.

\section{Results}

Local DRLs were obtained for head, chest, abdomen and lumbar column. The majority of the values were higher than the recommendation. The optimisation experimental tests allowed the definition of new exposure parameters with radiologist approval. The optimised local DRL's are according to the recommend values in most of the body regions. Image quality analyses revealed an expected increase of noise however no significant differences were founded for the majority of criteria.

\section{Conclusions}

The most common CT procedures were optimised. Dose reductions were obtained with diagnostic imaging criteria fulfillment and radiologist approval. 


\title{
Efficacy of clinical audit on administered activities to patients undergoing Sentinel Lymph Node
}

\author{
Sousa A. ${ }^{1}$, de Sousa V. ${ }^{2}$, Cardoso G. ${ }^{2}$, Joaquim G. Santos ${ }^{2}$, Santos A.I. ${ }^{2,3}$ \\ ${ }^{1}$ Faculdade de Ciências e Tecnologia - Universidade Nova de Lisboa, Lisboa, PORTUGAL \\ ${ }^{2}$ Hospital Garcia de Orta, Almada, PORTUGAL \\ ${ }^{3}$ Nova Medical School - Universidade Nova de Lisboa, Lisboa, PORTUGAL
}

Corresponding author: anaraquel64@hotmail.com

\section{Introduction}

It is important to audit administered activities in Nuclear Medicine procedures in order to verify the compliance with reference values. The aim of this study was to audit administered activities in Sentinel Lymph Node Scintigraphy, and to raise staff awareness in maintaining an optimization process, keeping the exposure levels as low as possible without compromising the effectiveness of the procedure.

\section{Methods}

A retrospective analysis of 31 procedures performed in 2016, with administration of ${ }^{99 \mathrm{~m}} \mathrm{Tc}$ albumin nanocolloid for sentinel lymph node mapping in breast cancer patients, was done, collecting gender, age, weight and administered activity. Reference activity (111 MBq) is a standard activity defined according to international guidelines. This analysis was compared with a similar study of 35 procedures collected in 2015, whose results had been discussed with the staff.

\section{Results}

The sample collected in 2015 had a median age of 65 [Min 31; Max 89] years and a median administered activity of 138.75 [Min 96.2; Max 214.6] MBq. Applying Wilcoxon Signed-Rank Test to this sample, administered activities were higher than the reference activities according to weight, with a strong statistically significant difference $\left(p\right.$-value $\left.=8.8 \times 10^{-7}\right)$. The sample collected in 2016 had a median age of 60 [Min 25; Max 86] years and a median administered activity of 86.95 [Min 40.7; Max 103.97] MBq. Applying the same non-parametric test to the sample of 2016, again, administered activities were higher than the reference activities according to weight, also with a strong statistically significant difference $\left(p\right.$-value $\left.=1.23 \times 10^{-6}\right)$. The Wilcoxon Rank-Sum Test showed a strong statistically significant reduction of the absolute errors between 2015 and 2016 ( $p$-value $=5.69 \times 10^{-12}$ ).

\section{Conclusions}

Considering the results obtained, this study demonstrates that the audit carried out in 2015, raising awareness among the staff, led to a significant reduction of administered activities in 2016. 


\section{Pedriatic Nuclear Medicine Exposure to Radiation}

\section{Ana Cristina Duarte ${ }^{1}$, Anna Mylkivska ${ }^{1}$, Maria Clara Alves ${ }^{1}$, Maria Raminhas Carapinha ${ }^{2}$}

${ }^{1}$ Licenciatura em Medicina Nuclear, ESTeSL-Escola Superior de Tecnologia de Saúde de Lisboa, Instituto Politécnico de Lisboa

${ }^{2}$ DCTRBS, ESTeSL-Escola Superior de Tecnologia de Saúde de Lisboa, Instituto Politécnico de Lisboa

Corresponding author: mariaclara306@hotmail.com

\section{Introduction}

In general, the procedures used in Nuclear Medicine (NM), involve a lower exposure to ionizing radiation when compared to the exposure of background radiation, which is $2.4 \mathrm{mSv}$. The importance and diagnostical value of these procedures, when performed properly, outweigh the potential risk of radiation exposure. Recently, the use of these innovative imaging techniques has increased exponentially, so there is a particular interest in understanding how these exposures affects the pediatric age, since children are more sensitive to them than adults.

\section{Methods}

A descriptive study based on a systematic review of the literature through PubMed, 6 articles were included that respect, at least, one of the following criteria: pediatric exposure in NM, the effects of low doses of radiation and doses optimization. The key words used in the PubMed: radiation exposure, paediatric nuclear medicine, risk. And application of Boolean markers AND, OR, NOT.

\section{Results}

The risk of the consequences due to radiation exposure is greater in younger individuals. The administered activity is a parameter of significant importance in the risk of radiation exposure in NM and communication can facilitate the understanding of this exposure and the associated risks.

\section{Conclusions}

Exposure to radiation due to procedures used in NM doesn't present an increasing risk to the normal occurrence of malignant diseases and its correct communication to the child and their family is important to ensure the safety of the patient and those who surround them during these procedures. Any activity is calculated according to the child's weight and height, taking into accounts the ALARA principle, in order to obtain a better diagnosis with the minimum required activity and consequent radiation exposure. 


\title{
Computed Tomography in children with brain trauma injures: Epidemiological trend in Centro Hospitalar Lisboa Norte - Hospital de Santa Maria
}

\author{
Aura Junqueira Lopes ${ }^{1}$, Ana Ferreira Coelho ${ }^{1}$, Cláudia Teles Martins ${ }^{1}$, Fábio Nogueira ${ }^{1}$ \\ ${ }^{1}$ Centro Hospitalar Lisboa Norte - Hospital de Santa Maria \\ Corresponding author: aura.lopes@gmail.com
}

\section{Introduction}

Computed Tomography (CT) is used as an important diagnostic tool in the exclusion of intracranial injuries caused by trauma in pediatric patients.

As an exam that plays such an important role in the pediatric emergency department, we need to quantify the incidence of the exam and its tendency over the last years in our institution wich isn't a pediatric hopital but a general hospital.

\section{Methods}

To epidemiologically analyze the occurrence of CT examinations prescription carried out on children subjected to traumatic brain injury.

Data will be retrospective collected through PACS (Picture Archiving and Communication System), two months a year (one summer month and one winter month) during three distinct years.

Our population was divided into four age groups: age group 1 ( 0 to 3 months); age group 2 (3 months to 1 year); age group 3 ( 1 to 6 years old); age group 4 ( 6 to 18 years old).

\section{Results}

We started our data collection with the month of January 2017 obtaining results from the following exams: 3 children from age group 1; 3 children from age group 2; 13 children from age group 3; 29 children from age group 4 . Work still in progress.

\section{Conclusions}

There are no conclusions yet, because the data collection is still in progress. 


\title{
(Low) Enrollment to a Dose Reduction Protocol in Conventional Radiology in Neonatology
}

\author{
Cláudia Teles Martins ${ }^{1}$, Fábio Nogueira ${ }^{1}$, Ana Ferreira Coelho ${ }^{1}$ \\ ${ }^{1}$ Centro Hospitalar Lisboa Norte (Serviço de Imagiologia Geral)
}

Corresponding author: claudia.teles.martins@gmail.com

\section{Introduction}

Exposure to X-ray of neonates hospitalized in Neonatal Intensive Care Units has been a concern about their possible carcinogenic effects. At Centro Hospitalar Lisboa Norte, an optimization program was created for these examinations, taking into account the reduction of the radiation dose and, simultaneously, the increase of the diagnostic quality.

Thus, the main objective of this work is to evaluate the impact of the optmization program on dose reduction and the enrollment of the Radiology Technicians to the same program.

\section{Methods}

This study was performed in a general hospital in Portugal. Data collection occurred retrospectively and focused on the examinations performed with a direct digital mobile $x$-ray unit. For each radiographic examination, several data were collected: sex, radiographic examination, projection, tube voltage $(\mathrm{kV})$, tube current-time product $(\mathrm{mAs})$, dose-area product DAP (dGycm ${ }^{2}$ ) and entrance dose ED (mGy). This study had two phases: before and after the implantation of the optimization program.

\section{Results}

On first phase it was registered 240 radiographic examinations: 173 chest examinations $(\mathrm{kV}=66,5 ; \mathrm{mAs}=1,6 ; \mathrm{DAP}=0,260 ; \mathrm{ED}=0,088), 40$ abdominal $(\mathrm{kV}=65,0 ; \mathrm{mAs}=2,02 ; \mathrm{DAP}=0,283$; $E D=0,102)$ and 27 babygrams $(k V=64,3 ; m A s=1,59 ; D A P=0,222 ; E D=0,070)$. On the second phase (data collection is ongoing) it was registered 133 examinations: 105 chest examinations $(\mathrm{kV}=65,0 ; \mathrm{mAs}=1,1 ; \mathrm{DAP}=0,1379 ; \mathrm{ED}=0,059), 8$ abdominal $(\mathrm{kV}=64,8 ; \mathrm{mAs}=1,1 ; \mathrm{DAP}=0,1694$; $\mathrm{ED}=0,053)$ and 12 babygram ( $\mathrm{kV}=65,5 ; \mathrm{mAs}=1,2 ; \mathrm{DAP}=0,2221 ; \mathrm{ED}=0,057)$. As regards to adherence to optimization protocol it was observed, for now, $47,7 \%$ for the tube voltage and $52,3 \%$ for the tube current-time product in chest examinations.

\section{Conclusions}

Although the percentage of adherence to protocol for chest X-ray is below expectations, a reasonable dose reduction was found as well as a decrease the variability of selected acquisition parameters. It is needed a greater investment in spreading the benefits of the protocol among radiology technicians, as well as increased awareness of the establishment of a culture of radiological safety. 


\title{
Analysis of DAP in different surgical procedures performed with mobile C-arm
}

\author{
Ferreira D. ${ }^{1}$, Cabral R. ${ }^{1}$, Cardoso G. ${ }^{1}$, de Sousa V. ${ }^{1}$ \\ ${ }^{1}$ Hospital Garcia de Orta, Almada, PORTUGAL \\ Corresponding author: david ferreira001@msn.com
}

\section{Introduction}

Since dose is different across surgical specialities and types of procedures, as a result of factors like procedure complexity and fluoroscopy time, it is important to have in account the effects of radiation dose for the patients. The aim of this study was to evaluate dose exposure to patients during different surgical procedures performed on two mobile C-arm, and its correlation with fluoroscopy time.

\section{Methods}

A retrospective analysis comprising 35 patients submitted to surgical interventions performed with two OEC C-arm from September 2016 to March 2017, was performed. Age, weight, height, fluoroscopy time (FT), dose area product (DAP) and type of procedure were collected for 3 specialities (Urology, Orthopaedic and Vascular Surgery) considering the most frequent procedures. The effective dose (ED) was calculated multiplying DAP values by an ED conversion factor $\left(0.2 \mathrm{mSv} / \mathrm{Gy} . \mathrm{cm}^{2}\right)$ given by European Commission on Radiation Protection Report $\mathrm{N}^{\circ}$ 154. Correlation between FT and DAP was also verified by calculating Pearson correlation factor.

\section{Results}

Stent placement from Urology was the most frequent procedure (16 patients), followed by peritrochanteric nail (PTN) from Orthopaedic (13 patients) and abdominal endovascular aneurysm repair (EVAR) from Vascular Surgery (6 patients). The mean values for DAP, FT and ED were: $55.32 \pm 36.17$ Gy.cm², $826.27 \pm 646.46 \mathrm{~s}$ and $11.06 \pm 7.23 \mathrm{mSv}$ for EVAR; $3.28 \pm 2.44$ Gy.cm ${ }^{2}, 61.59 \pm 59.59 \mathrm{~s}$ and $0.66 \pm 0.49 \mathrm{mSv}$ for Stent and $1.21 \pm 0.95 \mathrm{~Gy} . \mathrm{cm}^{2}, 45.28 \pm 33.21 \mathrm{~s}$ and $0.24 \pm 0.19 \mathrm{mSv}$ for PTN. The observed Pearson correlation factor was 0.930 for PTN, 0.929 for Stent and 0.928 for EVAR.

\section{Conclusions}

The highest DAP and FT was observed in EVAR procedures. As expected, it was also verified a correlation between DAP and FT for all procedures analysed. From all analysed procedures, only EVAR exceeds the value of $10 \mathrm{mSv}$ for ED, value which, regarding the European Commission on Radiological Protection, causes the possibility to develop solid cancer or leukaemia during lifetime in $1 / 1000$ patients. 


\title{
Radiation Safety overview in Radioguided Surgery
}

\author{
Milhões, $\mathrm{M}^{1}$; Rayo Madrid, $\mathrm{JI}^{2}$; Infante de la Torre, $\mathrm{JR}^{3}$ \\ ${ }^{1}$ Nuclear Medicine Dept. Dr Campos Costa, Oporto, Portugal \\ ${ }^{2}$ Nuclear Medicine Dept. Hospital Infanta Cristina, Badajoz, Spain \\ ${ }^{3}$ Nuclear Medicine Dept. Hospital Infanta Cristina, Badajoz, Spain \\ Corresponding author: marta.martamilhoes@gmail.com
}

\section{Introduction}

Radioguided surgery (RGS) is a chirurgical radio-guided tracer procedure. Due her benefits for patients and surgeons, her usage is been grown in a lot of diseases. Radiation Safety is a concern and is present in researchers minds. New scintigraphic tumor agents have been studied. Radiation detectors have become less cumbersome and friendly-user and being introduced in robotic surgery. Research has been done to study and ensure radiation safety of all medical staff. As a multidisciplinary technique, radiation safety should be part of the training programs.

\section{Methods}

This is a literature review work to summarize RGS radiation safety concerns and improvements. New radiopharmaceuticals have been introduced and technological investment has been done for patient and staff radiation safety benefit. Studies have been done recording dose exposure for all medical staff involved. Radiation safety should be part of RGS practices.

\section{Results}

$\beta^{-}$emitters are being studied as an option for RGS due lower absorbed dose and the short range of the electrons, reducing patient and medical staff radiation exposure. Radiation detectors are being reform to improve radiation detection, and/or to be part of robotic equipment. Even studies for non-radiation workers (case of sentinel lymph node biopsy) reported lower radiation exposure dose, good radiation-handling practices should be mandatory. Many factors like injected doses, surgery duration and staff experience could affect dose exposure. Radiation safety should be part of RGS training and education programs.

\section{Conclusions}

RGS application is increasing. Radiation safety is being part of researchers, investors and medical workers concern. New radiotracers have been studied; radiation detectors have been improved. Due multidisciplinary character radiation dose exposure studies have been done. Although the radiation levels measured were low, radiation safety policies and education programs should be done to ensure minimal radiation exposure. 



\title{
RADIOLOGICAL PROTECTION ISSUES: Day-by-day in an Operation Room Department
}

\author{
$\underline{\text { Lodeiro, Cátia }}{ }^{1}$;rindade, Mauro²; Pinto, Vânia ${ }^{3}$; Sousa, Pedro ${ }^{4}$ \\ CHTMAD: ${ }^{1}$ Radiology Department. ${ }^{2}$ Medical Physicist ${ }^{3}$ Operation Room Department ${ }^{4}$ Medical \\ Doctor-Radiology Head of Department.
}

Corresponding author: marta.martamilhoes@gmail.com

\section{Objectives}

To evaluate practices in Radiological Protection (RP) by health professionals who, in the operating room department of the CHTMAD-UVR (Centro Hospitalar de Trás-Os-Montes e Alto Douro-Unidade de Vila Real), are exposed to ionizing radiation.

\section{Contextualization}

Medical applications, especially those that incorporate ionizing radiation, are the largest artificial sources of radiation to which humans are exposed. Its use outside the Radiology Departments is increasing and in the operation rooms, as a complement to the surgical activity, is a daily practice. Therefore, its undesirable effects should be minimized, namely through measures of RP (Madrigano, 2014), which aim to contextualize specific security measures (Castro, 2014). However, there is no real RP education, in this context, with adequate training plans.

\section{Methods}

A cross-sectional study, carried out in the CHTMAD-UVR operating room department, on all health professionals exposed to ionizing radiation, applying a questionnaire divided into two parts: 1 - individual characterization data; 2 - questions about daily practices regarding RP.

\section{Results}

Despite the efforts to disseminate knowledge about RP, this is still an area with some gaps. With the application of this questionnaire we will verify the current state of knowledge and identify the most frequent errors and failures, to be able to apply an adequate training plan and to institute beneficial changes in the habits related to radioprotection.

\section{Conclusions}

Regarding health professionals exposed to ionizing radiation, a continuous training plan in RP is currently recommended so that they become aware of the importance of the proper use of protective equipment for their health and safety at work. 


\title{
Measurement of Radon in 16 Portuguese Thermal Establishments
}

\author{
Ana Sofia Silva ${ }^{1,2}$, Maria de Lurdes Dinis ${ }^{1,2}$ \\ 1 CERENA, FEUP/UP - Centre for Natural Resources and the Environment, Faculty of \\ Engineering, University of Porto \\ ${ }^{2}$ PROA/LABIOMEP - Research Laboratory on Prevention of Occupational and Environmental \\ Risk, Faculty of Engineering, University of Porto. \\ Corresponding author: mldinis@fe.up.pt
}

\section{Introduction}

Radon $\left({ }^{222} \mathrm{Rn}\right)$ is a naturally occurring radioactive gas generated by the decay of radium $\left({ }^{226} \mathrm{Ra}\right)$, which is part of the long decay chain of uranium $\left({ }^{238} \mathrm{U}\right)$. The health hazard from ${ }^{222} \mathrm{Rn}$ exposure does not come primarily from radon itself, but rather from the radioactive products formed in the decay of radon, after inhalation. Radon has been recognized as the natural source of most significant human exposure and the leading cause of lung cancer incidence, with the exception of tobacco. Thermal spas have been identified as one of the professional activities with potentially higher exposure to radon mostly due to the inhalation of radon released from thermal waters. Several studies have been conducted worldwide to measure the concentration of radon in water and in the air of thermal spas in order to estimate the exposure doses both for workers and for users.

\section{Methods}

The purpose of this work was to measure the radon concentrations in indoor air, as well as to evaluate the indoor gamma dose rates in different workplaces of Portuguese thermal spas. The measurements were carried out between November 2013 and February 2015. Indoor radon concentration measurements were performed using CR-39 detectors for periods between 25 and 45 days. Indoor gamma dose rates measurements were hourly acquired with a Geiger Counter from Gamma Scout and stored for a time period between 25 and 45 days.

\section{Results}

The reference level for the radon concentration in workplaces $\left(300 \mathrm{~Bq} / \mathrm{m}^{3}\right)$ was exceeded in $77 \%$ of the measurements taken in the indoor air of the ORL's, Vichy shower and technical area. The gamma dose rates ranged between $0,15 \mu \mathrm{S} / \mathrm{h}$ and $0,64 \mu \mathrm{S} / \mathrm{h}$. This may result in an annual gamma dose rate range of 0,30 and $1,24 \mathrm{mSv} / \mathrm{y}$, considering a normal occupational exposure pattern ( $8 \mathrm{~h} / \mathrm{d} ; 5 \mathrm{~d} / \mathrm{w} ; 48 \mathrm{w} / \mathrm{y})$ which is far below the effective dose limit for workers $(20 \mathrm{mSv} / \mathrm{y})$. However the great contribution for the effective dose will result from radon inhalation which is not included in this consideration.

\section{Conclusions}

The results showed that the radon concentration in indoor air, ranging between $73 \mathrm{~Bq} / \mathrm{m}^{3}$ and $3479 \mathrm{~Bq} / \mathrm{m}^{3}$, was above the reference level of $300 \mathrm{~Bq} / \mathrm{m}^{3}$ for workplaces and this level was exceeded in $77 \%$ of the measurements taken in the indoor air. Therefore, appropriate actions should be taken in order to reduce the hazard to health from radon indoors and the resulting occupational exposure. 


\title{
Analysis of radiation from radon rich spray on bioactive compounds present in Nasturtium officinale $\mathrm{R}$. Br leaves
}

\author{
$\underline{\text { M. Inácio }}{ }^{1,2}$, S. Soares ${ }^{1,2,3}$, E. Amaral $^{4}$ \\ ${ }^{1}$ Departamento de Física, Universidade da Beira Interior, Covilhã \\ ${ }^{2}$ Laboratório de Instrumentação e Física Experimental de Partículas, Lisboa \\ ${ }^{3}$ Centro de Matemática e Aplicações da Universidade da Beira Interior \\ ${ }^{4}$ Departamento de Química, Universidade da Beira Interior, Covilhã
}

\section{Corresponding author: minacio@ubi.pt}

\section{Introduction}

The main source of population exposure to ionizing radiation is nature, mainly through radon. This study examines the effect of ionizing radiation in bioactive compounds present in Nasturtium officinale leaves. Through exposure to atmospheres containing a different concentration of radon, it is possible to identify changes in bioactive compounds of samples submit-ted to higher concentrations.

\section{Methods}

To create an atmosphere rich in radon gas, was used a rock with uraniferous mineralization was placed into a completely closed box. Giving rise to a thermal atmosphere, with the propose to have $100 \%$ of relative humidity and an approximate temperature of $40 \circ \mathrm{C}$, a heating plate with a water container, were also included. The temperature was continuous monitored never reaching $40^{\circ} \mathrm{C}$, in order to preserve to the maximum all cellular constituents. Continuous radon gas monitoring was performed with the Durridge Rad7 equipment using Durridge Company Inc.'s (2010) specific protocol for the detection of radon in air.

The watercress leaves were analyzed by scanning electron microscopy and later all samples were subjected to the conventional extraction process using the Soxhlet extractor and using absolute ethanol as the solvent. The leaves were placed in cellulose cartridges and fed to the Soxhlet extractor. The methods of analysis that will be used, require the solvent to be methanol, whereby the extracts have been re-diluted in this solvent. For each extract sample in methanol its concentration was calculated.

The total phenolic content of the extract was determined by Folin-Ciocalteu's colorimetric and the total flavonoid content was evaluated by colorimetric method. The antioxidant activity of the extracts and standards was evaluated by the radical scavenging activity method using the 2,2- diphenyl-1-picrylhydrazyl (DPPH) radical, this method was applied for all samples and standard solutions.

\section{Results}

The watercress samples inside the box were subjected to an atmosphere containing the following radon concentrations: $152 \mathrm{~Bq} / \mathrm{m}^{3}, 3180 \mathrm{~Bq} / \mathrm{m}^{3}, 3570 \mathrm{~Bq} / \mathrm{m}^{3}$ and $5160 \mathrm{~Bq} / \mathrm{m}^{3}$.

Preliminarily, there was no change in plant tissue in the different samples.

The antioxidant activity index and IC 50 showed a growing trend with increasing radon concentration.

The total phenol content on the sample subject to a $152 \mathrm{~Bq} / \mathrm{m}^{3}$ concentration is approximately half of the total phenol content found in the sample subject to a of $5016 \mathrm{~Bq} / \mathrm{m}^{3}$ concentration.

\section{Conclusions}

It is therefore concluded that the higher the radon concentration, to which the leaves were subject to, the higher the total phenol concentration. 
The same conclusion was possible for flavonoids, albeit to a lesser extent. The antioxidating activity index and the sample concentration for a $50 \%$ inhibition (IC50), feature a linear increasing trend, for radon concentration of $152 \mathrm{~Bq} / \mathrm{m3}, 3180 \mathrm{~Bq} / \mathrm{m3}$ and $3570 \mathrm{~Bq} / \mathrm{m} 3$. Nevertheless as for the sample subject to a $5160 \mathrm{~Bq} / \mathrm{m} 3$ concentration that growth was reversed. According to the obtained results it is possible to conclude that this type of behaviour can be due to possible stress conditions the plant was subject to, inducing it into activating the main biosynthetic paths of theses secondary metabolites. 
Conference "Proteção Radiológica na Saúde 2017"

Poster Presentations - Others 


\section{NUCLEU2020 - A network of Horizon 2020 National Contact Points (NCP)}

\section{Sofia Guedes Vaz}

${ }^{1}$ Foundation for Science and Technology, Portugal

Corresponding author: Sofia.vaz@fct.pt

NUCL-EU 2020 is a H2020 CSA (Coordination and Support Action) project aiming to create an European wide active network of EURATOM NCPs. The ultimate objective of NUCL-EU 2020 is to ensure support to Horizon 2020 potential applicants, raising awareness about potential topics and increase the average quality of proposals submitted under the EURATOM Framework Programme for Research and Innovation and the overall success rate at EU level. For this to happen there is a need for letting stakeholders - prospective EURATOM applicants know of the existence and potential support of NCPs and in particular of a network of NCPs. For promoting more effective and successful participation in Horizon 2020, NUCL-EU 2020 offers training, partner search tools and brokerage events. NUCL-EU 2020 wants to contribute to a step forward on the R\&D landscape at EU level. 